Cahiers Charlevoix

Cahiers Charlevoix

Études franco-ontariennes

\title{
Germain Lemieux par lui-même (1914-1958)
}

\section{Jean-Pierre Pichette}

Volume 9, 2012

URI : https://id.erudit.org/iderudit/1039314ar

DOI : https://doi.org/10.7202/1039314ar

Aller au sommaire du numéro

\section{Éditeur(s)}

Société Charlevoix

Presses de l’Université d'Ottawa

ISSN

1203-4371 (imprimé)

2371-6878 (numérique)

Découvrir la revue

Citer cet article

Pichette, J.-P. (2012). Germain Lemieux par lui-même (1914-1958). Cahiers

Charlevoix, 9, 107-193. https://doi.org/10.7202/1039314ar
Résumé de l'article

Jean-Pierre Pichette publie la première tranche de l'entrevue qu'il a réalisée en 1995 auprès du fondateur de l'ethnologie franco-ontarienne. Ce long entretien consacré à la vie et à l'oeuvre du jésuite Germain Lemieux (1914-2008) a d'abord été diffusé sur les ondes de la radio d'État. Préparé de longue main, sur la base de la fréquentation continue des écrits et de l'homme, il a été enregistré sous la forme d'un autoportrait afin de permettre au père Lemieux de situer dans leur contexte les travaux de sa production scientifique et d'aller au-delà des écrits en livrant ses souvenirs et ses projets. Ce premier volet, qui couvre les années 1914-1958, aborde sous un jour personnel la période gaspésienne de ce chercheur - son enfance à Cap-Chat et ses études au séminaire de Gaspé -, puis son entrée et sa formation chez les jésuites de Montréal, jusqu'au début de sa période franco-ontarienne - son affectation au collège du Sacré-Coeur de Sudbury et ses premières enquêtes dans le nord de l'Ontario. Présentés dans leur chronologie, ces témoignages apportent un éclairage nouveau sur les origines paysannes de ce personnage marquant, sur sa formation, sur son tempérament et finalement sur son oeuvre dont ils révèlent les détours inédits. Cette édition est accompagnée de notes et de commentaires.
Ce document est protégé par la loi sur le droit d'auteur. L’utilisation des services d’Érudit (y compris la reproduction) est assujettie à sa politique d'utilisation que vous pouvez consulter en ligne.

https://apropos.erudit.org/fr/usagers/politique-dutilisation/ 


\title{
Germain Lemieux par lui-même (1914-1958)
}

\author{
JeAn-Pierre Pichette \\ Chaire de recherche du Canada en oralité \\ des francophonies minoritaires d'Amérique (COFRAM) \\ Université Sainte-Anne, Pointe-de-l'Église
}




\section{SOMMAIRE}

AvANT-PROPOS

Notice biographique de Germain Lemieux

I - Enfance À CAP-Chat (1914-1928) 118

II - Études AU SÉMINAIRE DE Gaspé (1928-1935) 136

III - ForMATION CHEZ LES JÉSUITES (1935-1950) 152

IV - Affectation au collège du Sacré-Ceeur (1941-1944) 161

V - Début des ENQuêtes en Ontario (1948-1958) 174

$\begin{array}{ll}\text { ÉPILOGUE } & 192\end{array}$ 


\section{Germain Lemieux par lui-même (1914-1958)}

\section{Avant-Propos}

En programmant 1'Ontario français et son patrimoine oral dans son modèle pédagogique, Germain Lemieux a marqué de façon pérenne la recherche au Canada. Il a notamment contribué à redéfinir le champ littéraire d'ici - souvent réduit aux catégories roman, nouvelle, poésie, théâtre, essai - et donner sa pleine extension au mot « littérature », incluant « tout usage esthétique du langage, même non écrit » précise le dictionnaire Robert, qui propose à juste titre comme exemple «La littérature orale». Son influence, auprès de ses élèves d'abord, pour qui il actualisait les humanités gréco-latines par le conte populaire ou l'histoire et les institutions du Moyen Âge par la vigueur de la tradition, allait déborder son enseignement. Il avait observé que le témoignage oral, dédaigné par l'école et l'histoire officielle, ajoutait une valeur documentaire parfois irremplaçable. Son œuvre, précisément fondée sur ce fragile matériau populaire, éphémère et incertain à la fois, s'avère néanmoins l'une des plus notoires du patrimoine écrit ontarois ${ }^{1}$. Tout en posant la pierre angulaire du patrimoine culturel immatériel de son pays d'adoption, elle touche aussi des problématiques qu'examinent de nombreux spécialistes : le rendez-vous international organisé à Sudbury en 1991, où « historiens, pédagogues, écrivains, artistes, musiciens, littéraires, éthiciens, linguistes, sociologues, médiévistes, muséologues et autres, sans oublier les

1. L'index du Dictionnaire des écrits de l'Ontario français 1613-1993 [DÉOF] (sous la direction de Gaétan Gervais et Jean-Pierre Pichette, Ottawa, Presses de l'Université d'Ottawa, 2010), recense 13 entrées à ses œuvres qui comptent 43 volumes, le rangeant ainsi parmi la dizaine d'auteurs les plus prolifiques avec les Francis-Joseph Audet, Marius Barbeau, Gaston Carrière, Jean Éthier-Blais, Emma-Adèle Lacerte, Gustave Lanctôt, Germain Lesage et Benjamin Sulte pour s'en tenir à ceux dont l'œuvre est terminée ; voir p. 988. 
premiers intéressés que sont les ethnologues » se sont entendus pour scruter l'impact artistique et scientifique de sa contribution à l'occasion du cinquantième anniversaire de sa carrière, en fournit la démonstration ${ }^{2}$. Ainsi, on attestait, entre autres, que certaines études sur le parler franco-ontarien seraient bien fragmentaires si elles négligeaient les milliers d'enregistrements que Germain Lemieux a produits durant ses trente-cinq années d'enquêtes sur le terrain ou, encore, qu'on aurait peine à dénombrer tous les créateurs - conteurs, chanteurs et musiciens, dramaturges, illustrateurs, peintres, sculpteurs, etc. - qui s'inspirent de ses écrits ou y puisent leur couleur locale . $^{3}$

La fréquentation des ouvrages de Germain Lemieux ${ }^{4}$ éclaire certes une bonne partie de sa démarche, comme le fait admirablement son petit guide sur Les Jongleurs du billochet, un condensé des techniques d'enquête qu'il préconisait et des succès obtenus auprès des conteurs en Ontario ${ }^{5}$. Cependant, afin de mieux connâ̂tre la source de sa passion pour le génie du monde ordinaire, apprécier le sens et le déploiement de ses travaux, un entretien direct avec le personnage paraissait opportun et, compte tenu de son âge avancé, pressant.

2. L'Euvre de Germain Lemieux, s.j. Bilan de l'ethnologie en Ontario français. Actes du colloque tenu à l'Université de Sudbury les 31 octobre, $1^{\text {er }}$ et 2 novembre 1991, sous la direction de Jean-Pierre Pichette, Sudbury, Éditions Prise de parole et Centre franco-ontarien de folklore, «Ancrages » 2, 1993, 529 p. L'ouvrage regroupe les études de 26 spécialistes de l'Acadie, du Québec, de l'Ontario et de l'Europe relevant des disciplines citées ; voir p. 10.

3. Outre le peintre Claire Guillemette-Lamirande (1938-2010), le sculpteur Maurice Gaudreault (1932-2000) et le conteur Camille Perron (1929-1995), qui ont reconnu ouvertement cette influence en participant à ce colloque, les noms de l'illustrateur et bédéiste Luc Robert, coauteur avec Germain Lemieux de Ti-Jean fin voleur (1992), et de Rachel Desaulniers, auteur de la pièce de théâtre Ti-Jean et le nénuphar de la destinée (2012), montrent la diversité et la continuité de son impact sur les créateurs.

4. On trouvera la synthèse de la plupart de ses écrits dans Jean-Pierre Pichette, Le Répertoire ethnologique de l'Ontario français. Guide bibliographique et inventaire archivistique du folklore franco-ontarien, Ottawa, Presses de l'Université d'Ottawa, « Histoire littéraire du Québec et du Canada français » 3, 1992, x-230 p. ; p. 213 (index).

5. Germain Lemieux, Les Jongleurs du billochet. Conteurs et contes francoontariens, Montréal, Bellarmin ; Paris, Maisonneuve et Larose ; [Sudbury], Société historique du Nouvel-Ontario [désormais SHNO], « Documents historiques » 61-6263, 1972, $134 \mathrm{p}$. 


\section{Sources}

Après le tourbillon du colloque de 1991, l'idée d'une telle entrevue se précisa graduellement. La relecture des écrits de Lemieux avait dégagé la chronologie de ses activités et les thèmes de prédilection de sa recherche. Ces notes et observations, avec citations de l'auteur à l'appui, composaient déjà un premier questionnement qui baliserait les échanges à venir et faciliterait le retour sur le chemin parcouru. Ainsi, par un entretien bien préparé, surgiraient peut-être d'utiles précisions et de claires explications de points en apparence nébuleux ou laissés dans l'ombre ${ }^{6}$. L'occasion se présenta en novembre 1994 quand un magazine à caractère patrimonial voulut faire connaître à ses lecteurs l'œuvre du chercheur franco-ontarien. Le court délai accordé limita alors la durée de l'entrevue et les sujets abordés'. Entre temps, la station locale de la Société Radio-Canada avait eu vent de notre projet et résolut d'y consacrer une série d'émissions destinée à ses auditeurs du nord de l'Ontario.

Par l'intermédiaire du réalisateur Roch Ducharme, l'entretien se déroula cette fois dans des conditions matérielles irréprochables aux studios de la station CBON à Sudbury entre le 6 novembre et le 11 décembre 1995. Enregistré durant les trois premières semaines de novembre à raison de trois séances hebdomadaires, espacées d'au moins deux ou trois jours pour solliciter la mémoire de ce témoin octogénaire et lui permettre un temps de récupération raisonnable, ce long tête-à-tête avec l'auteur de cet article s'acheva en décembre, quinze jours plus tard, par une séance complémentaire ; la version intégrale, d'une ampleur inaccoutumée, forme un quasi-marathon de plus de douze heures ${ }^{8}$. L'entrevue, qui

6. Germain Lemieux avait eu l'occasion de revenir une première fois sur son passé dans une allocution au colloque de 1991 : «Mon projet folklorique cinquante ans plus tard ", dans L'Euvre de Germain Lemieux, op. cit., p. 21-37.

7. Entrevue avec le père Germain Lemieux conduite par Jean-Pierre Pichette le samedi 26 novembre 1994 à Sudbury, au Centre franco-ontarien de folklore (Maison d'Youville). Collection Jean-Pierre Pichette, enreg. 3510. Durée : 1 h 56 min. $54 \mathrm{sec}$. (116 minutes 54 secondes). Transcription : Denise Savard. Des extraits ont été publiés : « Germain Lemieux. La Mémoire franco-ontarienne », dans Continuité, Québec, 63, hiver 1995, p. 40-43.

8. Entrevue réalisée en dix séances dans les studios de la station $\mathrm{SRC}-\mathrm{CBON}$ à 
avait d'abord été proposée comme série locale, a été présentée en dix émissions de quinze minutes à l'automne 1996 sous le titre Germain Lemieux sur le billochet ${ }^{9}$. Puisqu'il avait été convenu de laisser le témoin s'exprimer librement, ce dernier reformulait en ses mots le sujet discuté au début de son intervention ; aussi, après avoir détaché au montage les questions posées, ses propos et confidences ont-ils pu être diffusés sans discontinuité. C'est toutefois la station MF de Montréal qui la donna en primeur à son auditoire national du 22 juin au 31 août 1996, dans la série Les Gardiens de la mémoire ; ces dix émissions de trente minutes, montées autrement, conservaient questions et réponses ${ }^{10}$.

\section{Méthode et contenu}

Les souvenirs de Germain Lemieux, que nous présentons ici, sont essentiellement tirés de ce second entretien préparé de longue main pour la radio ${ }^{11}$. Il s'agissait autant que possible d'évoquer le cheminement particulier de ce « gardien de la mémoire » francoontarienne, depuis son enfance gaspésienne jusqu'à la fin de sa carrière active en Ontario. Le recours à un questionnaire ouvert, qui alignait brièvement et chronologiquement les épisodes et événements connus de sa vie, avec des citations pertinentes et quelques questions synthèses, visait à soutenir la remémoration du témoin. Et cet instrument se révéla efficace puisque Germain Lemieux ne se présenta jamais aux rencontres sans avoir soigneusement étudié, voire annoté son exemplaire et, en deux occasions,

Sudbury (les 6, 8, 10, 13, 15, 17, 20, 22 et 24 novembre, et le 11 décembre 1995). Réalisation : Roch Ducharme. Recherche et animation : Jean-Pierre Pichette. Collection Jean-Pierre Pichette, enreg. 3511-3520. Durée : 12 h 23 min. 34 sec. [752 minutes 34 secondes]. Transcription : Denise Savard.

9. Germain Lemieux sur le billochet : 10 émissions de 15 minutes préparées pour la station MF de Radio-Canada, CBON, Sudbury, diffusées à l'automne 1996.

10. Les Gardiens de la mémoire : Germain Lemieux : 10 émissions de 30 minutes diffusées à la station MF de Radio-Canada, Montréal, du 22 juin au 31 août 1996, reprises en rafale en décembre 1996 et hebdomadairement durant l'été 1997.

11. Le document de travail, intitulé « Projet d'une série d'émissions radiophoniques sur la carrière du père Germain Lemieux » $(25 \mathrm{p}$. ms. $)$, porte les dates du 27 février 1995 et du 20 octobre 1995. Conçu par l'animateur, J.-P. Pichette, il fut soumis à l'invité comme au réalisateur de la série et constitua la référence pour ces entretiens. 
annexé un court document significatif qu'il lui importait de citer. Au moment de ces enregistrements, l'octogénaire se montra donc tout à fait à l'aise, lucide, bien préparé, répondant simplement et sans détour à toutes nos questions, corrigeant les perceptions au besoin, mais pesant bien ses mots, atténuant ici leur portée ou s'abstenant là charitablement de nommer des personnes que son propos aurait pu gêner. Il est clair qu'il nous a confié ce qu'il voulait et de la manière qu'il l'entendait. D'où le titre de ce document : Germain Lemieux par lui-même.

L'ampleur de ses confidences ne permet évidemment pas d'en livrer la totalité dans ce cahier. Aussi, en donnons-nous une première tranche, soit la période de 1914 à 1958 environ, qui va de son enfance gaspésienne à ses premiers essais en folklore à Sudbury. Par l'évocation des expériences qui ont marqué ce long parcours de quarante-cinq ans, Germain Lemieux signale les grands moments de sa vie ; il dévoile certains traits de sa personnalité, les influences reçues et ses choix fondamentaux. Il met ainsi en lumière les motivations qui l'animent et qui fondent le projet qu'il porte. La seconde partie de l'entrevue, prévue pour un prochain volume des Cahiers Charlevoix, s'attachera à la carrière universitaire proprement dite.

\section{Établissement du texte}

Pour en établir le texte, la première étape s'est forcément résumée à la transcription stricte, mot à mot, de tous les échanges, avec questions et réponses, interruptions et reprises, tels que captés par l'enregistreuse avant tout montage. C'est là le travail préliminaire, ingrat et indispensable de notre assistante, Denise Savard. Puis nous avons pris le relais. Une nouvelle écoute intégrale fut nécessaire ; elle permit de résoudre les passages difficiles et favorisa la révision entière du texte. Pour se repérer aisément dans ce dossier, nous avons dressé le sommaire de chacune des dix séances avant de les fusionner en un seul document, un manuscrit de plusieurs centaines de pages. Mais l'édition de l'entrevue, comme le montage des émissions de radio, demandait un traitement différent afin 
que le parcours du narrateur se lise dans sa séquence historique. C'est pour respecter cette chronologie que nous avons remis à leur place un certain nombre d'épisodes. Enfin, comme la conversation est un discours spontané, qui s'improvise au fur et à mesure, il a fallu, pour alléger la lecture, opérer des recoupements dans le cas des redites, phénomène inévitable dans une série d'enregistrements étalés sur un laps de temps aussi long, de façon à retenir les passages les plus précis, et éliminer les inévitables tics, répétitions de mots ou imprécisions. Les titres des paragraphes, posés en guise d'apostilles pour guider la lecture, sont extraits des paroles du témoin. Ainsi soulagé des questions qui guidaient le témoin dans ses souvenirs et de légères incorrections, le présent montage diffère, il va sans dire, des émissions de radio au point de vue de la forme, mais non pas du contenu. Tel est l'essentiel de la restructuration de cette entrevue.

Le ton oral, qui pourrait paraître un peu artificiel, reste néanmoins celui du témoin, un professeur de collège qui transige entre le parler ordinaire de ses élèves et du milieu populaire, auquel il est resté attaché et au sein duquel il a mené ses enquêtes, et celui d'un entourage religieux et savant dans lequel il évolue, sa communauté jésuite d'abord ainsi que les chercheurs et les lecteurs pour lesquels il a écrit. Il en résulte une certaine hybridité de son récit oral, simple, familier et spontané, qui maintient les mots et les tournures de la langue vernaculaire, avec parfois aussi ses défauts, auprès d'une langue plus châtiée qui n'oublie à peu près jamais la particule « ne » de la négation, ce qui ferait croire à un nettoyage du texte ${ }^{12}$. Conscient que ces séances d'enregistrement sont destinées au grand public, il tient à communiquer dans une langue accessible. Par exemple, pour exprimer le collectif pluriel, il utilise tantôt le pronom on, tantôt le pronom nous; et, s'il privilégie la forme je vais, il n'en conserve pas moins je vas à quelques occasions. Au niveau du lexique, il emploie les mesures anglaises (pied, mille), toujours présentes dans le parler populaire,

12. Nous avons restauré ces quelques oublis, comme aussi le pronom il supprimé à l'occasion devant le verbe fallait. 
et les doublons dollar et piastre. Le ton familier demeure présent dans des expressions comme mon papa là où on attendrait mon père ${ }^{13}$. Pour la clarté du propos, une note explicative donne les équivalents de ces régionalismes quand c'est nécessaire ; il en va de même pour les personnages, les événements qui datent de cette époque et qui nuiraient à sa compréhension. Nos rares interventions dans le texte du témoin sont signalées par des crochets $[. .$.$] . En somme, notre travail s'est limité à réorganiser$ et à annoter l'exposé du père Germain Lemieux, pour le rendre accessible, sans jamais le récrire.

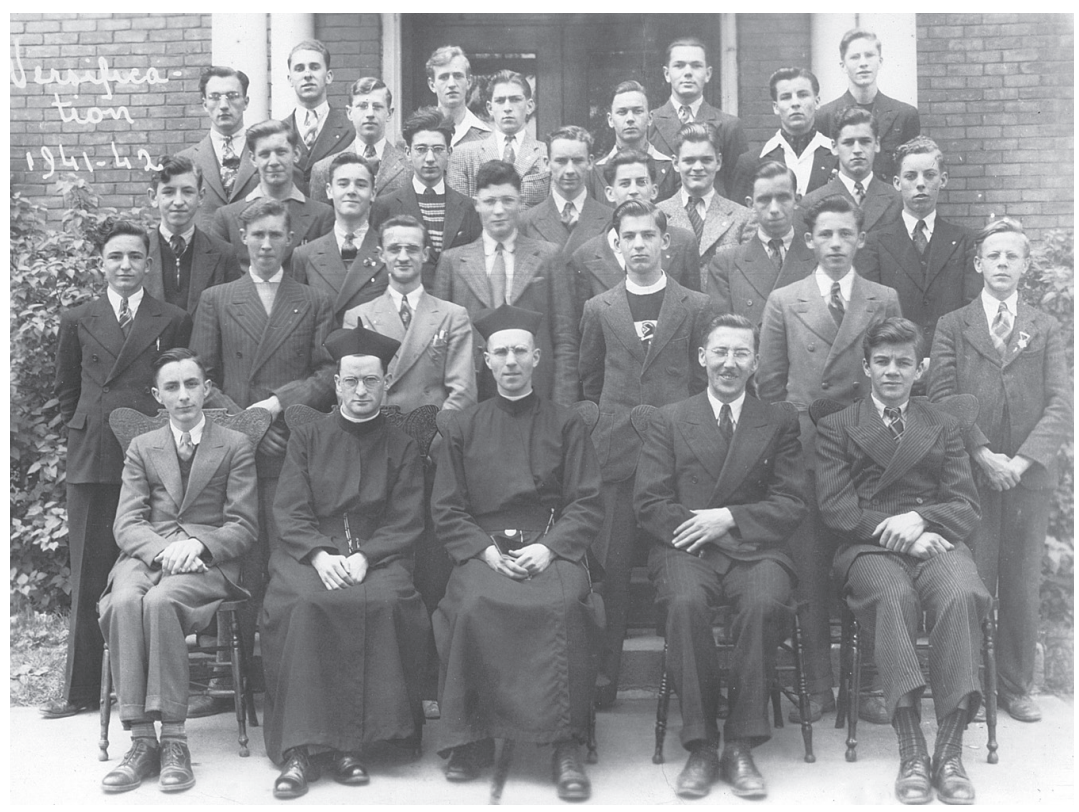

Classe de versification au collège du Sacré-Cœur, 1941-1942.

Germain Lemieux, coiffé de sa barrette, est assis au centre. Photographie : Centre franco-ontarien de folklore, Sudbury

13. Sauf quand il s'adresse à sa mère, il n'emploie pas de la même façon le mot maman ; est-ce alors pour lui une façon de distinguer son père ( papa) des pères jésuites? Mais il emploie aussi un mon-oncle (un oncle), la madame (la dame). 


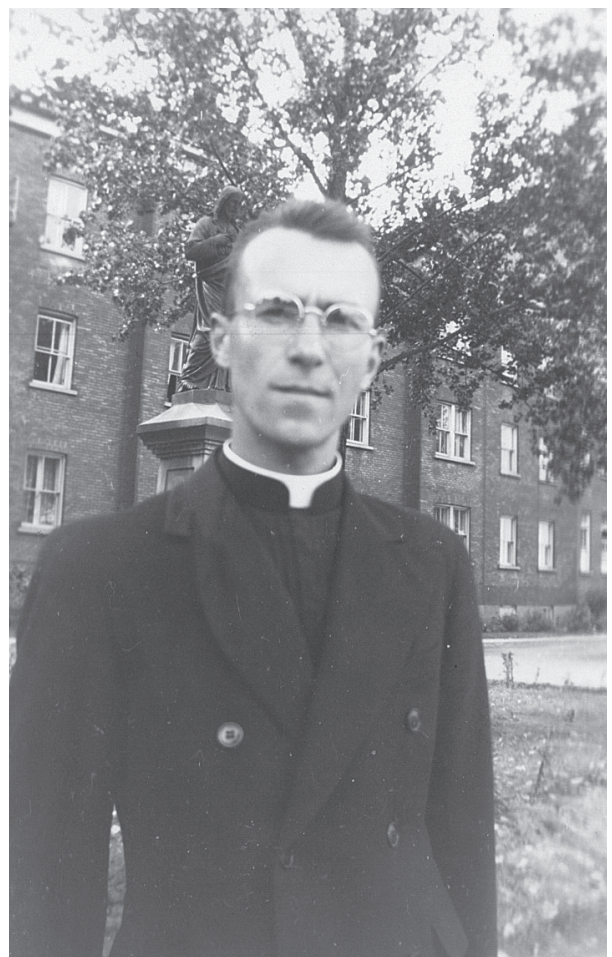

Germain Lemieux devant le collège du Sacré-Cœur, n.d. Photographie : Centre franco-ontarien de folklore, Sudbury

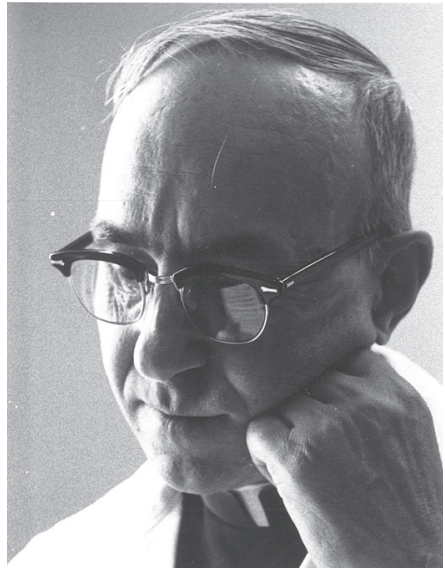

Germain Lemieux lisant dans son bureau, années 1990 Photographie : Centre franco-ontarien de folklore, Sudbury 


\section{Notice biographiQue de Germain LemieuX}

Né à Cap-Chat, dans le comté de Gaspé au Québec, le 5 janvier 1914, Germain Lemieux fréquente l'école primaire de son village (1920-1928) avant d'entreprendre ses études classiques au séminaire de Gaspé (1928-1935), dirigé par les jésuites. Entré dans cet ordre en 1935, il entreprend sa formation à Montréal et il est nommé à Sudbury en 1941 afin d'enseigner les institutions grecques et latines au collège du Sacré-Cœur (1941-1944, 19491953, 1956-1957) ; le père Lemieux, s.j., finira par s'y installer à demeure. À l'exception de séjours d'études à Montréal, pour sa licence en théologie (1944-1948), et à Québec, pour sa maîtrise (1953-1955) et son doctorat (1959-1961) en études canadiennes, il passera la plus grande partie de sa carrière active en Ontario, étant tour à tour professeur d'histoire à la nouvelle Université de Sudbury (1957-1959) puis à la Laurentienne (1961-1965), ou de folklore, d'abord lors d'un passage à l'Université Laval (1965-1968) avant de revenir s'adonner pleinement à l'enquête folklorique (1968-1975) et fonder, en 1972, le Centre francoontarien de folklore. Il retourne à l'enseignement au moment de l'implantation du programme de folklore à l'Université de Sudbury (1975-1980), puis sporadiquement jusqu'en 1988. En 1981, le Centre franco-ontarien de folklore s'établit au centreville de Sudbury, où le père Lemieux œuvrera à l'édition de ses collectes jusqu'en 1993, puis continuera d'occuper le poste de directeur de la recherche jusqu'à son départ pour Saint-Jérôme en août 2001. C'est là qu'il meurt le 26 mars 2008 à l'âge de 94 ans. Sa carrière de folkloriste, commencée en 1948 sous le patronage de la Société historique du Nouvel-Ontario, a été remarquée tant au Canada qu'à l'étranger, et la valeur de son œuvre, principalement les trente-trois tomes de la collection Les vieux m'ont conté, consacrée par plusieurs grands prix et distinctions. 


\section{I - Enfance À CAP-Chat (1914-1928)}

\section{"Je suis né à Cap-Chat, en Gaspésie"}

Je suis né à Cap-Chat, en Gaspésie (Québec), le 5 janvier 1914. J'étais le neuvième enfant d'une modeste famille de cultivateurs. Mes parents, Norbert Lemieux et Augustine Pelletier, eurent douze enfants. Ma mère, c'était une Pelletier Cabochon et, nous autres, nous étions des Lemieux Pélot - pour Pilote, Pilot comme disaient nos ancêtres. C'étaient les premières familles de Cap-Chat, les Pelletier et les Lemieux. Mon père s'appelait Norbert; il y avait deux Norbert, peut-être trois, dans la même paroisse ${ }^{14}$. Il y avait deux François Lemieux, c'était [le nom de] mon grand-père : il y avait un François-Michel et il y en avait un autre. Alors mon père, pour l'identifier, c'était Norbert à François-Michel Lemieux. Dans la paroisse, on distinguait souvent les Lemieux par Pélot ou Bat-l'iable ${ }^{15}$. Nous autres, c'étaient les Lemieux Pélot puis, eux autres, c'étaient les Lemieux Bat-l'iable.

C'étaient les familles Pelletier et Lemieux. Nous autres, les Lemieux, nous sommes arrivés au Canada un peu après 1640 ; les Pelletier sont arrivés à peu près vers les mêmes dates au XVII siècle. Il y a beaucoup de Pelletier par chez moi, beaucoup d'oncles et de tantes. C'étaient des gens qui s'étaient connus depuis longtemps ${ }^{16}$ et je pense que ma mère était aussi d'une famille

14. Ce prénom provient de la mission catholique de Saint-Norbert-du-CapChat, fondée en 1815. En 1845, on constitue la municipalité réunissant la paroisse de Saint-Norbert-du-Cap-Chat et le village de Saint-Norbert-du-Cap-Chat. La municipalité modifie son nom en Saint-Norbert-du-Cap-Chatte (1885-1957) avant de revenir à Saint-Norbert-du-Cap-Chat et d'adopter Cap-Chat en 1968. D'après le site La Mémoire du Québec en ligne... Édition 2012, « Cap-Chat ». La population de Cap-Chat était de 2300 habitants en 1931. Voir Jules Bélanger, Marc Desjardins, Yves Frenette avec la collaboration de Pierre Dansereau, Histoire de la Gaspésie, Montréal, Éditions du Boréal Express, Institut québécois de recherche sur la culture, « Les régions du Québec », 1981, p. 541.

15. Le père Lemieux n'a pas donné l'explication de ce surnom, prononcé " bâl'iâb' » pour " battre le diable », peut-être pour éviter d'offusquer cette branche de Lemieux. Le sobriquet tirerait-il son origine d'ancêtres querelleurs ou insoumis qui ne craignaient ni Dieu ni diable?

16. Il faut ici comprendre que les familles Pelletier et Lemieux se connaissaient déjà par les relations familiales et le voisinage, et que, par conséquent, les futurs époux avaient aussi fait connaissance bien avant leurs fréquentations. 
paysanne, fille de cultivateur. Alors, elle était prête à assumer ses fonctions de femme de cultivateur.

\section{"Mon papa avait peur de l'eau... c'était un bon cultivateur "}

Quand on venait de la Gaspésie, tout de suite on pensait que c'étaient des pêcheurs, mais non. On n'avait même pas une chaloupe chez nous pour aller à la pêche le dimanche comme d'autres le faisaient, et mon papa avait peur de l'eau ; alors il n'y avait pas de danger qu'il aille à la pêche ou [qu'il aille] se lancer dans la chasse au phoque ou autrement. Non, c'était un bon cultivateur et actuellement je dirais que c'était un gentleman farmer. Nous avions plusieurs fermes, une pour le bois [de chauffage], et nous en avions acheté une encore où on faisait de l'élevage ; et on vendait du bœuf, on vendait de la viande surtout à bord des bateaux. Souvent on recevait un téléphone ou quelqu'un nous arrivait : «Le bateau part demain matin à 7 heures, ils ont besoin de 1000 livres [454 kilos] de viande ou de 500 livres [227 kilos] de viande, de telle sorte de viande, du steak, et il faudrait que vous soyez rendus au bateau avant 7 heures $»$. D'ordinaire c'étaient des bateaux norvégiens, des bateaux anglais ; alors le cuisinier remplissait son frigidaire. La nuit, on allait souvent rapailler $^{17}$ les animaux pour l'abattoir. Deux de mes frères ont commencé le commerce de la viande, ils ont fondé l'abattoir et ils vendaient de la viande à domicile. On vendait du bois pour vivre parce que nous étions douze enfants, dont onze vivants. Quand les garçons, qui sont venus après cinq filles, ont commencé à grandir, c'était une aide appréciable pour le papa, soit à la ferme, soit à d'autres travaux. Les filles s'en tiraient, elles, pour aider la maman surtout, mais elles aidaient facilement aussi quand il y avait des récoltes, qu'il y avait de l'urgence ; les femmes et les filles venaient aussi aider à la ferme. Nous n'étions pas riches, mais nous n'avons jamais manqué de nourriture, que ce soit pendant le carême ou dans toute autre saison, nous en avions toujours, même si j'étais content de voir arriver le carême parce qu' on mangeait du hareng cru. J'étais

17. Rassembler, réunir les bêtes pour les conduire à l'abattoir. 
friand du hareng salé : on le faisait dessaler et on le mangeait cru avec des patates chaudes, avec des légumes chauds, de même que le poisson fumé ou la viande fumée ; j'étais friand de ça. Je me rappelle que l'on voyait les vieux qui mangeaient des huîtres. On se disait : " Ç'a l'air à être bon, ça ». On était assez petit ${ }^{18}$ qu'on avait le nez à la hauteur du comptoir ; on ne présentait pas plus qu'un dix sous et puis on avait trois huîtres avec ça. On se dépêchait d'aller ouvrir ça pour voir quel goût ç'avait.

\section{"Nous étions dix-sept à table "}

Dans ma famille, dans ma maison paternelle, il y avait jusqu'à quatre générations et même presque cinq générations. À un moment donné, nous étions douze enfants, papa puis maman ça faisait quatorze, grand-père et grand-mère ça faisait seize, l'arrière-grand-mère qui était là ça faisait dix-sept ; alors ça faisait une table qui était assez grande et puis ça prenait beaucoup de patates et beaucoup de poisson puis beaucoup de viande pour nourrir tout ce monde-là. Je vous dis qu'on n'a jamais pensé que ça coûtait cher de nourrir une famille pareille. Je n'ai jamais dit «j'ai faim », souvent. [Sij'avais dit:] «J'ai faim » [, on m'aurait répondu] : «Mais attends le repas - pour la discipline -, tu mangeras au repas ».

\section{"Grand-mère Désinas"}

J'ai connu mon arrière-grand-mère, la mère de mon grand-père, qui était née pas loin de Québec : Léa Gagné, qui était venue au monde en 1827 et qui était descendue en Gaspésie ; mon grandpère [François-Michel Lemieux] était venu au monde en Gaspésie en 1847. Il y avait mon père qui était né en 1874 et ça, c'était à la maison paternelle. Je me rappelle d'avoir entendu ma vieille grand-mère - on disait grand-mère Désinas, c'était Léa Gagné ; je ne sais pas trop pourquoi on l'appelait Désinas - ; elle nous racontait un peu toutes sortes d'histoires, de légendes. Elle nous avait raconté une fois qu'elle avait été cuisinière chez un seigneur,

18. Même si ce pronom a un sens collectif, l'accord reste au singulier. 
dans une seigneurie, et puis on avait louangé ses talents de cuisinière. Elle nous contait ça avec un brin d'orgueil. Une couple ${ }^{19} \mathrm{de}$ fois, je m'étais réveillé - j'étais jeune, peut-être cinq, six ans -, ma vieille grand-mère de sa vieille voix de 95, 96 ans, chantait une vieille complainte que j'ai recueillie ailleurs, pas exactement sur la même mélodie : [il chante]

Il descendit dans ses enfers

Pour l'y voir Marie, sa mie [...]

C'était une nouvelle épousée qui avait été amenée par le diable dans les enfers. Là, le diable lui a demandé ce qui la faisait souffrir, elle dit : «C'est mon jonc, enlève-moi mon jonc et je ne souffrirai plus ». Il lui a enlevé son jonc et la vieille grand-mère disait dans sa chanson :

J'étais ici seulement pour quelques années

Maintenant que tu me l'as ôté

Je suis ici pour l'éternité. ${ }^{20}$

Ça me frappait ça, ce vieux timbre de voix, ça me revenait souvent dans l'esprit.

C'était ça, la vie en famille : des gens, les plus jeunes qui s'informaient auprès des vieux des techniques artisanales; les filles qui étaient un peu orgueilleuses de voir qu'elles avaient réussi leur première soupe ou leurs premières crêpes au lard et le grand-père qui disait : « $\mathrm{Ah}$ ! Tu es bonne à marier, tu as fait de la soupe, tu es bonne à marier ; ton gâteau est extraordinaire, tu es bonne à marier ». Ça nous faisait rire, mais c'était la vie de famille ordinaire.

\section{"J'ai découvert que ma mère chantait"}

Savez-vous que j'ai découvert que ma mère chantait seulement quand j'ai eu mon enregistreuse ? Je lui ai dit que je voulais ramasser des chansons, et une de mes sœurs a dit : « Maman, chante-lui

19. Une couple de pour quelques ; approximation équivalent à plus d'une fois, peut-être deux.

20. Catalogue Laforte II-B-50 La jeune mariée emportée par le diable (Répertoire Coirault 8409). 
donc des chansons ». Et ma mère m'a chanté des chansons. Elle avait une très belle voix. À ce moment-là, elle était un peu timide comme bien d'autres ; comme moi-même d'ailleurs, j'étais très timide. Elle m'a chanté de belles chansons, d'anciennes chansons. Elle me chantait :

Je suis mal à mon aise

Parce que mon mari boit sans raison...

Elle m'avait chanté ça et, à partir de cette version-là, j'en ai recueilli plusieurs autres versions ${ }^{21}$. Elle m'a chanté aussi des complaintes $^{22}$.

\section{"Mon papa aussi chantait"}

Mon papa aussi chantait. Il était timide, lui aussi, mais il avait une bonne voix. Je me rappelle une de ses chansons qu'il nous chantait :
À boire, à boire, mes bons amis
Vous avez l'air tous endormis
À boire, ça nous réveille
Prends ton verre et moi le mien
Vidons cette bouteille. ${ }^{23}$

Il chantait ça au jour de l'An, après qu'il avait pris un petit coup de whisky; le whisky n'était peut-être pas fort, mais, en tout cas, il chantait sa chanson au jour de $1^{\prime} \mathrm{An}^{24}$. D'autres membres de ma famille aussi, mes frères, mes sœurs, que j'ai enregistrés, qui avaient appris le répertoire de la famille.

21. C'est-à-dire que, connaissant cette chanson, il a pu la demander à des informateurs et en recueillir d'autres variantes.

22. Sa mère, Augustine Pelletier, est née en 1878 (75 ans en 1953) et lui a chanté cinq pièces : Centre franco-ontarien de folklore [désormais CFOF], collection Germain Lemieux : « Je me suis mariée... guerre », enreg. 381 ; « Maman, mariez-moi donc», enreg. (?) ; « Je suis dans la tristesse (épouse trompée) », enreg. 419 ; « Amant repoussé à minuit », enreg. 420 ; et « La Fille-matelot », enreg. 473.

23. CFOF, collection Germain Lemieux, enreg. 409, « À boire, à boire, mes bons amis ».

24. Germain Lemieux a enregistré en tout cinq chansons de son père, Norbert Lemieux : CFOF, collection Germain Lemieux : "J'ai fait une maîtresse ", enreg. 382 ; « Chanson de table... trinquons bergère », enreg. 403 ; « Chant de bergère », enreg. 406 ; " Chanson à boire (Buvons, mes chers amis) », enreg. 421 ; et la chanson ci-dessus, enreg. 409. 
Quand on arrivait pendant le carême, pendant l'hiver, il y avait souvent du travail qu'on faisait à la maison, du travail manuel, soit pour carder de la laine ou simplement pour tenir la fusée de laine, comme on disait ${ }^{25}$, sur nos bras pour qu'on puisse la pelotonner. C'était la vie de famille, c'était la technique artisanale du paysan qui occupait ses soirées. Les femmes, les hommes, papa, qui réparait un collier, un autre attelage, etc. C'était la vie et on ne s'ennuyait pas ; jamais je ne me suis ennuyé et naturellement j'ai commencé à sept ou huit ans l'école.

\section{"Elle accroche le violon puis bagne! dans le poêle"}

J'ai commencé à jouer le violon, j'avais sept ans, huit ans ; les doigts n'étaient pas longs et un de mes frères ou un oncle avait fait un petit violon avec deux bardeaux de cèdre. Il n'y avait même pas d'âme - pas de pivot au centre - et puis le premier archet était fait avec du fil à coudre; on mettait de l'arcanson là-dessus et puis ça ne sonnait pas beaucoup, mais, pour le doigté, ça allait. C'est mon grand-père qui m'a montré à accorder mon violon.

Une cérémonie a tourné presque au tragique. En hiver, alors, on allait jouer dehors et puis le samedi c'était notre congé - on n'allait pas à l'école le samedi ${ }^{26}$ - et puis on allait jouer dans la neige. On rentrait les bottes pleines de neige, on se secouait les pieds et des fois on n'avait pas le temps de se secouer les pieds, puis on allait marcher sur le plancher qui venait d'être lavé. Maman nous avertissait : "Allez vous secouer les pieds ». On allait se secouer les pieds, mais des fois on avait laissé des traces. Surtout ce qui a provoqué sa colère, c'est qu'à un moment donné, on était gelé ; alors moi, j'accroche le violon et puis je tape du pied et les autres commencent à danser. Alors imaginez-vous la neige. Maman se choque, c'était une vraie colère, une sainte colère, elle accroche le violon puis bagne ${ }^{27}$ ! dans le poêle. On n'a

25. Et on disait bien, puisque c'est le premier sens figurant au mot fusée dans le Petit Robert : «Vx. Quantité de fil enroulé sur le fuseau d'une fileuse. »

26. Le samedi était jour de congé à l'école primaire.

27. Bagne! Interjection. «Pan! (Onomatopée qu'on emploie en parlant d'un coup soudain) ». Voir Société du parler français au Canada, Glossaire du parler fran- 
plus revu le violon, il a fallu prendre un autre violon. On avait un autre violon qui était plus gros par exemple. Mais il a fallu attendre d'avoir les doigts assez longs pour s'en servir.

\section{"On ne dansait pas chez nous"}

La danse chez nous, on n'en a pas fait beaucoup, sauf sauter, sautiller comme ça, parce que c'était défendu par l'Église, par les curés, de danser. À une des noces, au mariage de l'une de mes plus vieilles sœurs, on avait été demander au curé pour voir si on pouvait danser; il a dit non, parce que c'était une enfant de Marie $^{28}$ et que ce serait un scandale à donner de danser. Alors c'était fini, on ne dansait pas chez nous. Ailleurs, je ne peux pas dire. Je n'ai pas appris à danser ; j'aurais aimé danser, mais j'étais toujours le violoneux. À sept ans, je zigonnais ${ }^{29}$ et des fois c'était moi qui jouais du violon, surtout quand on était au séminaire, au collège ${ }^{30}$. J'aurais aimé ça, je trouvais ça élégant, je trouvais que c'était un sport intéressant, mais je n'ai jamais appris à danser.

\section{"Le bureau de poste, c'était un rendez-vous"}

C'était un rendez-vous chez nous parce qu'il y avait bien du monde, il y avait quatre générations. On avait le bureau de poste et puis les gens venaient chercher leurs lettres à différentes heures de la journée - c'était une de mes sœurs qui gardait le bureau et c'était mon père qui signait les papiers officiels - ou venaient se renseigner ou bien demander conseil, ou venaient acheter des

çais au Canada, Québec, Action sociale, 1930 ; réimpression : Québec, Presses de l'Université Laval, 1968.

28. L'association pieuse des Enfants de Marie immaculée a été créée en 1847, à la suite des apparitions de la Vierge qui en aurait fait la demande à sainte Catherine Labouré en 1830. Elle était destinée aux jeunes filles et aux célibataires qui s'engageaient à modeler leur conduite sur la Vierge Marie. Voir « Clin d'œil sur nos traditions. Les confréries », dans le Réseau de diffusion des archives du Québec (rdaq. banq.qc.ca, source consultée le 28 mai 2012).

29. Jouer un peu ou maladroitement du violon.

30. Au Canada français, on a « gardé le modèle du séminaire-collège que $\mathrm{M}^{\mathrm{gr}}$ de Laval avait inauguré au petit séminaire de Québec, pour former des prêtres et des chefs civils ». Voir Claude Galarneau, Les Collèges classiques au Canada français [1620-1970], Montréal, Fides, « Bibliothèque canadienne-française - Histoire et documents », 1978, p. 90. 
choses, de la viande, des patates. C'était notre vie de famille, une vie communautaire qui était intéressante parce qu'on connaissait tout le monde. Dès qu'il y avait quelqu'un dans le canton ou dans la paroisse qui était malade ou qui venait d'arriver, on le savait parce que toutes les nouvelles se transmettaient au bureau de poste. C'était cette ambiance, le bureau de poste, c'était un rendez-vous. C'était le rendez-vous chez nous, le grand rendez-vous ${ }^{31}$. Ç'a été la vie de ma famille en général.

\section{"Un monsieur qui avait une belle voix, un Larrivée"}

Et mon arrière-grand-mère, celle qu'on appelait grand-mère Désinas, était friande de chansons. Et il y avait un monsieur qui avait une belle voix, un Larrivée, une belle voix ronde, quelque chose de sonore. Dès qu'elle l'entendait rentrer - elle était complètement aveugle, mais elle avait une oreille extraordinaire -, dès qu'il mettait les pieds dans la maison : «Michel Larrivée est ici, va lui demander une chanson, va lui dire de venir ici, laisse-le pas partir avant qu'il ait chanté une chanson ». Quand il n'était pas trop pressé, il venait et puis il lui chantait une chanson; là, elle était contente. Et ensuite il faisait son affaire au bureau de poste. Souvent, quand il rentrait et qu'il était pressé, il mettait sa main sur sa bouche : «Parle pas à ta grand-mère ». Il filait. Ces chansons-là, je les ai entendues puis, quand j'ai eu mon enregistreuse, j'ai revu ce vieux monsieur Larrivée-là qui m'a chanté son répertoire $^{32}$. Il avait une voix forte et autrefois, une belle chanson, c'était une chanson qui [se chantait d'] une voix forte, une voix sonore où on faisait filer sa voix sur certains accords.

31. Ce témoignage illustre en partie le « rôle social du bureau de poste " (chap. 4) du livre de Chantal Amyot et John Willis, Le courrier est arrivé : la poste rurale au Canada de 1880 à 1945, Gatineau, Musée canadien des civilisations, " Collection Mercure », Musée canadien de la poste, 2, 2003, p. 105-120.

32. Michel Larrivée, 72 ans en 1953, lui a donné dix chansons : CFof, collection Germain Lemieux : " Par un automne (chantiers) », enreg. 309 ; "Vive la bosse et les bossus », enreg. 310 ; " À quoi sert-il de tant boire ? », enreg. 312 ; " Retour du soldat (mari)... le jour de », enreg. 357 ; « Oh verse, mon vieux, à boire », enreg. 363 ; «L'Habitant de Sainte-Barbe », enreg. 367 ; « Chanson d'amour », enreg. 427 ; « Le petit bonhomme se s'couait », enreg. 429 ; «La Petite Printanière ", enreg. 431 ; et «On ne meurt pas d'amour (romance) », enreg. 432. 


\section{"Je me rappelle très bien le bruit des carabines"}

Ensuite, il y avait cinq filles chez nous. Quand elles ont commencé à grandir, il y avait des petits gars qui venaient les voir. Ça ne dansait pas, mais ça chantait, ça faisait des jeux, ça racontait toutes sortes de choses. Pendant la guerre de 1914, je n'étais pas vieux, je devais avoir quatre ans parce que la guerre a fini en 1918, il y avait des gens qui venaient chez nous voir les petites filles et qui étaient déserteurs, pas déserteurs de l'armée, mais qui ne voulaient pas aller à l'armée. Ils vivaient dans le bois avec leur carabine pour faire peur aux gens qui allaient les déloger. Ils arrivaient à la maison, ils mettaient leur carabine sous le perron et ils rentraient. À un moment donné, maman leur a dit : « Ce n'est pas prudent ça, si les gens du gouvernement arrivaient, vos carabines sur la galerie, vous ne seriez pas capables de vous défendre ». Ils disaient : « Ils ne viendront pas, ils ne viendront pas ». C'étaient des scènes comme ça auxquelles on assistait puis je me rappelle très bien le bruit des carabines qu'ils mettaient sur la galerie : «Tiens, des gens qui arrivent du bois... » Ensuite, ça chantait, ça contait et, dans cette veine-là, il y avait un de nos cousins, un Chrétien, qui venait chez nous pour assister à ça, pas directement voir mes sœurs, mais il venait avec d'autres, parfois pour les conduire, et puis il chantait. Il avait un répertoire extraordinaire. Je l'ai revu cinquante ans après et il m'a donné son répertoire.

\section{"Toutes ces choses-là me rentraient dans l'oreille"}

Au bureau de poste, je me rappelle, une fois, il y avait un habitant qui était venu, vers 1930. Il voulait faire un emprunt pour réparer quelque chose à sa ferme. Il a envoyé ses paperasses et le ministère a répondu : «Le cadastre que tu me donnes ne correspond pas à la réalité. Les mesures des voisins ne sont pas les mêmes, la géographie n'est pas la même. » Alors il a dit : «Qu'est-ce que c'est que je vas faire ?... Je ne suis pas capable d'emprunter ». Mon grand-père, qui était dans les 85, 90 ans pas loin, lui dit : « Écoute un peu, quand j'étais jeune, il y a eu dans ce coin-là un glissement de terrain ou une catastrophe quelconque puis ils ont 
refait le cadastre pour en donner autant à l'un, puis à l'autre. Et, si tu allais à Percé ou à Sainte-Anne-des-Monts, peut-être que le vieux cadastre te donnerait raison parce que le cadastre a été changé ». Quelques semaines après, le monsieur est venu puis il a dit : «C'est ça, j'en ai référé à Percé et, d'après l'ancien cadastre, le cadastre a été changé à telle date... » Toutes ces choses-là me rentraient dans l'oreille.

\section{"Tout le monde parlait du naufrage du Delta"}

À un moment donné ${ }^{33}$, quelqu'un avait écrit qu'il avait eu connaissance d'un naufrage, le Delta, il se rappelait le nom ; il ne savait pas quelle était la date. Ça m'était resté dans la tête : le naufrage du Delta; il y avait eu plusieurs pertes de vie et il y avait eu du matériel de perdu, on dirait à ce moment-là pour un demi-million, c'était gros, tout un bâtiment. Imaginez-vous que, rendu à l'Université Laval, je me suis servi de ce souvenir-là, du naufrage du Delta, dont j'avais lu le récit vaguement, mais il n'indiquait pas la date. Alors j'ai proposé à monsieur Lacourcière ${ }^{34}$ : « Est-ce que ce serait possible de faire une enquête là-dessus pour voir la date approximative au moins de ce naufrage-là ? » Parce que ç'avait été courant par chez nous, tout le monde parlait du naufrage du Delta, mais ça faisait quasiment 100 ans que c'était arrivé, mais en tous les cas. Il m'a dit très bien et il a approuvé mon questionnaire. Le premier que j'ai questionné, il m'a dit : « La date, je peux bien te le dire, je vais avoir 80 ans dans quelques mois puis c'est arrivé l'année où je suis né. Mon père, grand-père François, il a été gardien à bord du bâtiment qui était sur le flanc et puis il fallait qu'il aille surveiller ça pour pas que les gens aillent voler trop souvent. Va voir madame Roy, elle a 96 ans, puis elle a assisté au naufrage ; tu vas avoir des renseignements ». Je suis allé voir la dame. Je l'ai questionnée, elle était tellement faible,

33. Date indéterminée.

34. Luc Lacourcière (Saint-Victor de Beauce, Qc, 1910-Beaumont, Qc, 1989). Professeur de littérature orale, fondateur du premier programme d'enseignement de l'ethnologie au Canada, les Archives de folklore, à l'Université Laval. Il a donné des cours à Germain Lemieux lors de ses études de maîtrise et de doctorat. 
elle était couchée. J'ai mis le microphone sur son oreiller puis j'ai dit : «Quand vous serez fatiguée, dites-le-moi ». Elle m'a raconté l'histoire du naufrage. C'étaient des souvenirs d'enfance, ce naufrage-là, et puis elle m'a raconté comment c'était arrivé35.

\section{"Mon vieil oncle, Jean-Mathias Lemieux"}

Il y avait un de mes oncles qui était à Ottawa, qui travaillait pour une compagnie d'assurances, et puis qui revenait chez nous pour passer ses vacances. Il n'enregistrait pas de chansons lui, c'était vers les 1922-1923, il les apprenait par cœur et il retournait à Ottawa et il les chantait à un monsieur Larose, un musicien, qui les mettait en musique ${ }^{36}$. J'ai vu dans le Romancero que Barbeau avait utilisé plusieurs chansons qui venaient de la Gaspésie et qui ont été recueillies par mon vieil oncle Jean-Mathias Lemieux, d'Ottawa ${ }^{37}$. C'est lui qui nous stimulait un peu, il nous chantait de ces chansons qu'il venait d'apprendre. Il organisait nos SaintJean-Baptiste : on organisait deux, trois voitures, des chevaux puis des arbres, des épinettes, le violon là-dedans, on tapait du pied puis on chantait. C'était l'ambiance de la Saint-JeanBaptiste stimulée par mon vieil oncle. J'aimais ça, chanter aussi,

35. Il a été impossible de préciser la date de ce naufrage par les registres officiels. La Base de données sur les navires, produite par Patrimoine canadien, compte 24 navires nommés Delta, mais aucun qui corresponde à un naufrage dans le SaintLaurent. De même, le chasseur d'épave Samuel Côté, responsable du portail www. lecimetieredusaint-laurent.com, n'a rien trouvé dans ses archives selon son courriel du 27 mars 2012.

36. Il s'agit vraisemblablement de Paul Larose (1906-1993), musicien d'Ottawa, organiste, professeur, compositeur et traducteur. Le fonds Paul-Larose (P345), déposé au Centre de recherche en civilisation canadienne-française de l'Université d'Ottawa, contient, entre autres, des arrangements d'œuvres de folklore.

37. Jean-Mathias Lemieux (1876-1943) fait en effet l'objet de quatre mentions dans le Romancero du Canada de Marius Barbeau ([Montréal], Éditions Beauchemin ; [Toronto, Macmillan], 1937) : en 1926, à Montréal, il chante à Édouard-Zotique Massicotte " Ramenez vos moutons du champ », version " apprise de $\mathrm{M}^{\text {me }}$ Joseph Beaulieu, vers $1880 »$ de Cap-Chates (Gaspé) (p. 251). Mais, les trois autres versions, toujours interprétées par J.-M. Lemieux d'Ottawa, sont inscrites dans la « collection Lemieux » : en 1930, «Les Roses blanches », " version apprise par M. Jean Lemieux, vers 1885, de Charles Côté, Cap-Chates » (p. 142); en 1931, « La belle a pris l'épée », « version apprise de Aug. Sergerie, du Cap-Chates, en 1929 » (p. 53) : et la même année, "Faites-moi un homme sans tête ", version " apprise de son grand-père, Michel Lemieux, au Cap-Chates, vers $1880 »$ (p. 241). 
et quand $\mathrm{j}$ 'avais cinq ans, peut-être avant, on me faisait choquer. Il paraît que j'avais une assez belle voix - je l'ai perdue malheureusement - je chantais une chanson : "Brave bâtiment... une tempête qui fait craquer la mâture ». J'ai appris, seulement quand j'ai commencé à vieillir un peu, pourquoi ils me faisaient chanter cette chanson-là ; ils riaient de moi parce que je disais « craquer la nature » au lieu de la mâture. Alors j'étais toujours intéressé à ça [la chanson], et quand mon oncle apprenait des chansons des vieux et qu'il nous chantait ça, chez nous aussi, ça m'intéressait.

\section{"La grand-tante Marguerite "}

Dans mon enfance, j'avais entendu des contes à l'âge de cinq ans, même avant que j'aille à l'école. Dans ma famille, il y avait deux vieilles tantes, des jumelles, les sœurs de mon grand-père - à ce moment-là, elles étaient dans les 75, 78 ans -, elles venaient visiter leur mère qui était la grand-mère Désinas, notre arrièregrand-mère. Elles restaient à peu près à un mille [1,6 km], un mille et demi $[2,4 \mathrm{~km}]$ de chez nous, et venaient à pied visiter leur maman. Il y en avait une surtout, la grand-tante Marguerite ; quand on la voyait venir, on sautait après elle puis on disait : « Ma tante, ma tante Marguerite, venez nous conter une histoire, venez nous conter un conte ». Elle disait : «Attendez, attendez un peu, attendez, on va rentrer dans la maison, on va s'asseoir... » Elle causait un peu avec sa vieille maman puis, ensuite, quand elle était disponible, elle nous contait un conte. Elle était assez bonne conteuse. Ç'a commencé à m'intéresser mais, à ce moment-là, comme je n'avais pas fait d'études encore, je n'ai pas fait le joint entre la tradition grecque puis la tradition orale canadienne ${ }^{38}$.

\section{"Il y avait des quêteux qui passaient"}

Il y avait des gens, je ne dirais pas des grands conteurs, mais des vieux qui venaient à la maison. C'étaient des légendes, surtout des

38. Voir plus loin, en quatrième partie, l'usage pédagogique qu'il tirera des rapports entre conte populaire et mythologie grecque dans ses premières années d'enseignement à Sudbury. 
faits qu'ils avaient ramassés. Il y avait des quêteux $x^{39}$ qui passaient. Il y a un vieux qui nous disait : " Vous savez, la radio s'en vient ; ça s'en vient la radio ». J'avais sept ans, c'était en 1920-1922. "Qu'est-ce que c'est ça, la radio ? - Tu vas entendre les gens parler, au loin, peut-être à vingt-cinq milles [40 km]; c'est ça la radio ». C'était impossible... un vieux quêteux... Mon père était allé passer une dizaine d'années aux États-Unis, à Manchester, et il savait un peu l'anglais. Il y avait un Anglais - ce n'était pas un vrai quêteux, c'était plutôt un bonhomme qui demandait à coucher chez nous ; papa le comprenait-, Thomas Devine. Je me rappelle son nom. Il nous faisait toutes sortes de tours et puis il nous racontait des bouts en anglais. Papa nous disait : il raconte telle légende, il raconte tel fait. Il y en avait d'autres qui parlaient français et qui venaient demander à coucher ou qui demandaient simplement à manger. Je ne me rappelle pas de contes qu'ils nous contaient, mais ils nous contaient des faits qui étaient arrivés ailleurs. Ces quêteux-là, ils partaient des alentours de Québec et même plus loin, puis ils aboutissaient en Gaspésie. Tout le monde dans les paroisses, là où ils couchaient, les gens leur donnaient leurs nouvelles. Ils avaient un paquet de nouvelles, un sac extraordinaire de nouvelles. C'était surtout ça.

Il y en a une couple de conteurs qui sont arrêtés chez nous. Je me rappelle vaguement le titre de leurs contes. Il y avait un vendeur d'instruments aratoires qui venait chez nous de temps en temps ; il était assez bon conteur. Un des premiers contes qu'il m'a contés, c'était une vie de saint, un conte hagiographique ; je sais qu'il nous en avait conté à plusieurs reprises. Quand on le voyait arriver, puis qu'il avait fini de vendre ses affaires et de proposer ses ventes, on s'assoyait puis on l'écoutait.

\section{"Alexis Thibault, lui, c'était un vrai conteur"}

Ensuite, quand j'étais d'âge scolaire, j'avais peut-être huit ans, neuf ans, il y avait un vieux conteur qui passait régulièrement

39. De quêteur, mendiant. Dans les villages, le quêteux était souvent accueilli et hébergé dans une famille pour un ou plusieurs jours. 
pendant le carême. Le vieil Alexis Thibault, lui, c'était un vrai conteur. Je ne sais pas si ses descendants vont m'entendre, on le trouvait laid, nous autres les jeunes. Laid, laid, laid, quand on le regardait, ça portait à rire. Il avait une grosse barbe blanche - qui avait déjà été blanche : il fumait la pipe et il avait laissé des traces dans sa barbe. Mais, dès qu'il commençait à conter, on oubliait cette laideur-là. On était assis par terre. Et, des fois, on n'était pas loin de la porte et la porte ne fermait pas juste, on était obligé de garder notre paletot pour endurer ça. On oubliait le froid, on oubliait la face du bonhomme, il était tellement bon conteur qu'on lui aurait pardonné n'importe quoi. Il nous disait, quand il était question du mariage : « Il sacre " $^{40}$ une claque en-dessous de la tasse à boire puis plouc ! il est marié ». On se mettait à rire puis à applaudir. Il y avait un verre à côté puis il prenait une gorgée. Il disait que c'était de l'eau, peut-être qu'il y avait d'autre chose dans l'eau parce qu'il allait souvent au verre ; il nous faisait applaudir souvent pour aller souvent au verre.

\section{"Là, j’ai pris gô̂t au conte "}

Il était tellement sympathique puis il contait tellement bien. On l'écoutait. Là, j'ai pris goût au conte. Le lendemain matin à l'école, les gens se risquaient à conter un bout de conte. Je me rappelle qu'une fois il y en avait un qui avait entendu le conte de « Ti-Jean qui joue des tours à son seigneur », puis il a vendu tous les cochons du seigneur à un boucher, mais il s'est réservé les oreilles et les queues, et puis pour montrer à son seigneur que les cochons s'étaient engloutis dans une vasière, il est allé dans la vasière puis il a planté deux oreilles et une queue ${ }^{41}$. Le petit gars nous contait à l'école : «Deux arleigues [oreilles], il s'en va dans la savane, deux arleigues puis une queue, puis deux arlei-

40. Sacrer, v. tr. Donner une claque, un coup.

41. Conte type Atu 1004 Les Cochons embourbés du cycle de l'ogre stupide Ати 1000-1029 Contrat de travail (le pari de la colère). Voir Hans-Jörg Uther, The Types of international folktales. A classification and bibliography based on the system of Antti Aarne and Stith Thompson, Helsinki, Academia Scientiarum Fennica, «FFC » 285,2004 , vol. 2, p. 9-10. 
gues puis une queue $»$. On riait, nous autres, mais on savait tout de même qu'il était allé entendre conter ce conteur-là puisqu'il était au courant des deux oreilles puis de la queue que plantait Ti-Jean dans la vasière. Alors les gens de notre âge, sept, huit, neuf, dix ans, faisaient une espèce d'exercice de mémoire et puis en même temps d'élocution devant les petits gars. Puis les autres écoutaient ça, même la maîtresse d'école, l'instituteur, venaient écouter ça pour voir ce qui nous intéressait tellement.

\section{"On avait la permission d'aller écouter le conteur"}

C'était un bonhomme excessivement intéressant et il y avait des légendes qui couraient à son sujet. Il y en a qui disaient que sa vieille ne pouvait pas l'endurer à la maison; elle disait : «Fous ton camp ». Lui, il allait conter des contes, il prenait un mois, puis il passait de maison en maison dans la paroisse et il contait des contes. On l'attendait, c'était surtout pendant le carême. Les gens faisaient des blagues, ils disaient que c'était pour économiser ; pendant le carême, il gagnait sa nourriture en allant de maison en maison pour conter des contes. Il venait dans notre canton à nous autres aussi et puis, quand on s'était bien conduit, qu'on savait bien nos leçons, qu'on avait un bon résultat, on avait la permission d'aller écouter le conteur, à partir de sept heures le soir, mais il fallait revenir pas plus tard que neuf heures et demie parce qu'on avait de la classe le lendemain matin; tout était organisé. Je me rappelle d'être allé plusieurs fois, plusieurs années même, écouter ce vieux conteur-là ${ }^{42}$. C'était peut-être sa pénitence de carême, une pénitence que le curé lui donnait : aller conter des contes pendant tout le carême. Il était très populaire et il venait à peu près à chaque année et je ne me rappelle pas qu'il nous ait conté le même conte deux fois. J'ai enregistré ensuite certainement un de ses garçons qui a prétendu me raconter le répertoire de son père ${ }^{43}$. Je ne sais pas s'il m'a tout conté, mais il m'en a

42. Il est toujours question d'Alexis Thibault.

43. Il s'agit d'Alfred Thibault, âgé de 60 ans en 1955, de Petits-Méchins (CapChat). Ses onze contes, dont sept ont été recueillis en 1955 et quatre en 1960, sont consignés dans la série Les vieux m'ont conté (vol. 31, p. 13-238). 
conté toute une batelée $e^{44}$. Ils étaient de ma paroisse, c'étaient des anciens marins. À ce moment-là, ils ne naviguaient plus, mais je sais qu'il y a souvent des souvenirs de leurs travaux sur la mer.

\section{"J'aimais énormément l'école "}

Je ne sais pas trop de qui je tenais ça, mais j'aimais ça énormément, l'école. J'appréciais le moindre renseignement, la moindre remarque de l'institutrice - on appelait ça une maîtresse d'école à ce moment-là. Au début, c'étaient des institutrices laïques qui étaient très dévouées et qui nous enseignaient tout ce qu'elles savaient, peut-être plus que ce qu'elles savaient. À ce moment-là, vous savez, à l'école élémentaire, c'était surtout la mémoire ; on étudiait nos leçons, le catéchisme, l'écriture sainte, l'histoire, et c'était de la mémoire ; il fallait apprendre tant de pages, tant de paragraphes par soir. Les maîtresses d'école trouvaient que j'avais une bonne mémoire et surtout que je ne refusais pas, comme bien d'autres, d'étudier. Elles disaient : " Celui-là, on devrait le faire étudier, il a un certain talent, il a une bonne mémoire ».

\section{"On avait la permission d'aller glisser et de faire du sport"}

Le soir, quand c'était beau [1'hiver], qu'on avait fait nos devoirs, appris nos leçons, on avait la permission d'aller glisser et de faire du sport. Une fois, on a failli se tuer, c'était sur la croûte le printemps, vers le mois de mars. Il venait une espèce de croûte sur la neige et c'était très glissant. On avait été chercher une traîne à bâtons ${ }^{45}$, une traîne à cheval comme on disait. On montait ça, ça nous prenait vingt minutes, une demi-heure à monter ça au sommet des côtes, et Dieu sait s'il y en avait des côtes chez nous ; puis on glissait près de la côte où c'était dangereux, il y avait un précipice là, il y avait une espèce de banc de neige. On embarquait sept, huit, dix là-dedans et, une fois que c'était parti, ça marchait. Il y en avait une couple qui gouvernaient ça avec des

44. Batelée, s. f., un grand nombre.

45. Voiture d'hiver, munie de bâtons fixés verticalement de chaque côté de la plate-forme, servant au transport du bois et d'autres marchandises. Elle est faite pour être tirée par un cheval. Voir Glossaire du parler français au Canada, op. cit. 
bâtons qu'ils mettaient entre les bâtons de la traîne pour faire un frein : parfois on tournait à gauche, on tournait à droite, et quand on arrivait sur le bord du précipice, la côte de la grève comme on disait, on tournait dans le banc de neige. Une fois, on a failli manquer notre coup. On est allé proche du précipice. On avait eu la frousse. On a remis la traîne à sa place et puis je ne dis pas qu'on ne s'est pas aventuré dans d'autres aventures...

\section{"Elle s'appelait Aurore Loranger "}

Quand j'ai quitté la petite école en dehors du village, j'avais treize ans, je suis allé chez les religieuses au couvent ; c'était l'école modèle ${ }^{46}$, pour me préparer au collège ${ }^{47}$. Je ne dis pas que j'avais une idée très précise d'être prêtre, mais c'était dans la tradition, on était très pieux chez nous. Ma vieille grand-mère disait le chapelet, on avait la prière en famille à tous les soirs et puis il fallait aller à la messe les premiers vendredis du mois ${ }^{48}$; ça, c'était sacré, malade ou pas malade, occupé à l'école ou non, on allait au premier vendredi du mois. Ma famille était en bonne relation avec le curé. Alors, que j'aie eu l'idée de la prêtrise, ce n'est pas impossible ; en tout cas, peut-être qu'on a flairé que j'avais le talent pour étudier au moins. Je suis allé étudier chez les sœurs, et là j'ai vu un dévouement extraordinaire ${ }^{49}$. À ce

46. C'était le nom qu'on donnait à un type d'école qui assurait la transition entre le niveau primaire et le secondaire. " Comme il n'y a ni école normale, ni académie, ni collège en Gaspésie au $19^{\mathrm{e}}$ siècle, c'est l'école modèle qui offre la possibilité au jeune de prolonger ses études et surtout de se préparer à l'enseignement ». Voir Jules Bélanger et al., Histoire de la Gaspésie, op. cit., p. 495.

47. Claude Galarneau remarque : «L'enseignement primaire et l'enseignement classique se sont développés côte à côte, tout en s'ignorant mutuellement à partir de $1840 »$ (op. cit., p. 51). C'est ce qui expliquerait la nécessité de cette préparation spéciale à laquelle devaient se soumettre à la fin de leur cours élémentaire les candidats aux examens du collège classique. Parfois, les élèves devaient faire une huitième année à l'élémentaire (alors que le cours en comptait normalement sept) ou une classe préparatoire au cours classique (ibid., p. 147-148).

48. Dévotion découlant de la promesse faite par Jésus-Christ en 1688, au cours d'une apparition à sainte Marguerite-Marie, d'accorder la grâce de la pénitence finale à ceux qui auront communié neuf premiers vendredis du mois consécutifs. Source : http://notredamedesneiges.over-blog.com/article-10703440.html (consultée le 28 mai 2012).

49. L'école était tenue par les Filles de Jésus de Kermaria, communauté française fondée en 1834 ; arrivées au Canada en 1902, elles se sont installées à Cap-Chat 
moment-là, le nom de famille des religieuses, c'était caché, ça. On était venu à bout de savoir que notre institutrice venait de Shawinigan et elle s'appelait Aurore Loranger ${ }^{50}$; et, en classe, dès qu'il y avait le mot aurore, on mettait l'accent là-dessus. Elle riait, elle savait bien qu'on savait son nom, mais jamais elle nous l'a dit officiellement. Sept jours par semaine, elle nous faisait la classe, même le samedi ${ }^{51}$. Nous allions la voir, nous étions quatre à nous préparer pour aller au collège. On l'aidait à laver sa sacristie, on l'aidait à laver son plancher, on l'aidait à enlever la poussière dans les escaliers et ensuite elle nous donnait une leçon d'orthographe, une leçon de mathématiques, une leçon d'analyse logique, d'analyse grammaticale. Elle avait toutes sortes de trucs pédagogiques qu'on aimait. Elle nous faisait rire, toutes sortes d'histoires, et puis tout à coup : bagne ! Là c'était sérieux, là on commence : «Il faut voir ça, voir ça, voir ça ». On a réussi. Et puis le dimanche, même le dimanche, on faisait la classe avant la grand-messe, il fallait aller à la grand-messe. Elle était sacristine ; alors, on allait l'aider à préparer la messe, puis ensuite elle nous donnait une leçon. Avant les vêpres, on avait notre leçon, après les vêpres on avait notre leçon et c'était sérieux.

\section{"Je n'ai jamais regretté d'avoir travaillé fort"}

Quand je suis arrivé au collège, au séminaire de Gaspé, la première lettre que j'ai écrite, c'est à cette sœur-là, parce qu'elle avait peur qu'on n'entre pas en élément français ${ }^{52}$; il y avait l'élément français et l'élément latin, et, pour entrer dans l'élément latin, il fallait passablement connaître, entre autres, son français, connaître entre autres son analyse logique, au moins son analyse grammaticale. On est entré au séminaire et puis il y avait des examens. On avait

en 1904. Voir Guy Laperrière, Les Congrégations religieuses : de la France au Québec (1880-1914), Sainte-Foy, Presses de l’Université Laval, 1996, vol. 2, p. 265, et p. 424-427 ; Jules Bélanger et al., Histoire de la Gaspésie, op. cit., p. 484 et p. 497.

50. Curieusement, le témoin n'a retenu que le nom de jeune fille de son institutrice, alors que le nom de religieuse était habituellement le seul connu.

51. Cette classe préparatoire commandait un horaire exceptionnel.

52. Le père Lemieux fait ici allusion à la maîtrise préalable du français dont la carence nécessitait une classe de rattrapage. 
certainement trois jours d'examens si je me rappelle bien, pour l'orthographe, pour l'analyse logique, pour l'analyse grammaticale, l'histoire, la religion, etc. Dans cette lettre, je lui ai écrit : «Ne vous en faites pas, des quatre que vous avez préparés, nous sommes trois arrivés les premiers à l'examen ». Je ne sais pas si j'étais le plus brillant, mais j'avais eu 82 ou 83 à cet examen-là. C'était la préparation immédiate que j'ai eue pour aller au cours classique et je n'ai jamais regretté d'avoir travaillé fort. Parce qu'il fallait travailler fort, se lever de bonne heure le matin. Souvent je me levais de bonne heure pour aller servir la messe du curé qui disait la messe chez les sœurs ; après ça, on embrayait dans les études. Même à la maison, il y avait un entraînement : il fallait travailler ; quand quelqu'un était désigné pour telle besogne, il fallait la faire, il n'y a personne qui disait : «Je n'ai pas le temps »; il fallait y aller. C'était la même chose quand les sœurs nous disaient : « Il faut faire ça »; c'est dur l'analyse logique, mais on va le faire. Alors on est arrivé au collège, c'était le même entraînement, on y allait.

\section{II - Études AU SÉMiNAIRE de GASPÉ (1928-1935)}

\section{"Je me croyais bien préparé"}

En 1928, je pars pour le séminaire de Gaspé. Chez les jésuites, il y avait les éléments français, pour ceux qui n’étaient pas encore préparés à étudier le latin; il y avait les éléments latins puis la syntaxe, la méthode, la versification, etc. C'était huit années de cours avec les deux années de philosophie ${ }^{53}$. Je me croyais bien préparé. J'ai entrepris les éléments latins et, comme j'étais habitué à travailler à l'école, surtout l'année préparatoire au séminaire, ça

53. Le cours classique durait normalement huit ans après sept années de cours primaire, et on désignait ainsi les classes : éléments latins [en France sixième/aujourd'hui au Québec secondaire I], syntaxe [cinquième/secondaire II], méthode [quatrième/secondaire III], versification [troisième/secondaire IV], belles-lettres [seconde/secondaire v], rhétorique [première/cégep I], suivies de deux années de philosophie : philosophie I [cégep II] et philosophie II. Voir Claude Galarneau, op. cit., p. 167. Les équivalences avec les systèmes actuels québécois (dont le primaire dure six ans) et ontarien (qui dure huit ans) sont fort approximatives. 
allait bien. Parfois je me permettais d'aider les autres : des gens qui venaient de la baie des Chaleurs et qui, parfois, savaient moins leur français que nous autres. Il y avait des petits Acadiens et il y en avait un qui me disait : "Risez pas de moi... " Alors, nous autres, on riait encore plus. Parfois on leur disait que c'était rire [et non riser] : ne riez pas de moi ${ }^{54}$. Mais, en tous les cas, c'étaient des petits essais de pédagogie comme ça.

\section{"Ils appelaient ça "sauter une année" "}

J'ai fait mon cours d'une façon assez sérieuse. Après quatre mois, on m'a dit comme à deux ou trois autres : «Vous êtes capables, si vous travaillez un peu plus fort, de faire vos éléments latins et votre syntaxe la même année ». Ils appelaient ça « sauter une année », mais il fallait accepter le régime. Au collège, le mardi après-midi, nous avions congé : mais, nous autres, il fallait retourner en classe ; le jeudi après-midi, c'était congé : il fallait retourner en classe ; le dimanche c'était congé : on faisait de la classe pour aborder le grec et s'avancer un peu dans le latin, le français et les petites sciences - il fallait faire les petites sciences aussi en syntaxe. Je me rappelle qu'avec notre professeur, qui avait accepté de nous faire à la fois le latin et le grec, nous allions le jeudi, au printemps, à la campagne, et il nous familiarisait avec les fameuses questions des cas du latin : les in, quand on reste là : je suis dans la maison in, c'est tel cas [ablatif]; puis si on va dans une ferme ou qu'on va chez un voisin, in, c'est un accusatif... et tout ça ; c'était très pratique. Ensuite, il nous montrait quelques petites chansons en latin ou en français pour appuyer ses trucs pédagogiques. Rendu au mois de juin, il fallait passer des examens en latin et en grec. Ce qui avait humilié énormément le professeur de syntaxe, c'est que deux au moins de notre groupe étaient arrivés, en grec, avant ceux qui avaient fait une année de grec. On est monté en méthode qu'on appelait, en troisième

54. Environ un millier d'Acadiens se sont réfugiés sur la rive gaspésienne de la baie des Chaleurs après la dispersion de 1755-1760 et, jusqu'en 1780, ils forment la majorité de la population établie à Carleton, Bonaventure, Paspébiac, Gaspé et Percé. Voir Jules Bélanger et al., Histoire de la Gaspésie, op. cit., p. 142-144. 
année au lieu de la deuxième. Je me croyais assez préparé aux études et je n'ai pas eu de misère du tout à faire la méthode. Et ç’a continué comme ça.

\section{"Nous restions au séminaire}

\section{pendant les vacances du jour de l'An"}

Les professeurs étaient intéressants en général ; surtout on avait remarqué qu'ils étaient très dévoués et même en dehors de la classe : si on voulait un renseignement ou si on avait une difficulté, en récréation on les rencontrait et ils nous donnaient facilement une solution. Je me rappelle surtout le dévouement de ces pauvres pères. J'étais du groupe de ceux qui n'allaient pas chez eux à Noël parce que nous n'avions pas de train chez nous. À ce moment-là, en 1928-1929, le boulevard Perron avait été fait ${ }^{55}$, mais on ne le déblayait pas en hiver de sorte que c'était très difficile de passer d'une paroisse à l'autre, même en voiture à cheval : on restait au séminaire. Il y avait trois élèves qui venaient de l'île d'Anticosti ; naturellement, au mois de décembre, il n'était pas question de traverser en bateau; et, nous autres, il n'était pas question d'aller chez nous. Nous étions huit ou dix qui restions au séminaire pendant les vacances du jour de l'An. C'était un sacrifice, mais tout de même on s'amusait très bien. Les pères se prêtaient assez facilement à nous donner des petites conférences. Le père Dallaire, qui venait de la Beauce, recevait des petits cadeaux de ses parents, du sucre d'érable, de la tire d'érable... et il nous emmenait dans le bois assez régulièrement pour luncher, comme on disait. Il y avait toujours un peu de sirop d'érable, de sucre d'érable, et le lendemain ou deux jours après, même quand il faisait froid, je me rappelle avoir mangé des crêpes dans le bois et le sirop gelait sur la crêpe ; on mangeait ça quand même, c'était bon. Ils étaient comme ça pendant les vacances du jour de l'An, du 22 décembre jusqu'au 4 ou 5 janvier. Ils nous amusaient. Pendant ce temps-là, on avait le temps de lire et d'apprendre un peu toutes sortes de

55. Le boulevard Perron, ouvert en 1929, est devenu la route 132 qui ceinture la Gaspésie. 
choses ; on faisait la classe pratiquement, on rédigeait nos fameux cahiers dans lesquels on devait mettre en rouge et en bleu nos déclinaisons et les principales difficultés du grec et du latin. On faisait ça pendant les vacances du jour de l'An, ça nous occupait.

\section{"La vie du séminaire, c'était une vie de famille"}

Les gens nous prenaient un peu en pitié de rester au séminaire, mais nous autres on était content. Je suis allé chez nous une fois, en philosophie, et si j'avais eu une autre année au séminaire, je n'y serais pas retourné [dans ma famille]. Imaginez-vous que c'est deux jours où nous avons été sur le train pratiquement, en voyage. Il y avait eu un raz-de-marée dans la baie des Chaleurs. Il y avait des gens qui enlevaient les glaçons devant le train pour qu'on passe, on avançait à petite vitesse. Quand on a été rendu à Mont-Joli, on a appris que le raz-de-marée avait eu lieu la veille sur le bord du fleuve. La plupart des poteaux de télégraphe et de téléphone avaient été cassés, brisés : pas moyen de télégraphier, de téléphoner chez nous qu'on était en retard; ils s'en sont doutés d'ailleurs. Là on a dit à quelqu'un : «Tâchez donc de vous informer quel est l'état de la route. » Les gens nous disaient : " C'est impassable parce qu'il y a des immenses banquises de glace qui sont restées dans la route et, à côté, les poteaux et les clôtures sont abattues ». On a attendu deux jours à Matane ${ }^{56}$ et on a trouvé quelqu'un qui nous a dit : «Je vais vous descendre à condition que vous m'aidiez». On a embarqué des pics et des pelles dans la voiture, on était cinq, je pense, dans la voiture, et puis on est parti. Au bout d'une dizaine de milles [16 km], on débarque et on prend le champ. Puis on se fait un trou dans la clôture, on picoche ${ }^{57}$ les glaçons puis on s'en va chez nous. Ça nous a pris une journée à

56. La voie ferrée, achevée en 1911, faisait le détour par la baie des Chaleurs, depuis Gaspé à Matapédia $(325 \mathrm{~km})$, rejoignait le fleuve Saint-Laurent à Mont-Joli par la vallée de la Matapédia $(148 \mathrm{~km})$ et revenait vers Matane $(62 \mathrm{~km})$ où elle s'arrêtait, soit un trajet total de $535 \mathrm{~km}$ qui, par la route aujourd'hui prendrait $7 \mathrm{~h}$; le tronçon Matane-Gaspé, qui n'a jamais été construit, aurait réduit à $216 \mathrm{~km}$ la distance entre Cap-Chat et Gaspé, soit 2 h 35 de route. Voir Jules Bélanger et al., Histoire de la Gaspésie, op. cit., p. 458-469.

57. Picocher, v.tr., frapper avec un objet pointu pour casser la glace. 
faire 45 milles [72 km], mais on s'est rendu quand même. Je ne sais pas comment le pauvre monsieur est revenu tout seul, mais je pense qu'on lui avait ouvert la route puis il a été capable de s'en revenir. Ç'a été la seule aventure pendant les vacances du jour de l'An et je n'aurais pas voulu qu'elle se répète.

La vie du séminaire, c'était une vie de famille. Nous étions 66 au maximum au séminaire. Tout le monde se connaissait. Tous les pères nous connaissaient par notre petit nom ${ }^{58}$. Tous les pères connaissaient nos petits défauts et nos petites qualités.

\section{"La grande fête qu'on avait au séminaire : c'était la Sainte-Cécile "}

Nous avions une chorale et il y avait une tradition; c'était une fête extraordinaire, la grande fête qu'on avait au séminaire : c'était la Sainte-Cécile ${ }^{59}$. Seulement ceux qui s'intéressaient à la musique, qui étaient dans la chorale ou qui apprenaient le piano ou le violon étaient admis à ce banquet-là. C'était extraordinaire, imaginez-vous qu'on était exempté d'aller à l'étude de cinq heures. L'étude de cinq heures, c'était sacré ça : malade pas malade, tu étais obligé d'aller à l'étude de cinq heures. Mais là, cette journée-là, imaginez-vous, je ne sais pas quel miracle qui arrivait, on était exempté de l'étude de cinq heures et, au lieu d'aller à l'étude, nous allions au réfectoire. Là, les sœurs qui nous faisaient la cuisine nous préparaient des mets extraordinaires. Pour moi, c'était extraordinaire de manger des petits pâtés feuilletés avec trois ou quatre huîtres dedans, avec de la sauce naturellement, et on en avait tant qu'on voulait. Il y avait de la tire... On bambochait, comme on disait, au lieu d'aller à l'étude, de cinq heures jusqu'à six heures et demie, et là on soupait, on s'en allait et on était encore exempté de l'autre étude. À la Sainte-Cécile, il y avait une fête, les gens chantaient. Souvent c'était la date où on devait aller préparer les patinoires. Il fallait que tout le monde

58. Prénom.

59. La fête de sainte Cécile, la patronne des musiciens, est célébrée le 22 novembre. 
y aille. En général, les gens ne se laissaient pas traîner les pieds parce qu'ils savaient qu'à la Sainte-Catherine on commençait à patiner $^{60}$. La fête de la Sainte-Cécile finissait là, mais ça laissait quelque chose dans l'estomac; ça laissait surtout beaucoup dans la mémoire et je me rappelle encore de ces fêtes-là. D'ailleurs il y a deux, trois jours, j'ai fêté la Sainte-Cécile, j'ai fait de la tire d'érable pour ceux qui croyaient encore à la Sainte-Cécile, patronne des musiciens. C'était notre vie du séminaire.

\section{"Il nous lisait du Jules Verne "}

Nous avions un très bon professeur en mathématiques. Il se mettait en train de nous expliquer toutes sortes de choses, surtout en dehors du cours. Mais c'était un scientiste ${ }^{61}$ et il avait un culte pour Jules Verne ${ }^{62}$. Il y en avait quelques-uns dans la classe qui étaient assez bons mathématiciens pour suivre aussi tous les calculs de Jules Verne. Ce professeur-là disait : « On va faire ça... Quand vous aurez compris, dites-moi-le puis on lira Jules Verne ». On écoutait très bien, deux oreilles, trois oreilles, et on disait : «On a compris, père... Jules Verne ! " Moi, dans cette classe-là, j'étais le plus jeune parce que c'était seulement ma deuxième année au séminaire, mais j'étais en troisième année. J'étais le plus jeune, mais peut-être le plus haïssable. Les gens me disaient avant de rentrer en classe : « Il faut que tu nous aies une demi-heure de Jules Verne, au moins un quart d'heure ; si tu n'obtiens pas ça, tu vas en entendre parler. " À un moment donné : «Y a-t-il des questions ? - Oui, père, Jules Verne, père, Jules Verne. - On n'a pas fini ça. - Demain, on en fera plus long et vous allez voir qu'on va réussir. - Très bien, prenez Jules Verne ». Et il nous lisait du Jules Verne, il allait au tableau et nous l'expliquait. Il y en a toujours un qui demandait une question à la fin, quand il savait qu'il restait seulement dix minutes, il allait peut-être couper sur la lecture du Jules Verne, mais il posait une question en

60. La Sainte-Catherine est célébrée le 25 novembre.

61. Sans doute pour savant ou adepte de littérature d'anticipation.

62. Jules Verne (1828-1905), écrivain français auteur de romans d'anticipation. 
mathématiques : comment ça se fait, comment ça se fait...? Le père continuait puis là il reprenait son livre puis il disait : « Voistu ce qui arrive... ? » Alors on s'amusait, il était bon professeur, bon compagnon, il avait cette petite faiblesse-là ; ça ne nous a pas retardés dans nos études, on a vu le programme quand même.

\section{"La tradition orale, c'était mal vu"}

En versification, nous avions au programme les institutions grecques et latines et c'était évident que le professeur, ou bien n'aimait pas ce cours-là ou bien il n'était pas préparé à le donner. Il nous faisait lire un bout dans un livre qu'on avait, les institutions grecques et latines, et quand on avait lu un paragraphe ou deux il nous disait : " Maintenant vous allez lire dans l'Iliade et 1'Odyssée ${ }^{63}$ la traduction de telle chose, par exemple le passage où Ulysse a crevé l'œil du cyclope et si vous avez des questions, vous me les demanderez ». On disait : « Comment ça se fait... comment ça se fait... ? » Des fois, il n'avait pas la réponse, mais tout de même, on s'apercevait qu'il n'était pas très compétent làdedans. On rencontrait les mêmes phénomènes puis les mêmes personnages que dans les contes que j'avais entendus à l'âge de six, sept, huit ans. Alors, ça m'a posé un point d'interrogation d'autant plus que, pendant notre cours classique, c'étaient des jésuites qui nous enseignaient naturellement; tous des gens qui venaient de la ville alors et qui n'étaient pas au courant du tout de la tradition orale ${ }^{64}$. Et je m'étais aperçu que, dès qu'on voulait glisser quelque chose de tradition orale, c'était mal vu.

63. Ces deux épopées de la littérature grecque ont été attribuées à Homère, auteur mythique qui aurait vécu au $\mathrm{IX}^{\mathrm{e}}$ siècle avant Jésus-Christ.

64. Si le retour des jésuites dans leur milieu semblait la règle quand il y avait un collège, il faut noter qu'on n'avait certainement pas encore formé un jésuite au collège de Gaspé, dont l'ouverture avait eu lieu deux ans avant l'arrivée de Germain Lemieux, et que ces « gens de la ville» dominaient probablement. Plus loin, il notera que tous les jésuites formés à Sudbury y sont revenus, mais leur nombre était insuffisant : « Le fait que la plupart des professeurs jésuites entre 1913 et 1956 viennent du Québec montre clairement que peu de ces professeurs jésuites sont recrutés à Sudbury ». Voir André Bertrand, L'Éducation classique au collège du Sacré-Cœur, Sudbury, SHNO, « Documents historiques » 86, 1988, p. 51. 


\section{"J'avais raconté une aventure à laquelle j'avais assisté "}

Des professeurs - ce n'était pas de l'indiscrétion - se voisinaient entre professeurs et ils lisaient nos copies. En composition, ils nous disaient : vous allez décrire une tempête sur la mer, une tempête dans le bois, une chasse à l'ours, toutes des choses comme ça ; on n'avait jamais chassé l'ours à ce moment-là, mais il fallait s'inventer une chasse. Ils nous donnaient de temps en temps un sujet libre. Une fois, j'étais en versification, j'avais raconté une aventure à laquelle j'avais assisté. J'étais assez jeune, six ou sept ans.

Il y avait un bonhomme puis une bonne femme qui se chicanaient de temps en temps. Le bonhomme allait tendre sa rets, comme on disait, pour prendre du poisson. Il était allé assez tard l'automne, c'était en novembre, et sa bonne femme ne voulait pas :

- Tu vas te noyer, vieux fou, vas-y pas...

- Je vais y aller, je vais te montrer que je suis un homme puis je vais y aller.

Il est parti, rame, pour aller sur ses tangons, comme il disait, et le courant l'a emporté, il n'a pas été capable de ramer assez fort le vieux, le courant l'a emporté. Sa bonne femme ne le voyait plus. Alors, elle a averti les gens des alentours :

- Mon bonhomme est parti, il va peut-être se noyer...

Le bonhomme est descendu avec le courant. Toute une équipe a mis les chaloupes à l'eau - je me demande si ce n'est pas en décembre parce que les chaloupes étaient pas mal toutes montées sur le bord -, mais le bonhomme lui s'entêtait à aller tendre ses rets. Les gens ont couru le long de la route - c'était arrivé ça peut-être à une trentaine de milles [48 km] à l'ouest de chez moi. Le bonhomme à un moment donné ils l'ont repéré pas loin de chez nous, derrière une banquise, et là ils nous ont dit : - Allumez un feu pour qu'on vous repère - parce que là, la nuit était arrivée - et avec ce feu-là on va tâcher de se repérer et de le ramener.

Ils sont partis deux et ils sont arrivés au vieux bonhomme. Il était découragé et il était couché dans sa chaloupe et il se laissait aller; il était décidé à mourir. Ils sont venus à bout de le ramener, ils ont eu assez de misère à le ramener mais tout de même. 


\section{"Ça m'avait donné un peu d'assurance" "}

C'est ça que j'avais raconté et le professeur m'avait donné une note quelconque, c'était toujours sur vingt, j'avais eu un petit treize ou quatorze sur vingt. Un autre professeur qui était allé chez mon professeur a dit : «C'est bon, cette affaire-là, il a fait une bonne copie, c'est un bon sujet, il s'exprime assez bien ; regarde la description qu'il a faite du bonhomme... » Le professeur a gardé sa même note, mais l'autre professeur qui avait lu ma copie m'a dit : « J'ai lu ta copie, c'était bon, tu devrais continuer. » Ça m'avait donné un peu d'assurance. J'avais dix-sept ans, j'étais en versification, et là j'ai eu l'impression que je pouvais écrire quelque chose qui était lisible par des gens instruits. En général, nos professeurs, quand on leur donnait un sujet comme ça, un sujet local, ça ne les intéressait pas du tout, parce qu'ils n'avaient pas eu connaissance de ce qui se passait à la campagne. Franchement, ils ne nous comprenaient pas beaucoup quand on leur parlait du milieu. Alors ça me posait des points d'interrogation; je me disais : il y a probablement quelque chose de riche là-dedans qu'on pourrait exploiter, même pendant le cours classique ${ }^{65}$.

\section{"Je voulais être premier"}

Le cours s'est passé comme ça, d'une classe à l'autre, et, je ne sais pas si c'était vraiment de l'ambition ou si c'en n'était pas... je voulais être premier, même à la petite école et à l'école modèle. Je voulais être premier, pas plus que deuxième; quand j'étais troisième, c'était une humiliation extraordinaire. Au collège, c'était la même chose. Naturellement quand on est arrivé en méthode, qu'on avait sauté une classe, j'étais résolu à lâcher la première place. J'arrivais quatrième, cinquième, deuxième, troisième et puis tout

65. Par comparaison, on peut lire l'expérience de l'écrivain Jacques Ferron (1921-1985) inscrit vers la même époque au collège Jean-de-Brébeuf à Montréal. En inculquant aux élèves la « conviction de leur propre supériorité », les jésuites leur transmettent le goût des belles choses, avec un snobisme qui en pousse quelques-uns à rechercher des modèles littéraires « exclusivement français », à « parler pointu »; en contrepartie, cette aliénation intellectuelle, qui les détache de leur milieu, les conduit à dénigrer l'étroitesse de la production locale. Voir Marcel Olscamp, Le Fils du notaire. Jacques Ferron, 1921-1949. Genèse intellectuelle d'un écrivain, Montréal, Fides, 1997, p. 132-223. 
à coup je suis arrivé premier en grec. Imaginez-vous qu'on avait fait une classe spéciale de grec, et le grec ça m'allait ; le latin, j'étais assez fort parce que je savais très bien mon français. Les nuances en latin puis en grec, à cause des nuances du français, j'arrivais à me débrouiller très bien.

\section{"En rhétorique, j'étais avec le père Cadieux"}

Ensuite, en rhétorique, j'ai aimé ça parce que j'étais avec le père Lorenzo Cadieux ${ }^{66}$ qui nous faisait travailler. Il était très entreprenant. Il nous bousculait et on voyait tout de suite qu'il nous faisait travailler parce qu'il travaillait lui-même. C'est ça qu'on m'a conseillé quand je suis venu enseigner : «Tu peux être exigeant pour tes élèves, mais sois exigeant pour toi-même : travaille si tu veux les faire travailler ». Cadieux avait le don de nous faire travailler. Il organisait un peu toutes sortes de scénarios pour tâcher de nous exprimer en public, faire des discours, parce que la rhétorique, c'était la classe où l'on s'exerçait à l'éloquence, où on apprenait à parler en public, à développer un sujet. Moi, j'étais timide et je ne parlais pas facilement en public mais, là, j'ai été obligé de me déboutonner et Cadieux disait : « Secoue-toi, tu es capable, toi aussi, de faire un discours, tu t'exprimes assez bien ; c'est parce que tu es trop timide. Lance-toi comme untel qui n'est pas plus intelligent que toi ». Il m'encourageait et je suis venu à bout de faire des discours. Pour les écrire, ça allait bien et on était obligé d'en écrire passablement pour le baccalauréat.

66. Lorenzo Cadieux (Granby, Qc, 1903-Sudbury, Ont., 1976) a étudié au collège Sainte-Marie de Montréal et au collège d'Edmonton. Entré chez les jésuites en 1924, il enseigne la rhétorique au séminaire de Gaspé de 1931 à 1933 ; après ses quatre ans de théologie et son année de spiritualité, il est nommé professeur en 1939 au collège Saint-Ignace, à Montréal, et il arrive à Sudbury en 1940 où il fondera en 1942 la Société historique du Nouvel-Ontario et l'animera durant plus de trente ans. Il obtient un doctorat en histoire de l'Université Laval en 1958. Professeur d'histoire du Canada à l'Université de Sudbury (1957-1960) puis à l'Université Laurentienne (1960-1973), il fut directeur du département d'histoire de 1965 jusqu'à sa retraite en 1973. Il est l'éditeur des Lettres des nouvelles missions du Canada (1843-1852) (Montréal, Bellarmin ; Paris, Maisonneuve et Larose, 1973, 950 p.). Germain Lemieux a rappelé sa carrière dans un périodique gaspésien : " Le Père Lorenzo Cadieux, s.j. Un professeur du séminaire », dans Revue d'histoire et de traditions populaires de la Gaspésie, vol. Xv, $n^{\circ} 1$ ( $\left.{ }^{\circ} 57\right)$, janvier-mars 1977, p. 4-6. 
On avait une discussion philosophique de quatre heures à faire. Il fallait savoir comment aborder le sujet et comment défendre notre thèse. Quand il s'agissait de m'exprimer, c'était assez facile. Dès la [classe de] belles-lettres, il y avait un préfet de discipline, le bonhomme qui avait affaire à tout le monde et qui organisait les fêtes... À deux ou trois reprises, il m'a dit : «Aujourd'hui, c'est la fête du recteur, c'est toi qui vas faire le discours ». Je disais : « Je ne suis pas capable. » Il disait : «Vas-y, tu es capable, tu es capable. » Alors, quand j'étais obligé comme ça, que les gens me disaient que j'étais capable, ça me donnait un peu de force puis j'y allais. C'est arrivé à trois ou quatre reprises que j'ai fait les discours comme ça devant le recteur et devant le groupe.

Chez les jésuites, je n'ai jamais eu connaissance qu'ils aient découragé un élève. J'en voyais de pauvres diables, il y en a un, entre autres, d'Anticosti, je pense qu'il avait fait trois ans en éléments français et ensuite il avait fait quatre ans en éléments latins. Il coulait et il recommençait. Ses parents voulaient absolument qu'il fasse son cours classique. Il l'a fait, mais je pense que ça lui a pris au moins quinze ans à le faire ${ }^{67}$. Je les trouvais un peu misérables, ces gens-là qui travaillaient dur et qui ne réussissaient pas. Je les prenais en pitié et souvent j'essayais de les aider, surtout quand ils me demandaient de l'aide.

Plus tard, quand on est arrivé en philosophie, je n'étais pas plus intelligent que les autres pour comprendre la philosophie. Quand c'était trop loin de la physique, je ne m'intéressais pas beaucoup à ça, mais j'avais une espèce d'intérêt. Le professeur m'avait dit ça : quand il s'agissait d'un principe de philosophie, qu'on avait une thèse à défendre par exemple, dès que je comprenais le prin-

67. Est-ce vraiment une exagération quand le taux d'abandon des collèges classiques était alors considérable, « environ $40 \%$ d'abandon après la classe de sixième [éléments latins] au milieu du Xx $x^{\mathrm{e}}$ siècle », et que « $25 \%$ à $35 \%$ des inscrits complètent leurs études de huit années »? L'introduction d'un test d'aptitude a réduit ce taux de décrochage et « le nombre des redoublants, dont certains mettaient parfois jusqu'à onze ans pour faire un cours complet, tout en permettant à un groupe de 15 à $30 \%$ d'élèves de terminer en sept ans au lieu de huit. " Voir Claude Galarneau, op. cit., p. 148-149. À Sudbury, les taux d'abandon étaient comparables : voir André Bertrand, op. cit., p. 28-29. 
cipe, j'avais toujours une histoire à raconter ou quelque chose de pratique et je partais de là pour énoncer.

\section{"Moi, je voulais apprendre la musique comme ça"}

Rendu en philosophie, on était choyé parce qu'ils nous avaient envoyé des professeurs qui étaient vraiment compétents. Le restant des cours, en mathématiques, en physique, en chimie, c'étaient des gens très compétents. Il y avait un bon père jésuite, le père Boileau, notre professeur de chimie - il faisait un peu de mathématiques aussi - qui avait une voix extraordinaire. Il avait fait au moins quatre ans de conservatoire et puis il m'avait incité à apprendre la musique. Je ne comprenais pas, j'étais absolument frappé par sa facilité de lire de la musique qu'il ne connaissait pas. On lui achetait une feuille de musique et tout de suite il chantait ça sans préparation; en prenant seulement le ton du piano, le ton du diapason, il nous chantait ça immédiatement. Moi, je voulais apprendre la musique comme ça et puis il m'a dit : " Vas-y ». C'est lui qui m'a aidé à apprendre la musique dans très peu de temps. Il m'a donné des conseils et ça m'a rendu énormément service. Ce n'est pas parce que j'étais intelligent, mais je voulais tellement apprendre, ça faisait tellement longtemps que je chantais à l'oreille que, dans trois, quatre jours, je suis passé à travers une bonne partie de la musique guidonienne, grégorienne, différentes façons de noter la musique, et puis ça m'a préparé de loin à être folkloriste, pour enquêter dans la chanson et être capable de rédiger ma musique assez facilement.

\section{"Chez les jésuites, la technique de base, c'est le rabâchage"}

Quant à la façon dont nous étions éduqués, c'était admirable. On nous disait, c'était de la tradition orale ${ }^{68}$, que, dans plusieurs collèges de séculiers, les élèves étaient menés à coups de pied. Notre recteur, qui discutait avec un abbé à la tête des élèves dans un autre collège de séculiers, disait: « Nous autres, nous essayons de les faire raisonner, nous les prenons par la raison. » L'autre

68. Par ouï-dire. 
dit : « Nous autres, nous les faisons résonner, un coup de botte dans le derrière, il faut que ça marche. » Ce n'était pas la même résonnance. Jamais je n'ai eu connaissance que quelqu'un nous ait bousculés... Raisonnés ? Oui : «Écoute un peu, toi, il ne faut plus que tu fasses ça; si tu le fais, tu entendras parler de moi ». Ils nous raisonnaient et, en classe, c'était la même chose pour les gens qui n'étaient pas trop travaillants. Encore là, la méthode des jésuites... Quand nous étions en arrière sur une matière - moi, ça ne m'est pas arrivé souvent, mais je sais qu'il y en a plusieurs autres qui étaient en arrière, en grec et en latin, en mathématiques, en anglais - là, ils donnaient un cours spécial le soir ou des journées de congé, le [samedi] après-midi ou le jeudi après-midi : « Tu vas venir après-midi, à une heure et demie, puis je vais te donner une heure et je vais t'aider ». C'était la méthode générale, la pédagogie des jésuites. Plusieurs nous disaient : « Nous autres, chez les jésuites, la technique de base, c'est le rabâchage ${ }^{69}$ ", c'est-à-dire qu'on revient souvent; quand on a déjà enseigné une matière, on revient là-dessus ; même quand on a déjà fait comprendre une règle en grec ou en latin, on revient encore ; ça c'est du rabâchage. Des fois, je dis ça à mes élèves, moi aussi, quand on fait de la musique pour revenir aux mêmes intervalles : c'est du rabâchage. Je m'étais aperçu que c'était efficace.

\section{"Nous avons assisté aux fêtes de Gaspé" "}

Le cours classique a duré huit ans, sept ans pour moi parce que j'ai sauté un an. En 1934, la dernière année, on a eu un événement extraordinaire. Nous avons assisté aux fêtes de Gaspé ${ }^{70}$. Il était venu des délégués de France. Je me rappelle d'une scène que je n'ai pas oubliée. Il y avait le commandant du bateau Champlain ${ }^{71}$

69. Ce mot un peu fort ne doit pas être pris péjorativement ici : on mettait l'accent sur les répétitions fréquentes de façon à faciliter l'apprentissage. 1534.

70. Célébrations du $400^{\mathrm{e}}$ anniversaire de l'arrivée à Gaspé de Jacques Cartier en

71. Navire de transport frigorifique, le Champlain a été lancé à Brest en 1919, a servi en Méditerranée et a été sabordé en 1942 à Toulon. Source : http://atf40. forumculture.net/t475-la-marine-marchande-et-navires-auxiliaire (consultée le 28 mars 2012). 
qui amenait toute la délégation française. Le bateau n'était pas rentré au quai, il était trop immense, il n'aurait pas pu passer endessous du pont, mais il était resté dans le large, dans la baie de Gaspé, pas loin de Cap-des-Rosiers, et puis il y avait une vedette qui allait chercher les délégués. Un sénateur qui était à la tête du banquet de 1934, le banquet officiel, avait mis un petit scout à la porte et il a dit: « Laisse entrer personne qui n'a pas sa carte. S'ils ont été invités, ils ont une carte ; ne laisse entrer qui que ce soit qui n'a pas sa carte ». Le grand commandant, qui était à la tête du bâtiment, de la délégation française, il arrive avec tout son état-major, toutes ses décorations et ses galons, et il vient pour entrer dans la tente. Le petit scout était là : «Monsieur, votre carte. Si vous êtes vraiment invité, vous devez avoir une carte. C'est ce qu'on m'a dit ». Le sénateur n'était pas là, alors il n'a pas pu lui dire : «Laisse-les entrer, tu vois bien par leurs habits que ce ne sont pas des guenilloux $x^{72} »$. Le petit gars a dit : «Non ». Le commandant est retourné et nous a fait une scène. Il a dit à son adjoint : «Faites venir ma vedette immédiatement. Moi, à la tête de la délégation française, on vient de m'interdire l'entrée du banquet. Tu vas envoyer un télégramme tout de suite au bateau pour qu'il m'envoie la vedette. Tout de suite... » Le sénateur était presque à quatre pattes devant le commandant : « Vous savez bien que c'est une gaffe, le petit gars va disparaître, je lui avais dit aussi d'être sévère... Restez, ça n'a pas de bon sens, vous allez nous gâter toute la fête ». Finalement, le commandant est resté. Il est entré dans la tente, et comme le petit gars avait eu l'ordre de surveiller les cartes et un peu cette scène-là, il n'en est pas venu beaucoup. C'était une tente qui pouvait recevoir au moins trois cents personnes et on était à peu près soixante dans la tente; on avait de la place. Naturellement, nous autres étudiants, quand on a vu que tout le monde rentrait, on est rentré sans montrer de carte et le petit gars n'était plus là. J'étais à côté d'un abbé de l'Ontario, on avait causé de l'Ontario. Il y a eu d'autres incidents à ce banquet-là, mais je passe...

72. Hommes vêtus en haillons. 


\section{" Est arrivé le commandant Beaugé avec un}

\section{bateau océanographe "}

En 1934, peut-être une semaine ou deux après, est arrivé le commandant Beaugé ${ }^{73}$ avec un bateau océanographe. D'abord il nous a invités, tous les élèves, ou ceux que ça intéressait, d'aller à bord du bateau. Je vous assure que c'était propre et bien tenu. Il nous a montré les laboratoires et comment fonctionnait tel ou tel instrument - pour chercher de l'eau à telle distance ou pour dépecer les poissons -, et ce que c'était la vie normale à bord de ce bateau océanographe. Le soir, il nous donne une conférence. $M^{\text {gr }} \operatorname{Ross}^{74}$ y assistait. Il a dit à M ${ }^{\text {gr }}$ Ross : « Vous devriez envoyer au moins quelqu'un à l'étude de l'océanographie, à Halifax. Je l'organise puis on a des bons professeurs et je promets une bourse de trois ans à n'importe qui que vous choisirez ». C'était un cours de cinq ans - trois ans à l'école d'Halifax, deux ans en laboratoire - et, dès que le candidat est à l'œuvre et qu'il fait du service à bord du bateau, il est rémunéré. C'était assez alléchant. On écoutait ça d'une oreille et, de l'autre oreille, ça ne nous intéressait pas beaucoup. Le commandant Beaugé a dit à un monsieur qui était spécialisé dans les pêcheries : «Préparez un examen de deux jours et celui qui arrivera le premier, ou que monseigneur choisira, sera éligible à la bourse de cinq ans d'étude ». Il nous prépare l'examen. J'y suis allé. D'ordinaire, j'étais très froussard, j'avais la frousse tout le temps quand il y avait un examen comme ça officiel. Mais, cette fois-là, je n'étais pas nerveux du tout. Le professeur nous avait dit : « Ce sera un bel exercice pour votre baccalauréat au mois de juin ». L'examen se passait en décembre, je pense bien. Je suis allé à l'examen. La première journée, ç'a bien été ; la deuxième journée, ç'a été aussi bien. Ç’a pris une semaine avant que les copies aillent à Rimouski, que le spécialiste

73. Lucien Beaugé (1879-1958), officier de marine et océanographe, à qui fut confié le commandement du Président Théodore-Tissier, premier navire océanographique français. Source : www.fecamp-terre-neuve.fr/Historique/1900-fin.html (consultée le 27 mars 2012). Une rue de Québec porte le nom de Beaugé depuis 1994.

74. $\mathrm{M}^{\mathrm{gr}}$ François-Xavier Ross (Grosses-Roches, Rimouski, Qc, 1869-Québec, Qc, 1945), premier évêque du diocèse de Gaspé (1922-1945). 
en océanographie corrige nos copies. J'étais tellement peu énervé que je suis arrivé premier là-dedans, j'ai eu 88 sur 100 ou quelque chose comme ça. Les pères ont dit : «Va voir $M^{\text {gr }}$ Ross pour te déclarer ». $\mathrm{M}^{\mathrm{gr}}$ Ross était rendu Ad limina, il était à Rome ${ }^{75}$. Ça lui a pris quelques semaines, parce que, à ce moment-là, les avions ne partaient pas à tous les matins, en 1934 ; il fallait qu'il y aille en bateau, passer par New-York, ça lui prenait du temps. D'ailleurs, il avait intérêt à ce que ces voyages-là soient le plus long possible pour se reposer en même temps. J'ai attendu que $M^{\text {gr }}$ Ross soit revenu pour lui dire que c'est moi qui étais arrivé le premier dans le concours.

\section{"C'est peut-être ma chance d'aller sur la mer"}

Entre temps, nous avons fait notre retraite de décision. Rendu en philosophie, en 1934, moi, je devais quitter en 1935, il fallait faire une retraite à la façon des jésuites. J'aimais la mer et quand j'ai vu ça, j'ai dit : « Tonnerre d'affaire ! C'est peut-être ma chance d'aller sur la mer ». Surtout la physique, la chimie, j'aimais ça et j'avais vu le travail qu'ils faisaient au laboratoire sur le Théodore-Tissier, je me rappelle encore le nom du bateau, le Théodore-Tissier, premier bateau océanographe du commandant Beaugé. J'ai fait ma retraite sérieusement et j'ai pensé à ça, puis j'ai pensé à d'autres choses. Je suis allé voir le directeur spirituel et je lui ai dit ça : " J'aime beaucoup les sciences, surtout sur la mer ; mais d'un autre côté je pense aussi que je pourrais rendre service dans le clergé. - Le clergé séculier ? - Non, j’ai dit non ». Je ne vous dirai pas pourquoi mais... il y avait la vie religieuse, il y avait les jésuites qui étaient tout proches. Pendant sept ans, j'avais vu les jésuites à l'œuvre, je trouvais qu'ils faisaient une belle œuvre et surtout qu'ils avaient un sens d'aborder les élèves,

75. Chaque évêque doit se rendre à Rome tous les cinq ans pour la visite « Ad limina apostolorum » qui comporte, entre autres, une audience avec le pape, à qui il doit soumettre un rapport sur l'état de son diocèse (canon 399), et vénérer les tombeaux des apôtres Pierre et Paul (canon 400). À moins d'empêchement légitime, l'évêque ne peut se faire remplacer. Les articles 399 et 400 du code de droit canonique de l'Église catholique romaine [CIC] sont explicites à cet effet. Source : http://www.vatican.va/ archive/FRA0037/_P1C.HTM (consultée le 17 mai 2012). 
et beaucoup de charité, beaucoup de dévouement. J'ai débattu ça pendant la retraite, trois ou quatre jours, et finalement j'ai dit : « Je n'irai pas sur la mer. Peut-être plus tard, si je deviens prêtre, peut-être que je serai aumônier dans la marine ». J'aurais aimé ça. Quand $\mathrm{M}^{\text {gr }}$ Ross est arrivé, je suis allé... non pas lui dire que j'avais choisi la marine, mais que j'avais choisi la vie religieuse. Il fallait demander à $\mathrm{M}^{\mathrm{gr}}$ Ross pour entrer dans la vie religieuse. Heureusement, nous étions trois qui partions chez les jésuites et il y en avait quatre qui partaient chez les séculiers. $M^{\text {gr }}$ Ross, qui était toujours un peu nerveux, a dit : «Aussi longtemps que les jésuites ne m'en prendront pas plus qu'ils m'en donnent, je vas vous le permettre : allez, allez, allez chez les jésuites ». Il en est resté un chez les jésuites et peut-être plus que ça chez les séculiers. Ç’a été une des expériences de ma vie où j'ai été obligé de choisir sérieusement entre la prêtrise et un travail scientifique. Mon directeur spirituel m'a dit après : «Écoute un peu, la prêtrise puis la vie religieuse, ça ne s'oppose pas à des études scientifiques. Si tu aimes les sciences, tu vas pouvoir le faire chez nous aussi et plus tard si tu veux aller dans la marine, on ne t'empêchera pas ». Ça m'a rassuré et, en 1935, je suis parti pour entrer chez les jésuites à Montréal.

\section{III - FORMATION CHEZ LES JÉSUITES (1935-1950)}

\section{"Nous avions deux ans de noviciat (1935-1937)"}

Le 8 septembre 1935, j'arrive à Montréal, j'entre officiellement chez les jésuites. Naturellement on ne prenait pas la soutane tout de suite, on restait en laïc pendant une semaine ou dix jours pour voir si nous avions un peu la vocation. Il y en avait quelques-uns qui trouvaient ça un peu trop austère et qui foutaient ${ }^{76}$ le camp après trois jours, quatre jours. Là, il fallait passer par la filière. Nous avions deux ans de noviciat fait de spiritualité ; il y avait quelques cours qui se donnaient en plus de ça. Entre autres, il y avait un cours de musique. Ce n'était pas très glorieux comme

76. Fouter le camp, v. tr., même sens que foutre : ficher son camp, s'en aller, déguerpir. Voir Glossaire du parler français au Canada, op. cit. 
cours de musique, mais il fallait le suivre, être là pendant l'heure où il se donnait. Deux ans de noviciat et pendant ces deux années-là, on faisait des expériments ${ }^{77}$. Aller dans les hôpitaux par exemple, on allait passer un mois. À tous les matins, on partait pour aller dans un hôpital pour avoir soin des malades, aller jaser avec eux autres. Ceux qui n'aimaient pas les malades ou qui avaient peur des morts n'y allaient pas ; ils refusaient ou ils s'en allaient. Moi, c'était la cuisine. Il fallait voir si on avait des aptitudes pour la cuisine ou si on avait la patience au moins de peler des patates, des légumes, pendant un mois. Il y avait un autre expériment : un pèlerinage d'un mois. J'étais allé jusqu'à Montmagny; on avait fait 354 milles [569,7 km] à pied. C'étaient des expériments comme ça qu'on nous donnait et il fallait passer à travers. Si on ne voulait pas passer à travers ou si, à un moment donné, on voyait que la charge était trop lourde pour ses études, on disait : « Je vais m'en aller ». J'en connais un, un bonhomme qui avait fait son cours avec moi à Gaspé. Lui, c'était la mer. Ce n'étaient pas les expériments, ce n'étaient pas les cours, ce n'était pas la vie religieuse qui l'embêtait, mais il lui manquait la mer. Son père était mort au début de sa deuxième année de noviciat, il devait aller naturellement pour enterrer son père et, la première chose, quand il est revenu, il m'a dit : «J'ai vu la mer, c'était bleu... » Il m'a décrit la mer, il y avait des banquises. C'était ça qui lui manquait et, au bout de deux ans, il n'en pouvait plus. Alors, il est entré en médecine et il a fait un très bon médecin. C'étaient deux ans de noviciat comme ça.

\section{"Au juvénat (1937-1939) "}

Au bout de deux ans, on passait au juvénat. Au juvénat, c'était surtout pour reprendre toutes nos études classiques. On faisait des études un peu plus profondes en grec, surtout comment l'enseigner, des études plus profondes en latin, contrôler les traductions qui avaient déjà été faites, du latin au français ou du grec au français, ou du grec au latin ; le grec biblique, on commençait

77. Expériment : stage dans le vocabulaire jésuite. 
à étudier ça. Ensuite on étudiait l'histoire, on faisait des travaux et on avait des professeurs qui étaient vraiment compétents en histoire et qui nous disaient comment nous y prendre. C'est là que j'ai appris à aimer l'histoire et à rédiger quelque chose qui avait du bon sens au point de vue scientifique : « Vois-tu, tu annonces telle chose et tu n'as pas prouvé exactement, il faut que tu prouves ce que tu as avancé... » On apprenait à travailler comme ça et on avait une bibliothèque extraordinairement riche; on avait le droit d'aller à la bibliothèque à la condition naturellement de faire ce que l'on fait dans toute bibliothèque, d'inscrire notre nom quand on prenait un volume. On pouvait lire, on pouvait se faire aider par un autre, souvent on s'entraidait dans la lecture. On faisait deux ans de juvénat pour refaire le cours classique, mais d'une façon plus approfondie.

\section{"On passait à la philosophie (1939-1941)"}

Après deux ans, on passait à la philosophie. Ceux qui avaient fait deux ans de philosophie dans les collèges en faisaient un an ; ceux qui voulaient prendre la licence en philosophie, il fallait qu'ils fassent deux ans et faire une thèse. C'est là qu'on m'a donné comme sujet l'action à distance. Ce qui était intéressant, c'est qu'il y avait des gens qui venaient de plusieurs pays, au moins de trois ou quatre pays. On avait des cours, comme au collège, des journées où on avait congé ou seulement un demi-congé. On avait un régime qui était très humain. Du côté physique, pour ne pas perdre notre santé, on était obligé de faire des promenades, d'aller à la campagne - on avait une belle maison de campagne le long du Saint-Laurent, dans le bout de Boucherville--, de faire de l'exercice, de la rame, etc., de suivre les études ordinaires et d'être plutôt au-dessus de la moyenne que plus bas que la moyenne. Même si quelqu'un était plus bas que la moyenne, qu'est-ce que vous voulez, s'il avait la vocation ; même s'il ne savait pas combien d'années avait pris[es] saint Thomas pour rédiger sa Somme, et qu'il n'était pas au courant de tous les tomes de la Somme, il pouvait être jésuite quand même. Alors, en deuxième année de 
philosophie, nos études étaient un peu plus approfondies et on avait le droit, ceux qui voulaient, de faire une thèse et on sortait de là avec une licence en philosophie.

\section{"On appelait ça la régence (1941-1944)"}

Après la philosophie, on appelait ça la régence. On nous dirigeait vers l'enseignement pour voir si on avait le don de l'enseignement. Pendant notre formation, on voyait si les gens avaient de l'éloquence, s'ils étaient capables de bâtir un discours en vue des conférences ou des sermons qu'on donnerait plus tard. Les gens s'étaient entraînés et on allait en régence dans les collèges. On ne savait pas dans quel collège on irait ${ }^{78}$. Le 31 juillet, c'était la bombe qui éclatait ${ }^{79} .$. « Où est-ce que je vais aller ?» On recevait toujours la bombe atomique le 31 juillet : j'étais nommé pour Sudbury, afin d'être directeur de la chorale et enseigner la versification à Sudbury. Là, on faisait trois ans d'enseignement. Comme je l'ai déjà signalé, on devait enseigner d'après la méthode des jésuites, le rabâchage, et puis aider les élèves, ne pas les décourager et être le plus $f i n^{80}$ possible avec les étudiants pour ne pas les détourner du cours classique. À la fin de la régence, après trois ans - il y en avait qui faisaient quatre ans : des petits accidents ; [s']ils n'avaient pas été assez bons en classe, ils faisaient une quatrième année ; ce n'était pas une punition, mais c'était une chance de se familiariser plus longtemps avec l'enseignement on revenait à Montréal pour la théologie.

78. Les jésuites possédaient huit collèges classiques : trois à Montréal (SainteMarie, fondé en 1848 ; Jean-de-Brébeuf, 1929-laïcisé en 1986 ; et Saint-Ignace, 1927-fusionné au collège Ahuntsic en 1967), un à Québec (collège Saint-CharlesGarnier, 1930-laïcisé en 1982), un à Gaspé (séminaire de Gaspé, sous la direction des jésuites, 1926-1938, puis des clercs de Saint-Viateur, 1938-1947), et trois autres du côté ouest : en Ontario (collège du Sacré-Cœur, Sudbury, 1913-1967), au Manitoba (collège de Saint-Boniface, fondé en 1833, incorporé en 1871 et dirigé par les jésuites de 1885 à 1967) et en Alberta (collège Saint-François-Xavier d'Edmonton, 1913-1942).

79. Le 31 juillet est la date de la mort d'Ignace de Loyola (1491-1556), fondateur de l'ordre des jésuites, et jour de la célébration de sa fête dans le calendrier catholique ; c'est aussi le moment où le provincial fait connaître le «status », c'est-à-dire l'affectation des membres de l'ordre.

80. Aimable, attentionné. 


\section{"On faisait quatre années de théologie (1944-1948)"}

Là, c'était sérieux. On faisait quatre années de théologie et on était ordonné après trois ans, ce que le clergé séculier nous enviait un peu ${ }^{81}$. C'était admis par le droit canon, par Rome et par les évêques, qu'au bout de trois ans on était ordonné prêtre et on pouvait même avoir juridiction ; on ne demandait pas tous la juridiction ${ }^{82}$. Ensuite, on faisait une quatrième année de théologie et on pouvait faire encore d'autres travaux supplémentaires... On était entré en 1944, c'était pendant la guerre. Ce qu'il y avait d'intéressant, c'est qu'il y avait des gens de partout : des Allemands qui s'étaient sauvés, qui avaient fait leurs études de philosophie à Toronto et ils aboutissaient chez nous. Il y avait une couple de Chinois. On avait trois ou quatre Mexicains. On avait des gens de trois pays de l'Amérique du Sud, ils parlaient tous l'espagnol. J'avais appris l'hymne chinois. J'étais intéressé aux hymnes nationaux. Pendant ma régence, on faisait du chant et j'avais montré jusqu'à vingt-trois hymnes nationaux à mes étudiants, que ce soit en chinois, même en japonais - ce n'était pas un hymne, en fait c'était une prière. Ce qui m'avait intéressé, c'était un thème grégorien. J'avais appris l'hymne mexicain, c'était aussi martial que La Marseillaise. J'avais appris l'hymne allemand. Je me suis fait des amis dès le début avec les Allemands, parce que ces deux bonshommes-là fumaient et moi aussi je fumais la pipe. Naturellement, ils étaient tellement pauvres, ils n'appartenaient plus à la province allemande, ils étaient au Canada comme on disait des vagus $^{83}$, un peu acceptés par n'importe quelle province. Je disais : «Venez chez moi et vous prendrez une pipée de tabac ». Ça s'est adonné que c'était leur fête nationale. Moi, j'avais appris à mes élèves leur hymne national. Ils ont commencé à m'apprendre l'allemand et il y avait un de mes professeurs de philosophie qui m'avait dit : «Tu es bon en hébreu ». Moi, j'avais fait de l'hébreu

81. Au lieu de quatre ans chez les séculiers.

82. La juridiction ou mission ecclésiastique est le pouvoir d'exercer le ministère sacerdotal qui est conféré par l'évêque d'un diocèse.

83. Prêtres indépendants. 
par moi-même, j'avais fait deux ans d'hébreu au lieu d'un an. Il dit: «Tu pourrais enseigner l'hébreu, mais il faudrait que tu saches l'allemand parce que les grandes études en hébreu sont allemandes, tu aurais avantage de commencer à apprendre l'allemand ». Avec les Allemands, chaque jour, on faisait une chanson et à un moment donné j'étais plus à l'aise en allemand qu'en anglais. Je ne raconterai pas comment je me suis sauvé de deux bandits une fois en leur parlant allemand; j'étais certain que même si je faisais des fautes en allemand, ils ne me comprendraient pas. En plus des études, c'était cette ambiance cosmopolite. On rencontrait un Espagnol, on rencontrait un Chinois, il avait des nouvelles, il était inquiet de la guerre... On n'avait pas le droit d'avoir de radio à ce moment-là, mais on rencontrait toujours un professeur qui avait une radio et qui nous disait les dernières nouvelles.

\section{"J'ai fait deux ans de régence (1948-1950) et un an de spiritualité (1950-1951)"}

Après quatre ans de théologie, on pouvait retourner en régence, c'est-à-dire enseigner ou filer tout droit au cours d'un an de spiritualité. C'était notre deuxième noviciat, on avait fait deux ans et là on retournait encore au noviciat pour nous entraîner à l'humilité parce qu'il fallait retourner, absolument comme des novices, faire à peu près les mêmes expériments et voir si on était assez solide, en santé et en humilité, pour accepter toutes les tâches principales des jésuites. Moi, je n'y suis pas allé tout de suite. Ce n'est pas que j'étais en punition, mais la maison était trop petite pour accepter tous les tertiaires, on appelait ça des tertiaires à ce moment-là. Non, je n'ai pas été puni souvent dans ce domaine-là. Alors, j'ai fait deux ans de régence, à partir de 1948, et je suis allé en 1950 faire mon année dans le nord des Laurentides ; j'ai bien aimé ça. J'ai prolongé de quelques mois mon année parce que j'étais ami avec un bonhomme de l'évêché, monsignor quelconque, qui voulait organiser un centenaire ou une fête extraordinaire au mois d'août et il m'a dit : «Tu m'aiderais énormément si tu préparais la chorale pour cette fête-là ». Alors, je suis resté un mois ou deux de plus. 


\section{"J'ai été nommé au collège des jésuites de Québec...}

j'ai rebondi à Sudbury (1951-1953)"

Après ça, je devais aller enseigner la musique au noviciat et puis j'ai été nommé professeur de latin en rhétorique au collège des jésuites de Québec. Je ne vous dirai pas comment ça s'est terminé, mais c'était ça ${ }^{84}$. Ensuite, j'ai rebondi à Sudbury en 1951 pour continuer l'enseignement et, en 1953, j'ai quitté l'enseignement pour aller à Laval, de 1953 à 1955. Je suis revenu à l'enseignement puis l'Université de Sudbury était en train de s'organiser. En 1959, j'ai quitté encore l'université pour aller prendre le doctorat, j'avais eu la maîtrise en $1955^{85}$. Quand je suis revenu de Laval, j'ai rebondi à l'Université Laurentienne pour enseigner l'histoire médiévale et l'histoire ancienne.

\section{" J'ai demandé d'être missionnaire en Chine "}

Une fois que j'ai été rendu chez les jésuites, en 1935, à la fin du cours classique, j'étais décidé à faire ce qu'ils me commanderaient. Et puis j'étais entré chez les jésuites pour faire carrière, pas nécessairement dans l'enseignement, car les jésuites pouvaient aller partout comme missionnaires. Je me rappelle qu'à un moment donné j'ai demandé d'être missionnaire en Chine, pour voir comment les Chinois chantaient et si je pourrais apporter un peu d'aide aux missionnaires qui souvent n'avaient pas beaucoup d'oreille, ce qui les empêchait de maîtriser le chinois. Alors j'ai demandé d'aller en Chine : ils n'ont pas voulu. À ce momentlà, j'avais une petite santé ; j'étais destiné à donner trois, quatre

84. Ce séjour à Québec, qui se serait mal terminé, aurait duré à peine quelques mois. Un problème d'adaptation à une élite jésuite et à un milieu bourgeois urbain, joint à un complexe d'infériorité en seraient peut-être la cause. C'est ainsi qu'on peut interpréter la façon dont il juge ci-après le milieu " très humble » et «providentiel » de Sudbury, ouvert à des gens « sans prétention », « qui n'était pas surveillé par des gens à triple doctorat », contrairement à « un collège de parvenus » où il n'aurait pas été bien préparé ni «à l'aise pour faire la classe à des fils de ministres ou de députés » et où il craignait de ne pas être « à la hauteur de la situation ».

85. «En 1953, on m'avait envoyé à l'Université Laval de Québec où j’ai obtenu une maîtrise en histoire (1955) et un doctorat en études canadiennes (1960) » [1961]. Voir Germain Lemieux, " Mon projet folklorique cinquante ans plus tard », dans L'Euvre de Germain Lemieux, op. cit., p. 29. 
années de service avant de mourir, avant d'aller au ciel tout de suite. On me considérait comme une béquille ; une béquille, c'était quelqu'un qui ne vivait pas longtemps. À notre maison de campagne qui était le long de la rivière des Prairies, où nous allions à tous les jeudis, je m'étais organisé un hamac attaché à deux arbres, puis je m'étais retiré là et on ne me voyait pas. D'autres à côté parlaient de moi, ils disaient : « Il ne toffera ${ }^{86}$ pas longtemps, lui, c'est une béquille, il n'a pas une grosse santé ; la vie des jésuites, il va trouver ça trop dur, il va fouter le camp ». Ça me faisait rire. Après coup, au bout de cinq, six ans, j'ai dit à ces gens-là : «Votre béquille, elle est encore solide, elle est encore debout ». C'étaient les taquineries ordinaires que l'on se faisait dans la famille des jésuites.

\section{"Ils m'ont apporté une pipe puis un sac à tabac"}

Après ma formation, j'ai été sérieusement malade. À un moment donné, on voulait m'envoyer à l'opération chez les Mayo ${ }^{87}$. Les médecins de Montréal m'avaient dit qu'il s'agissait de couper des intestins puis de mettre un tuyau d'argent et, au bout de quatre, cinq ans, c'était la mort. Je me suis guéri. Ça me fait rire puis ça fait rire les autres parce que c'est absolument invraisemblable. J'étais pris en vacances ${ }^{88}$ et j'étais malade des intestins, tout était bloqué. Et ils [mes confrères] ont dit : «Va donc de l'autre côté du lac, il y a un vieux médecin, il a 85,86 ans, il est à sa retraite, mais il parait qu'il est bon. On va y aller ». Ils sont partis à la rame et ils sont allés chercher le vieux médecin. Il est venu, il m'a questionné, il a parlé : «Je vais m'en aller et je vais t'envoyer un remède, tu vas guérir avec ça ». Ça m'a rassuré, pas besoin d'aller subir une opération aux États-Unis. Les gens reviennent en chaloupe : ils m'ont apporté une pipe puis un sac à tabac. «Qu'est-ce que je vais faire avec ça ? - Le médecin a dit de fumer, après le repas de fumer puis tu vas voir ce que ça va donner. Tu vas voir, ça

86. Toffer. V. intr. De l'anglais tough : il ne résistera pas, il ne restera pas.

87. Il s'agit de la Clinique Mayo, un établissement de soins de grande réputation situé à Rochester (Minnesota) aux États-Unis.

88. Cet incident survient à la maison de vacances des jésuites, à la campagne. 
va te faire boire et tu vas te guérir avec ça. " J'avais une horreur de la pipe, et surtout de la senteur de la pipe ${ }^{89}$. Après le repas, je mets ma pipe puis... Aie, maususse d'affaire ${ }^{90}$ ! J'avais envie de vomir, mais en tout cas, c'est l'obéissance. Pour me débarrasser de ce goût abominable du tabac, je vais boire puis boire pour tuer ce goût-là. Le lendemain matin arrive le déjeuner, je déjeune, prends la pipe et fume encore ; puis de l'eau, de l'eau, de l'eau. Savez-vous que rendu à Montréal, à peu près trois semaines, un mois après, je suis retourné à l'Hôtel-Dieu ; à l'hôpital, ils m'ont passé un autre examen et ils m'ont dit : « Savez-vous que ça va mieux ? Ça va mieux votre affaire. Vous avez un bout d'intestin qui était atrophié puis un autre bout d'intestin qui était dilaté puis c'est pas pire : continuez à fumer ». C'était une permission extraordinaire chez les jésuites de fumer, surtout fumer la pipe. J'ai persisté, j'ai fumé quatorze ans. C'est un de mes anciens élèves qui est médecin qui m'a dit qu'est-ce qui m'avait sauvé là-dedans, il dit: « C'est parce que vous ne buviez pas suffisamment et, par le fait de boire, toutes les fonctions du système sont revenues à la normale. Ce n'est pas la pipe directement qui vous a sauvé, ce n'est pas le tabac, c'est l'eau que vous buviez ». J'ai trouvé que c'était passablement logique aussi... Les gens riaient : « Tu t'es tiré d'une grave opération seulement avec la pipe, tu nous en contes un peu. " Mais non. J'ai continué à boire au moins deux litres d'eau par jour, peut-être trois litres d'eau par jour pour me tenir le système à point.

\section{" J'ai eu un entraînement constant dans la musique "}

Du folklore, j'en avais fait depuis longtemps, pas d'enquête par exemple, mais j'apprenais beaucoup de chansons de mémoire et, comme je savais ma musique - $\mathrm{j}$ 'avais appris la musique avant de quitter le séminaire de Gaspé et je pouvais transcrire ma musique

89. Cet épisode est à situer avant ses quatre années de théologie (1944-1948), car alors il fumait la pipe.

90. Maususse ou mausus de Moses (Moïse en anglais), atténuation de maudit dans les jurons. Voir Jean-Pierre Pichette, Le Guide raisonné des jurons, Montréal, Quinze, « Mémoires d'homme », 1980, p. 234. 
en entendant une mélodie -, je pouvais l'écrire immédiatement sur une portée de musique et je questionnais les vieux. J'étais allé à la campagne une fois; il y a des gens de Montréal qui étaient venus nous voir et j'avais fait une enquête. J'écrivais simplement, je n'avais pas d'enregistreuse, alors j'écrivais le texte et j'écrivais la musique à côté, c'est comme ça. Je ne faisais pas d'enquête d'une façon systématique ; j'ai commencé l'enquête systématique seulement en 1948. De 1941 à 1944, je me suis servi du folklore, c'est-à-dire que je suis retourné à mes vieux souvenirs, mes vieux contes, mes vieilles chansons... Au fond, c'était la suite de ce que j'avais fait depuis ma sortie du séminaire de Gaspé. Au noviciat, les gens me faisaient transcrire des chansons. Il y avait une tradition chez les jésuites : dès qu'il y avait une fête, la fête du recteur, la Saint-Jean-Baptiste, la fête de Saint-Jean-Vianney - il y avait des saints à toutes les semaines quasiment -, on pouvait faire des chansons. Je prenais un fait quelconque, c'était comique, pour taquiner quelqu'un. Souvent quelqu'un arrivait, et puis c'était un novice qui était plus jeune que nous autres, qui avait entendu une autre mélodie qu'on ne connaissait pas ; alors on se promenait après le dîner, on se promenait dans le jardin et il disait : « Je voudrais faire une chanson, au réfectoire, et puis je n'ai pas la musique, le bonhomme untel va accompagner ma chanson, mais il n'a pas la musique ». Je disais : « Chante-moi-la. » Alors, il me chantait la chanson, on s'appuyait sur un arbre, je transcrivais sa musique, je la lui donnais et il allait voir son pianiste et puis il était content de ça. J'ai eu un entraînement constant dans la musique de sorte que, quand je suis arrivé dans l'enquête directe, j'étais très bien préparé. C'est ça que je disais à mes étudiants après, à l'université : « Préparez-vous solidement, n'importe quoi, ça va vous servir dans l'enquête folklorique ; musique, littérature ou histoire, ça va vous servir $\gg$.

\section{IV - Affectation au collège du Sacré-Ceur (1941-1944) "On m'a nommé au collège Sacré-Cour (1941-1944)"} Moi, Gaspésien, de rebondir à Sudbury, ça peut surprendre un 
peu. Il faut dire que je suis un jésuite ; comme tout jésuite, on doit obéir. Alors en 1941, j'avais fini mon deuxième cours de philosophie ; j'étais censé venir aider dans les collèges et on m'a nommé au collège Sacré-Cœur pour diriger la chorale et pour être titulaire du cours qu'on appelait à ce moment-là la versification - actuellement, c'est probablement la douzième ${ }^{91}$ ou quelque chose comme ça -, et je suis venu par obéissance à Sudbury. Si les jésuites ne s'étaient pas retirés du séminaire de Gaspé en 1938, j'étais destiné à y aller en 1941. Mais les jésuites n'étaient plus là ; alors, on m'a envoyé ici. C'était tout à fait dans les règles des jésuites de renvoyer les gens dans leur région quand il y avait un collège. Tous les gens de Sudbury, qui avaient fait leurs études à Sudbury et qui étaient rentrés chez les jésuites, sont revenus ici pour l'enseignement.

\section{"C'étaient des gens très humbles"}

Je savais par ceux qui étaient venus que ce n'était pas un collège de parvenus ou de fils de politiciens ou de juges ou d'avocats : c'étaient des gens très humbles, c'était ça la tradition. Comme je venais de la campagne, de la Gaspésie, je n'avais pas les qualités nécessaires pour aller enseigner à Brébeuf par exemple ou au collège des jésuites Garnier. On allait envoyer des gens qui connaissaient mieux la région et qui pourraient mieux s'adapter à cette mentalité-là ${ }^{22}$. Ici à Sudbury, on envoyait des gens plutôt qui n'avaient pas de prétention, qui n'avaient pas de doctorat ; et moi-même je n'avais pas de doctorat à ce moment-là et puis je n'avais pas de qualifications spéciales, sauf que je savais lire ma musique. Et, quand on m'a nommé pour diriger la chorale, je savais qui est-ce qui avait poussé le supérieur à me nommer

91. Ce serait plutôt la onzième, si l'on compte simplement les années d'étude.

92. Cet avis se vérifie aisément par une lettre rédigée en 1940 par le recteur jésuite de Brébeuf, le père Antonio Dragon, qui affirme sans ambages que son collège « ne convenait pas aux enfants, même bien doués, qui n'appartiennent pas à une classe aisée. La plupart de nos élèves sont élevés dans une certaine opulence et ont des habitudes de vie qu'il n'est pas bon de faire prendre à des enfants de condition plus modeste. » Il semble qu'on ait choisi les professeurs d'après ce même gabarit. Voir Claude Galarneau, op. cit., p. 156. 
à la chorale, parce que j'avais eu quelques malentendus avec un directeur de musique de notre compagnie, et puis qui m'a [fait] nommer ici pour ne pas avoir de difficultés là-bas [où il était] ; même s'il m'avait nommé dans un autre collège, je n'aurais pas eu de difficultés avec lui parce qu'on n'était pas de la même maison. J'ai soupçonné charitablement que c'était lui qui avait poussé un peu pour m'envoyer à Sudbury parce qu'il manquait un directeur de chorale et ça me donnait l'occasion d'avancer un peu dans mon enseignement de la musique, la lecture musicale, etc.

\section{"J'étais heureux d'être ici "}

Ensuite, on m'avait mis ici, à la chorale ; je n'ai pas été directeur de la chorale la première année, ç'a été en 1942. Et puis il y avait la mentalité ici de Sudbury : on me disait que c'étaient des fils de mineurs et de fermiers ; c'était à peu près la même chose à Gaspé, sauf qu'à ce moment-là il n'y avait pas de mineurs, mais il y avait beaucoup de fermiers. J'étais heureux d'être ici, de ne pas aller à Montréal - à Brébeuf ; par exemple, au collège Sainte-Marie, c'était moins pire - ou à Québec, parce qu'il y avait des fils de grande famille et puis je ne me serais pas senti bien à l'aise pour faire la classe à des fils de ministres ou de députés. J'y suis allé d'ailleurs en 1951 et puis j'avais bien visé ; j'avais bien deviné les problèmes que ça créait, cette histoire-là, en tous les cas. Je suis venu à Sudbury en 1941 et puis je me suis placé assez facilement. J'enseignais le latin, le grec, l'histoire puis la littérature française. J'en avais assez pour occuper mon temps, occuper mes loisirs. Je devais suivre la technique de l'enseignement des jésuites. Alors, avec les autres, en questionnant, j'essayais de m'adapter à la pédagogie des jésuites. Ça allait assez bien. Il y a eu quelques difficultés, j’ai essayé de les résoudre.

\section{"Dans un collège huppé, je n'aurais pas été à la hauteur"}

Savez-vous que ç'a été providentiel d'être nommé à Sudbury? Probablement que, si j'étais allé dans un collège huppé, je n'aurais pas été à la hauteur de la situation. Je me serais senti un peu trop 
bas et j'aurais peut-être fait des gaffes, et je n'aurais pas pu me lancer comme je me suis lancé ici. Dans un autre collège par exemple, où le préfet de discipline ou le préfet d'étude était plus sévère, plus à cheval, comme on disait, sur les principes, peutêtre que je n'aurais pas été assez souple, que lui-même n'aurait pas pris en considération mon peu de préparation à affronter des élèves de telle catégorie. En arrivant ici, à Sudbury, c'était quelque chose de très simple, on était très pauvre, très pauvre, et puis tout le monde était sur le même pied et surtout on s'entraidait ${ }^{93}$. Il y avait un esprit de famille extraordinaire dans la communauté du collège de Sudbury et, ça, c'était connu à Montréal que les gens de Sudbury avaient un esprit de famille très développé. Ça m'a aidé, et je pense que c'est providentiel que les supérieurs m'aient envoyé ici à Sudbury pour ma propre satisfaction, mon développement personnel, et ensuite pour les initiatives que j'ai pu prendre ici dans le milieu qui n'était pas surveillé par des gens à triple doctorat.

\section{"Pourquoi ne pas se former une chorale?"}

J'avais découvert, entre autres, que les gens de Sudbury avaient des bonnes voix, ils avaient des bons poumons ${ }^{94}$. À un moment donné dans ma classe, j'avais des gens qui étaient un peu durs et que les autres classes qualifiaient des chevaux du père Lemieux parce que, dès qu'il y avait un mauvais coup de fait au dortoir, au réfectoire ou en récréation, c'étaient toujours mes chevaux qui étaient punis. C'est parce qu'ils étaient durs un peu, durs d'oreille et durs de bride, comme on dirait en Gaspésie. Ils n'écoutaient pas facilement et ils avaient un esprit de clan, un esprit de classe, et

93. La pauvreté des collèges classiques au sortir de la crise économique et au moment de la Deuxième Guerre mondiale est notoire : ces années ont été " misérables sur le plan matériel. On assurait le minimum. Aucune construction, aucun achat d'équipement nouveau n'était possible. Les frais d'inscription n'étaient pas toujours acquittés à temps par des parents qui n'en pouvaient plus. Et le collège, pour garder ses élèves, diminuait son tarif. Comme institutions privées, les collèges classiques ne recevaient en principe rien de l'État. » Voir Claude Galarneau, op. cit., p. 59.

94. Ici, le père Lemieux fait une observation personnelle sans arrière-pensée ; il n'ironise pas, même s'il connaissait les problèmes respiratoires causés par le travail dans les mines. 
ils fonçaient à peu près tous ensemble ; c'était difficile et il fallait trouver une sortie pour les avoir de mon côté sans les frapper trop de front. Alors, je leur ai proposé : « Vous avez des bonnes voix, vous chantez bien, pourquoi ne pas se former une chorale? Je suis tanné, fatigué, moi, d'entendre les autres classes vous qualifier de chevaux du père Lemieux ». - D'après la pédagogie des jésuites, le samedi après-midi ${ }^{95}$, on avait un quart d'heure de dialogue avec nos élèves où on se disait la vérité ; les élèves disaient la vérité aux professeurs, les professeurs essayaient de dire la vérité aux élèves. - Alors, j'ai dit : « Je suis fatigué, moi, d'entendre parler des chevaux du père Lemieux. Pourquoi ne pas trouver un autre moyen pour s'illustrer d'une façon différente? Je vous propose non seulement une chorale, mais de vous apprendre à lire la musique. Je vous donne une journée pour vous décider. Vous viendrez me voir ». Alors, le président de classe est venu me voir puis il dit : «Très bien, on va accepter de former une chorale ». J'ai dit : « Dites-vous bien que, moi, j’ai mes exigences de mon côté ; quand on dira qu'il y a un exercice, il faudra que tout le monde y soit ». J'avais comme théorie, plutôt que de donner entre deux classes de suite le Deo gratias $^{96}$ - tout le monde pouvait parler, se lever, marcher en classe, et souvent ils se fatiguaient, on avait de la misère à les remettre en place -, alors j’ai dit : « On va chanter nous autres en classe, de temps en temps, ce cinq minutes-là »parfois ça allait à dix minutes.

\section{"Dès qu'on a commencé à chanter, les gens nous ont respectés "}

Alors je les ai mis dans une classe un peu en dehors du collège pour ne pas que les autres classes nous entendent. Tout de suite, mes gars ont installé un tableau, tout ce qu'il fallait pour la classe ordinaire et puis on s'est lancé là-dedans. Ç’a été passablement bien. Dès qu'on a commencé à chanter, les gens nous ont respectés. C'est comme ça que j'ai eu ces gars-là, je pouvais leur faire

95. À la différence du cours primaire, les élèves du cours classique avaient congé le jeudi après-midi et le samedi après-midi.

96. Expression latine couramment utilisée dans les collèges classiques pour désigner la pause de quelques minutes entre deux cours. 
faire n'importe quoi. La plus grosse punition que j'ai trouvée en classe, c'était de supprimer le chant pendant deux jours ; ce n'est pas allé plus que trois jours. J'avais ce que je voulais. Ce sont des petites expériences comme ça qui m'ont aidé à contrôler mes chevaux et, les années d'ensuite, les gens savaient à quoi s'en tenir et puis je n'ai jamais eu de misère en classe, ni à faire de la discipline avec mes élèves. D'après la pédagogie des jésuites, chaque classe devait donner une séance chaque année et avoir une chanson de classe. Moi, je ne demandais pas mieux que de leur composer une chanson de classe. Mais de fonder une chorale, ça revenait au directeur de musique et non au professeur. Moi, ce [en quoi] j'avais innové, c'était de chanter en classe et de faire de la musique pendant les cinq minutes de repos. À un moment donné, on savait les chants par cœur ; j'avais mon diapason toujours. C'est comme ça que je m'en suis tiré.

\section{"Il y avait des problèmes linguistiques"}

J'ai été très heureux parce que, en arrivant ici, je me suis aperçu qu'il y avait des problèmes linguistiques à Sudbury, problèmes que j'avais connus à Gaspé pendant mes études : à un moment donné, on avait chassé du bureau de poste, de la gare du Canadien National et de plusieurs magasins, tous les francophones; puis là on a tâché de remettre en place tous ces francophones-là. Alors, à Sudbury, je me suis aperçu qu'il y avait des problèmes comme ça, de français et d'anglais, et puis je ne m'étais pas trop trompé parce que, dès 1941-1942, on a eu quelques petits accrochages. C'était pendant la guerre. Quand on allait faire une petite promenade à la paroisse Sainte-Anne, on avait un quart d'heure de marche, et puis on parlait français naturellement et, à un moment donné, quelqu'un qui nous suivait disait : «Speak white ». On continuait à parler français, mais il y avait une grosse rivalité entre Français et Anglais. Il y avait eu des réunions pour les emprunts de la Victoire ${ }^{97}$; quand ç'avait lieu l'après-midi, on demandait la fanfare

97. Pour financer les dépenses militaires de la Deuxième Guerre mondiale, le gouvernement canadien a dû emprunter de l'argent des entreprises et des particuliers. Selon Norman Hillmer, « Du 15 juin 1941 au $1^{\text {er }}$ novembre 1945, on lance successi- 
du collège pour aller faire la musique dans ces circonstances-là. Une fois, au parc athlétique, le maître de cérémonie a annoncé : "Maintenant, c'est l'hymne national : National Anthem ». On avait National Anthem sur nos feuilles, près de nos instruments, puis on a joué God save the king. Alors, le petit gars qui était président de la fanfare s'est levé puis il est allé dire en anglais au maître de cérémonie : «Nous autres, notre National Anthem, c'est O Canada ; c'est ce qu'on va jouer ». Le maître de cérémonie a été un peu pris au dépourvu, il a abandonné le garde-à-vous ; le petit gars est revenu puis il a dit : « Jouons O Canada ». On a joué $O$ Canada et on s'est aperçu que les trois quarts de la foule qui était là ont chanté $O$ Canada en français avec tout leur cœur. On a joué une couple de marches et, le soir, il y avait encore une réunion de cet organisme-là dans un théâtre. Alors il a gagné de jouer $O$ Canada à deux reprises comme ça. C'était, je ne dirais pas une bataille, mais il y avait toujours une petite guerre, une guerre larvée entre francophones et anglophones. Les anglophones ne voulaient pas que le français prenne trop de pavé et puis les francophones ne voulaient pas en perdre trop. C'était ça. C'est pour ça que je vous dis que c'était la même chose qu'à Gaspé. Là-bas, c'était simplement un petit village de 3000 habitants à ce moment-làa ${ }^{98}$, et ici c'était une ville un peu plus importante ${ }^{99}$. Alors je me trouvais un peu préparé à cette mission des revendications des droits linguistiques.

\section{"En 1948, j’avais remarqué déjà une amélioration"}

Il faut dire d'abord que, à partir de la guerre (1939-1945), les francophones ont pris conscience de leur force et les écoles ont

vement neuf emprunts de la Victoire qui rapportent près de 12 milliards de dollars ». Source : L'Encyclopédie canadienne en ligne : http://www.thecanadianencyclopedia. com/articles/fr/emprunts-de-la-victoire (consultée le 16 mai 2012).

98. En 1917, Gaspé avait une population de 1150 habitants ; on peut présumer que 2000 habitants en 1928 serait plus près de la réalité. Voir Jules Bélanger et al., Histoire de la Gaspésie, op. cit., p. 315.

99. La population de Sudbury était de 32203 habitants en 1941, dont le tiers était d'expression française. Voir Donald Dennie, « Le Comportement démographique de deux paroisses canadiennes-françaises de la région de Sudbury », Revue du NouvelOntario, no 16, 1994, p. 14. 
commencé à réagir. D'ailleurs, le collège y a mis un peu du sien aussi pour renforcer son rayonnement francophone. On aurait dit que les anglophones avaient plus de respect qu'autrefois pour les francophones. Ils ont été obligés d'admettre que les francophones de Sudbury ou de l'Ontario avaient fait leur large part dans l'emprunt de la Victoire et dans tous les organismes pour mener la guerre à bonne fin. Quand je suis revenu en 1948 - je suis parti en 1944 -, j'avais remarqué déjà une amélioration, que les anglophones étaient moins fanatiques contre les Canadiens français.

\section{"La francophonie s'organisait petit à petit "}

Il y avait le journal que mon homonyme Camille Lemieux ${ }^{100}$ avait fondé dans ces années-là... [en 1942]. Rodolphe Dubé101, qui était professeur de belles-lettres, avait encouragé cet ancien élève du collège, qui était très patriote, à fonder son journal, L'Ami $d u$ peuple. Il répandait certaines idées. Il y avait ensuite la Société historique du Nouvel-Ontario ${ }^{102}$ qui avait une réunion presque à chaque mois au collège. Une cinquantaine de francophones se réunissaient parfois, ils assistaient à des conférences et puis il y avait toujours des petits mots de passe [des consignes] pour re-

100. Camille Lemieux (Saint-Charles, Ont., 1917-1955), fondateur de L'Ami du peuple (1942-1968), un hebdomadaire de Sudbury qui « prône le pancanadianisme d'Henri Bourassa et l'idéologie nationaliste de Lionel Groulx ». Voir Lionel Bonin, dans le DÉOF, op. cit., p. 33. C'est le jésuite Rodolphe Dubé, arrivé à Sudbury à l'été 1941, qui aurait incité ce nouveau bachelier du collège du Sacré-Cœur (1941) à «mettre sur pied un journal français à Sudbury. Suite à quelques rencontres il convainc Lemieux de fonder un journal ; quand Dubé quitte Sudbury en 1942, on lui attribue le titre de fondateur et d'initiateur de L'Ami du peuple! » Voir Serge Dignard, Camille Lemieux et l'Ami du peuple, Sudbury, SHNo, " Documents historiques » 80, 1984, p. 10-11.

101. Rodolphe Dubé (Rivière-Ouelle, Qc, 1905-Montréal, Qc, 1985), qui a fait carrière sous le nom de François Hertel, était professeur au collège du Sacré-Cœur de Sudbury en 1941-1942. Anticonformiste, il quitta la compagnie de Jésus en 1946 et fut laïcisé l'année suivante.

102. Société d'histoire fondée à Sudbury en 1942 par le père Lorenzo Cadieux. Voir Daniel Bouchard, La Société historique du Nouvel-Ontariode 1942 à 1976, Sudbury, ShNo, «Documents historiques » 94, 1997, 203 p. Elle fut la première à répondre à l'invitation de Lionel Groulx et à s'affilier à son Institut d'histoire de l'Amérique française créé en 1946. Voir Michel Bock, Quand la nation débordait les frontières. Les minorités françaises dans la pensée de Lionel Groulx, Montréal, Hurtubise HMH, " Cahiers du Québec 142 - Collection Histoire », 2004, p. 394-397. 
médier à telle et telle carence ; et puis ça marchait comme ça. Il y avait très souvent les directeurs d'écoles qui en faisaient partie. Il y avait certains encouragements pour les écoles ou des procédés qu'on recommandait, et la francophonie s'organisait petit à petit. Avant cela, c'était simplement les écoles séparées, les écoles élémentaires, qui pouvaient enseigner le français. Ç’a été une bataille, ç'a été seulement à partir de 1927 que le Règlement XVII a été aboli ${ }^{103}$. C'est à ce moment-là qu'on a pu enseigner le français dans les écoles, quoique, avant, il y avait des petites échappées. Monseigneur Côté ${ }^{104}$, qui était curé à Chelmsford, nous a raconté plusieurs incidents qui étaient arrivés à l'occasion de la visite des écoles par un inspecteur qui ne savait pas un mot de français.

103. Adopté par le gouvernement de l'Ontario en 1912, le Règlement XVII faisait de l'anglais la langue d'instruction dans toutes les écoles de la province. Il fut modifié en 1927 « à la suite des recommandations du Rapport Merchant-Scott-Côté, qui révélait que la réussite dans l'apprentissage de l'anglais devait commencer par l'enseignement de la langue maternelle ». Jamais abrogé, il cessa cependant d'être reconduit en 1944. Sources : http://www.salic-slmc.ca/showpage.asp?file=legislations_ling/ documents_hist/1912_reglement_17\&language=fr\&updatemenu=false\&noprevne xt ; et http://www.crcef.uottawa.ca/passeport/IV/IVD1a/IVD1a.html (consultées le 20 mai 2012). Pourtant, la perception de son abolition en 1927, exprimée ici par le père Lemieux, est confirmée par d'autres témoins : voir Alphonse Raymond, s.j. 19141978. Mes souvenirs présentés par Huguette Parent, s.c.o., Sudbury, SHNO, « Documents historiques » 93, 1995, p. 86 : « Je suis allé entendre, vers 1928, le père Charles Charlebois, o.m.i., aumônier de l'AcFÉo, alors que le Règlement XVII, antifrançais, venait d'être aboli [...]»). Des chercheurs l'ont également interprété ainsi : André Lalonde (Le Règlement XVVI et ses répercussions sur le Nouvel-Ontario, Sudbury, SHNo, « Documents historiques » 46-47, 1965, 71 p.) consacre un chapitre à la « suppression du Règlement XVII » et à son abolition le 22 septembre 1927 (p. 51-54); de même Victor Simon (Le Règlement XVII : sa mise en vigueur à travers l'Ontario 1912-1927, Sudbury, ShNo, « Documents historiques » 78, 1983, 58 p.) écrit que « le gouvernement conservateur du premier ministre G. Howard Ferguson abroge le Règlement XVII » en 1927 (p. 36). Enfin, notre collègue Gaétan Gervais (" Le Règlement XVII (1912-1927) », dans la Revue du Nouvel-Ontario, no 18, 1996, p. 123-192), parle plutôt de la fin du Règlement XVII en 1927 (p. 185).

104. M Mr Stéphane Côté (Saint-Barthélémy, Joliette, Qc, 1876-Sturgeon-Falls, Ont., 1952). Ordonné prêtre en 1899, il est professeur à Montréal puis missionnaire en Colombie-Britannique (1900-1903). Ensuite, il fera carrière comme curé en Ontario : d'abord à Blezard-Valley (1903-1906), il dirige longtemps la paroisse Saint-Joseph de Chelmsford (1906-1945) avant de terminer sa carrière à la cure de Sturgeon-Falls (1945-1948). Voir Jean Archambault, s.j., Mgr Stéphane Côté, p.d., v.g. (1876-1952), Sudbury, SHNO, « Documents historiques » 30, 1955, 48 p. 


\section{"Valoriser la culture française des Franco-Ontariens "}

Valoriser la culture française des Franco-Ontariens? Sans trop me le dire, sans trop méditer cette pensée-là, c'était latent, derrière mon toupet de ce moment-là. Et quand le père Cadieux a fondé la Société historique en 1942, je me suis dit : « Si nos gens chantent encore en français, s'ils chantent de vieilles chansons médiévales ou de la Renaissance, s'ils content encore des contes populaires en français, ça veut dire qu'ils sont français ; seulement, il faudrait vérifier ça ». Je suis parti de là pour dire au père Cadieux : " Il faudrait tenter notre chance, il faudrait que la Société historique patronne mes enquêtes... »A Après quelques réunions de la Société historique, on a décidé qu'on allait tenter quelques enquêtes dans la région pour voir si nos francophones étaient vraiment francophones et s'ils croyaient encore à la culture française.

\section{"Je voulais avoir quelque chose de concret"}

À ce moment-là, j'étais à ma deuxième année d'enseignement. J'avais déjà essayé mes petites ailes dans le domaine de l'utilisation de la tradition orale dans mes cours de civilisation grecque et latine. Je voulais en général avoir quelque chose de concret. Même quand j'ai enseigné à l'université, quand je parlais d'une technique, je voulais avoir devant moi une maquette pour montrer à mes élèves comment ça fonctionnait... En classe, quand j'ai commencé à enseigner les institutions grecques et latines, je trouvais que c'était trop plat et trop monotone de dire aux petits gars : « Lisez donc un bout de l'Iliade et de l'Odyssée, et ensuite vous me direz si vous comprenez ou vous ne comprenez pas, et qu'est-ce que vous comprenez ${ }^{105} »$.

\section{"Je reprenais les contes entendus à l'âge de sept ans"}

En 1941, à Sudbury, j'avais au programme les institutions grec-

105. « Je me rappelais assez clairement que, pendant mes études classiques, ce cours était le plus ennuyant de la semaine ; il consistait à faire lire un paragraphe du volume et de recommander aux étudiants de lire tel passage de l'Iliade ou de l'Odyssée où l'on rencontrait les dieux, les déesses, les hauts faits d'Ulysse ou de Circée. On s'endormait sous les yeux du professeur. » Voir « Mon projet folklorique cinquante ans plus tard », dans L'CEuvre de Germain Lemieux, op. cit., p. 25. 
ques et latines. Je me rappelais bien que, au collège classique, à Gaspé, c'était assez plat comme classe. Alors, je me suis dit : « J'ai le même programme, mais il ne faut pas que je sois aussi plat que ce professeur-là qui n'était pas préparé ${ }^{106}$. Moi, je vais essayer de me préparer et d'être un peu plus vivant que ça ». C'est pour ça que j'ai pensé d'introduire la tradition orale là-dedans. Je connaissais des contes et, au lieu de parler d'Ulysse puis du cyclope, je parlais de Ti-Jean poilu qui avait crevé l'œil du géant Rien-qu'un-œil. Je disais : « Regardez Hercule qui était allé nettoyer les écuries d'Augias; Ti-Jean a fait la même chose : Ti-Jean est allé, a rencontré le roi puis le roi a dit : "Si mes écuries, qui ont eu 70 chevaux pendant sept ans, ne sont pas nettoyées, propres, demain matin, tu vas être pendu". Ti-Jean était piteux, mais il y avait une petite fille qui était un peu sorcière puis qui lui a dit : "Couche-toi la tête sur mon genou, tu vas dormir puis tu vas voir ; quand je te réveillerai, tu verras que ton écurie sera nettoyée." » C'était exactement les mêmes scènes, sauf qu'Hercule avait dévié un fleuve pour passer dans l'écurie qu'il a nettoyée. Alors je leur montrais ça. C'est comme ça que j'ai tâché d'améliorer ce que j'avais reçu en versification de mon professeur.

\section{"Je leur montrais qu'une civilisation était composée d'emprunts"}

Ensuite, j'enseignais l'histoire ancienne, l'histoire du Moyen Âge. Je leur montrais que notre civilisation canadienne, notre culture franco-ontarienne, elle venait du Québec. Et les gens du Québec ont pris la culture française où? De France ; les Français, des Latins ; les Latins étaient en communication avec les Grecs ; les Grecs étaient en communication avec les nations un peu plus à l'est. Et c'est comme ça que la civilisation s'est transmise de l'est à l'ouest, et c'est comme ça qu'on a une civilisation. Et je

106. Ce témoignage illustre la médiocrité pédagogique de certains professeurs de collèges classiques, qui sont formés en quelque sorte " sur le tas ». Pour eux, « la préparation essentiellement théologique et morale tient lieu de théorie et l'enseignement dans les classes élémentaires en même temps que la surveillance fournissent le véritable apprentissage ». Voir Claude Galarneau, op. cit., p. 165. 
leur montrais que, quand on s'installe dans un pays, quand un conquérant arrive, il y a des échanges, des échanges au point de vue culturel, au point de vue linguistique, au point de vue des coutumes. Je prenais par exemple le cas, ici en Ontario, des Indiens, les Ojiboués ${ }^{107}$ qui ont connu les Français, et puis les Français ont pris certaines coutumes, certaines techniques des Indiens : faire des canots par exemple, ils ont trouvé ça extraordinairement pratique, aller sur l'eau avec un canot, une plume hein. Par contre, les Français savaient que les Indiens faisaient du sucre d'érable qui était plus ou moins de bonne qualité ; ils ont dit : « Nous autres, on va en faire dans des grands chaudrons de cuivre, des grands chaudrons d'acier puis il va être meilleur ». On a échangé comme ça, même dans le domaine de la linguistique, il y a des mots qui sont passés en français : la ouananiche ${ }^{108}$ par exemple, le poisson. Je leur montrais qu'une civilisation était composée souvent d'emprunts. Mais on acceptait un mot, on acceptait une coutume puis on la reprenait d'après sa propre culture, son propre esprit. La ouananiche, un mot indien, on allait l'écrire d'après l'oreille des Français. C'est ce qui était arrivé entre les Sumériens, entre les Grecs puis les Égyptiens, jusqu'en France avec les Gaulois, les Gaulois qui nous ont donné notre langue avec du latin, etc. Je leur montrais qu'il y avait un échange continuel ${ }^{109}$.

107. Francisation du terme employé par le père Lemieux. Selon le " Glossaire des noms des tribus indiennes ", annexé à l'article de Jacques Rousseau et George W. Brown, "Les Indiens du Nord-Est de l'Amérique », dans le Dictionnaire biographique du Canada (vol. 1, Presses de l'Université Laval, 1966, p. 5-16), ce mot désigne les Sauteux : « Ojibwa. V. Sauteux. » (p. 15) ; «Sauteux (Saulteux, peuple du Sault ; en anglais, Chippewa ou Ojibwa). [...] Les premiers Sauteux rencontrés par les Français avant 1660 furent ceux de la région actuelle de Sault-Sainte-Marie, d'où le nom de "Saulteux" » (p. 16). Dans Wikipédia sous Ojibwés, on trouve d'autres graphies : " Ojibwés, Ojiboués ou Anishinaabes (Anishinaabeg, Anishinaabe-Ojibwe[g] de Chippewa[y]) ». Source : http://fr.wikipedia.org/wiki/Ojibwés (consultée le 18 mai 2012).

108. Selon le Glossaire du parler français au Canada, op. cit. : « s. f. Sorte de saumon d'eau douce "».

109. Germain Lemieux développe cette thèse dans son essai De Sumer au Canada français, sur les ailes de la tradition (Sudbury, SHNo, «Documents historiques ", nos 51-52, 1968, 73 p.) : " Et, si nous retrouvons, dans les littératures de peuples étrangers, des récits qui comportent les mêmes faits mythologiques, pourquoi ériger le hasard en loi, au lieu de recourir simplement à un phénomène d'emprunt appuyé par l'histoire des conquêtes et des migrations ? » (p. 9). 


\section{"C'est de bouche à oreille" "}

Pour notre classe de civilisation grecque et latine, on était obligé d'étudier la littérature ; et puis les jeunes disaient : "Comment ça se fait...?» À ce moment-là, je n'avais pas étudié beaucoup la tradition orale, je disais : «C'est de bouche à oreille. Moi, j'ai entendu ce conte-là puis je vous le reconte puis, vous, vous allez le reconter encore. Prenez nos ancêtres qui ne savaient pas lire ni écrire, puis ils nous ont transmis ces contes-là d'une façon assez précise. - À ce moment-là, je n'avais pas encore retrouvé l'épopée de Gilgamesh en Ontario, mais j'avais entendu parler qu'elle était dans le Québec, et puis ils n'avaient jamais entendu parler de Gilgamesh ${ }^{110}$; ils ne connaissaient pas l'hébreu ou le sumérien où a été écrit la première version de Gilgamesh, mais ç'a été lu par quelqu'un qui l'a conté à l'autre puis à l'autre... - et c'est comme ça que je peux vous conter maintenant un passage de nos contes canadiens qui rejoint la civilisation grecque ou l'Iliade et l'Odyssée. " Les élèves étaient très intéressés. Je voyais cela dans leur figure, ils tendaient le cou dès que je contais une histoire. Je m'apercevais, quand je les questionnais sur les institutions grecques et latines, qu'ils avaient retenu exactement l'histoire, le parallèle entre Hercule par exemple et Ti-Jean poilu ou un autre. Des fois, ils m'en ajoutaient : ils avaient entendu eux aussi des contes, de leur grand-père ou je ne sais pas trop de qui, et ils ajoutaient ça. Je me disais : «Ils ont compris et ils aiment ça ». La classe d'ensuite, je leur en servais une autre portion. Petit à petit, comme ça, je me suis aperçu que ces gens-là étaient sympathiques à la tradition orale et au conte oral ${ }^{111}$.

110. Récit mythologique retrouvé dans « l'antique bibliothèque du roi assyrien Assurbanipal », L'Épopée de Gilgamesh « rapportait un épisode de la vie de Sargon I, empereur d'Akkad vers les années 2700 avant l'ère chrétienne » (ibid. p. 4).

111. « Je me suis donc servi de ces réminiscences pour agrémenter ce cours passablement sec et très peu pratique pour de jeunes Franco-Ontariens. Je me suis vite aperçu que les bribes des contes oraux intéressaient mes auditeurs et provoquaient des questions et des discussions intéressantes. / De 1941 à 1944, je m'en suis tenu à mes souvenirs d'enfance. » Voir « Mon projet folklorique cinquante ans plus tard », dans L'Euvre de Germain Lemieux, op. cit., p. 26. 


\section{V - Début DEs ENQUêtes EN ONTARIo (1948-1958)}

\section{"Sortir du livre" "}

De 1941 à 1944, j'utilisais seulement les contes que j'avais lus ou que j'avais entendus dans ma jeunesse. Dans la chanson, vous avez beaucoup de traits caractéristiques de certaines institutions du Moyen Âge ; par exemple, la façon dont on punissait les malfaiteurs, les meurtriers. On les battait à coups de bâton, ou on les vergeait ${ }^{12}$, varger comme on disait; et puis le supplice de la roue. Qu'est-ce que c'est, le supplice de la roue ? Ça donnait une occasion de sortir du livre qu'on avait en main et puis de montrer qu'on n'avait pas inventé ça, que si on n'avait plus le supplice de la roue au Canada, on s'en rappelait au moins par la chanson ${ }^{113}$. Alors c'est comme ça que, petit à petit, je passais de la tradition orale ou de ce que nos anciens, nos paysans, avaient conservé pour étoffer mes cours.

\section{" Je me suis adressé au père Cadieux... faire une enquête "}

Quand je suis revenu en 1948, je me disais qu'il faudrait faire une enquête pour avoir d'autres documents oraux et pour alimenter ma classe d'institutions grecques et latines parce que c'était toujours au programme. Je me suis adressé à la Société historique du Nouvel-Ontario, surtout au père Lorenzo Cadieux, que je connaissais très bien; je m'étais dit : « Si je peux recueillir des contes, des légendes, des chansons, peu importe, ça m'aidera dans mon enseignement ». Le père Cadieux avait été mon professeur de rhétorique. Il était à Gaspé et c'est là que je l'ai connu. Quand je l'ai retrouvé en 1941, ça faisait déjà un an qu'il était installé ici à Sudbury. Je me suis aperçu qu'il y avait moyen de collaborer avec lui, l'aider et me faire aider. Je l'ai convaincu que ça serait très utile pour la Société historique de faire une enquête pour voir

112. Frapper de verges. Ce mot figure au Glossaire du parler français au Canada, op. cit., sous Verger, prononcé varger, comme v. tr. et intr., au sens de battre, corriger, frapper fort.

113. Voir Germain Lemieux, «Mon projet folklorique cinquante ans plus tard », dans L'Euvre de Germain Lemieux, op. cit., p. 26. 
si nos gens de la région de Sudbury étaient demeurés vraiment français, plus que francophones, demeurés français. J'ai dit : « S'ils chantent encore des chansons folkloriques françaises, des contes et des légendes, là on pourra conclure que vraiment ils sont encore francophiles ». Alors il m'a dit : «On va y aller ${ }^{114} »$.

\section{"J'ai été obligé d'improviser"}

Bien entendu les travaux de Marius Barbeau ${ }^{115} \mathrm{~m}$ 'ont inspiré en ce sens qu'ils m'ont donné le goût de faire de l'enquête ; seulement, on ne donnait pas la technique de l'enquête. C'est la technique que j'ai été obligé d'improviser. Comment questionner les gens? Comment préparer mon enquête ? Quand j'ai donné un cours à trois ou quatre reprises à l'Université de Sudbury sur la technique de l'enquête à domicile, j'insistais sur la préparation lointaine, parce que je l'avais eue, moi, la préparation lointaine de la musique, de la littérature ancienne, médiévale, ensuite d'autres documents que j'avais, des lectures. Je ne laissais pas partir mes gens en enquête avant qu'ils me garantissent qu'ils aient lu ou qu'ils aient retenu ou qu'ils aient écrit au moins une centaine de titres de chansons ou de contes pour questionner les gens. Ça, je l'avais

114. Lorenzo Cadieux était en bonne relation avec l'abbé Lionel Groulx. Il l'avait invité à prononcer une conférence en 1944 et l'avait fait publier : Confiance et espoir, conférence prononcée par le chanoine Lionel Groulx le 13 novembre 1944 à Sudbury, Sudbury, Éditions de la SHNo, Collège du Sacré-Cœur, « Collection francoontarienne » $1,1945,22 \mathrm{p}$. Ce dernier saluera à son tour les travaux du père Lemieux sur la chanson dans sa Revue d'histoire de l'Amérique française : d'abord sa brochure anonyme Folklore franco-ontarien. Chansons [I], Sudbury, SHNo, « Documents historiques »17, 1949 (RHAF, vol. 3, n 2, septembre 1949, p. 280-281); puis Chanteurs franco-ontariens et leurs chansons, Sudbury, SHNO, « Documents historiques » 44-45, 1963-1964, 113 p. (RHAF vol. 19, n² 2, 1965, p. 319-320) qu'il qualifie de « véritable épitom[é] de la science folklorique »; et enfin ses deux séries de Contes populaires franco-ontariens, Sudbury, SHno, «Documents historiques » 25, 1953, 40 p. (RHAF vol. $7, \mathrm{n}^{\circ} 2,1953$, p. 300) et Contes populaires franco-ontariens II, Sudbury, SHNo, «Documents historiques » 35, 1958, 60 p. (RHAF, vol. 12, n 3, 1958, p. 434-435). Voir Michel Bock, op. cit., p. 400.

115. Marius Barbeau (Sainte-Marie-de-Beauce, Qc, 1883-Ottawa, Ont., 1969), anthropologue et folkloriste qui fit carrière au Musée national d'Ottawa de 1911 à 1948, auteur du Romancero du Canada (1937). Voir notre article « Le Chercheur de trésors ou l'influence d'un livre. Marius Barbeau et le Romancero du Canada », dans les Cahiers Charlevoix 7. Études franco-ontariennes, Sudbury, Société Charlevoix et Éditions Prise de parole, 2006 [2007], p. 85-141. 
assez dans la tête. J'avais lu Marius Barbeau. Alors je savais que telle chanson était assez rare, je la demandais et j'exigeais que mes élèves aussi passent par la même technique que la mienne pour préparer de loin leur enquête. Quand on part pour l'enquête, le lendemain ou le soir même, c'est une préparation immédiate : savoir quelles questions poser et quels microphones puis quels rubans apporter, parce que, au début, je n'avais pas l'expérience pour la codification de mes pièces.

\section{"J'ai conservé tous ces cahiers d'enquêtes"}

Au bout de trois ou quatre enquêtes, je me suis dit : « [Comment faire] si j'ai à me servir de ces documents-là... » - et j'ai eu à m'en servir parce qu'il fallait que je rende compte à la Société historique de mes travaux. J'ai vu tout de suite que, si je voulais publier ces chansons-là ou y référer, il fallait une cote quelconque, un numéro, que le ruban ou la bobine soit numéroté pour que je sache à quel endroit, dans telle bobine ou tel ruban, était telle chanson ou tel conte. J'étais obligé de coder mes rubans, chaque pièce avait son numéro. Je disais avant le début d'une chanson ou d'un conte, qui était l'informateur, de qui il avait appris ça, quelles étaient ses sources, etc., la date, tout. Ça m'a rendu énormément service après coup. J'ai conservé tous ces cahiers d'enquêtes ${ }^{116}$. D'ailleurs, j'ai conservé aussi tous les cahiers de mes élèves qui m'ont aidé à faire de l'enquête, et c'est excessivement précieux, même actuellement, pour retracer certaines transcriptions qui ont été mal faites, une date qui a été mal interprétée. Alors j'ai recours à ces cahiers d'enquêtes-là pour corriger la faute.

\section{"Ma première enquête" "}

Je me suis lancé absolument sans aucune expérience de l'enquête. Là, je profitais de mes voyages, de mon ministère, pour le transport ${ }^{117}$. D'ordinaire, au début, j'y allais seulement le samedi soir

116. Ces documents sont déposés au CFOF à Sudbury.

117. Les pères jésuites du collège entretenaient des relations suivies avec les paroisses et leur rendaient de précieux services : assistance dans le ministère les fins de semaine ou dans les temps forts de l'année (messe, confession, prédication, orga- 
et le dimanche parce que j'allais en ministère à Verner et puis la Société historique n'avait pas les moyens encore de payer mon passage sur l'autobus ; alors j'attendais que le curé me demande. Le curé me demandait à toutes les semaines pour aller l'aider le samedi soir et le dimanche matin.

Et la première expérience où j'ai enregistré des chansons, ç'a été à Verner, de monsieur Donat Poirier ${ }^{118}$, un descendant d'Acadien qui demeurait tout proche du presbytère. Je signale ça parce que j'avais un bagage assez considérable : traîner l'enregistreuse puis tout un paquet de fils, de microphones puis de cahiers; il ne fallait pas que ça soit très loin du presbytère. Il était presque en face du presbytère ; alors je suis allé le voir. Je me suis aperçu qu'il avait un bon bagage. Au début, j'avais une enregistreuse assez primitive, mais assez précise quand même, l'enregistreuse à fil. Après trois ou quatre enquêtes, j'ai été obligé de traîner un réducteur d'électricité parce que, dans la plupart des maisons, ça m'est arrivé chez monsieur Poirier, à un moment donné il partait un moteur, soit dans la cave, soit dans le grenier, et puis l'électricité baissait. Et, quand j'étais en train d'enregistrer une chanson, c'était perdu; il fallait attendre que l'électricité se rétablisse. J'ai trouvé ce truc. Ça pesait seulement vingt-six livres [12 kilos], mais il fallait le traîner quand même : on mettait ça dans la prise, et même si le moteur partait, ça maintenait quand même l'électricité

nisation de retraite, etc.) ; de même, les activités collégiales profitaient à l'ensemble des diocésains (concerts de la chorale, de la fanfare, présentation de pièces de théâtre, manifestations patriotiques). En retour, les curés facilitent le recrutement, « accordent des bourses aux élèves et secourent le collège dans les temps difficiles ». Voir André Bertrand, op. cit., p. 36-37.

118. Donat Poirier, âgé de 45 ans en 1948, était, selon Germain Lemieux, un " artiste consommé dans l'art de la chanson dite à reprises » et la valeur de sa version de "Mes souliers sont rouges ", première pièce franco-ontarienne recueillie le 18 septembre 1948, « ne le cède en rien aux versions québécoises publiées jusqu'ici »: voir Folklore franco-ontarien. Chansons [I], op. cit., 1949, p. 4. Elle figure, paroles et musique, aux p. 6-7 de cette brochure et sera reprise dans son Chansonnier francoontarien 1 (Sudbury, ShNo, « Documents historiques » 64, 1974, p. 86-87). Donat Poirier a donné en tout neuf chansons au collecteur : voir CFOF, collection Germain Lemieux, enreg. 30, 32, 37, 38, 42, 43, 101, 108 et 418. Son épouse, Éva Gagnon ( $\mathrm{M}^{\mathrm{me}}$ Donat Poirier, 56 ans en 1958), a donné en 1958 quatre contes (enreg. 948-951) publiés dans la série Les vieux m’ont conté (Montréal, Bellarmin, 1974, vol. 2, p. 155189). 
à 110 [volts]. C'est pour ça que je me rappelle facilement l'une des premières chansons que j'ai enregistrées, «Les Souliers du vieux Poirier. Mes souliers sont rouges, ma mignonne, ma mignonne, mes souliers sont rouges, ma mignonne et mes amours ».

Il m'a raconté comment il avait remanié la chanson apprise au Québec, parce qu'il était natif du Québec. Il n'aimait pas cette chanson-là et il m'a dit timidement qu'il l'avait remaniée à sa façon. Vous savez ce qu'est la mentalité de notre peuple, il attaquait dans sa chanson plusieurs vieux : le vieux Gagnon, le capot du vieux Thibault, les chaussures du vieux Poirier, parce qu'il m'a dit que son grand-père avait des pieds assez développés et il avait des godillots en proportion. Alors il a mis « les souliers du vieux Poirier » puis tout le monde s'est mis à rire du vieux Poirier, comme lui il riait des autres. C'est comme ça qu'il m'a dit qu'il avait remanié sa chanson. Elle était très bien remaniée, c'est une des chansons canadiennes où la rythmique, l'isorythmie était parfaite : «Mes souliers sont rouges ma mignonne... » Chaque accent était au bon endroit. Ce sont les souvenirs de ma première enquête. J'y suis allé régulièrement. Le samedi soir, dès que j'avais fini les confessions et le travail que le curé me demandait, je filais chez monsieur Poirier et là, on a attiré plusieurs chanteurs, des voisins, et puis quand à un moment donné il m'a dit : « Je ne sais plus de chansons », j’ai dit : « Connaissez-vous des gens qui en savent ? - Oui, il téléphonait, puis : Viens ici ». Je réunissais trois ou quatre chanteurs là. Et ensuite, quand j'ai été un peu plus libre, j'allais dans d'autres familles.

\section{" Je voyageais en autobus"}

Je ne vous dis pas toutes les difficultés que j'ai rencontrées à cette époque-là. Je voyageais en autobus, alors il fallait que je paquette ${ }^{119}$ tout mon bagage, mettre ça dans l'autobus pour que ça ne se brise pas : une grosse enregistreuse, un contrôleur d'électricité - un power pack comme on disait -, deux ou trois micros, parce que l'expérience m'avait appris dès le début que parfois

119. Du verbe paqueter, emballer ses affaires ; prononcé « pacte ». 
un microphone fonctionnait très bien chez nous et, quand on arrivait devant l'informateur, il ne fonctionnait pas ; il fallait que je m'en traîne deux ou trois. Il fallait que j'apporte des bobines. Au début, c'étaient des bobines en acier, après c'était du plastique ; tout ça il fallait que ça arrive. Et puis je m'apportais une grande extension $^{120}$, un grand fil, parce que parfois j'ai été obligé d'aller chercher l'électricité chez le voisin parce que le chanteur ou le conteur ne voulait pas sortir ou n'avait pas la santé nécessairement pour sortir chez le voisin ${ }^{121}$. Ensuite, le gros problème était le dimanche soir quand l'autobus passait. Quand je voyais passer l'autobus, j'avais à peu près dix minutes; alors, il fallait que je ramasse tout mon bagage. Heureusement que mes informateurs connaissaient mes problèmes ; ils m'aidaient à ramasser mes microphones, ma paperasse, ma sacoche et puis ils venaient même m'aider à transporter ça à la station d'autobus et je n'ai jamais manqué l'autobus. Parfois j'arrivais juste, mais il fallait que je retourne au collège et que je sois là le lendemain matin pour ma classe parce que j'enseignais au collège Sacré-Cœur. Ç'a été le début de mes enquêtes, mes expériences. Je peux dire qu'au début, n'ayant aucune expérience dans l'enquête, j'ai été obligé d'improviser, et puis j'ai appris, par ma propre psychologie, je venais d'un milieu paysan, comment passer à travers les quilles sans trop les renverser, ne pas poser de questions indiscrètes, ne pas parler de politique, etc., toute une série de principes que j'observais et que j'observerais encore. L'expérience et la psychologie m'avaient enseigné ça.

\section{"C'était pour leur montrer..."}

Pendant les enquêtes que j'ai faites à partir de 1948, j'allais dans les familles et puis souvent ils me montraient quelque chose. On

120. Fil de rallonge, prolongateur.

121. «Chaque samedi, après la classe, il me fallait préparer mon copieux bagage : malle personnelle, enregistreuse, malle contenant 35 ou 40 mètres de fil électrique, deux ou trois microphones, deux ou trois rubans sonores ou bobines de fil d'acier, cahier d'enquête, calepin où étaient consignés les détails d'une pré-enquête, etc. » Voir Germain Lemieux, « Mon projet folklorique cinquante ans plus tard », dans L'Euvre de Germain Lemieux, op. cit., p. 30. 
visitait le garage, parfois les étables, pour voir la construction, l'architecture, etc. ; [c'était] pour questionner les gens, pour montrer que je m'intéressais au passé. À Warren, quelqu'un me dit : « Ça, c'est une vieille hache - une hache à équarrir -; je vais envoyer ça au dépotoir ». Je disais : « N'envoyez pas ça au dépotoir, voulez-vous me la donner ? - Bien certain, ça va nous débarrasser ». Tel instrument de musique qui était un peu avarié : « Je vais m'en servir moi ». Tel autre instrument : « Si vous voulez vous en débarrasser, je vais le prendre ». Ils étaient intéressés eux-mêmes de voir que j'étais intéressé à leurs vieilleries et puis, moi, j'apportais ça en classe. Quand je donnais un cours sur la civilisation canadienne-française sous le Régime français, je parlais par exemple des poutres équarries avec lesquelles on bâtissait des maisons, même des églises. Je disais aux élèves : «On équarrissait les poutres dans la forêt et voici : c'est une hache à équarrir. Regardez comment ils s'y prenaient : quand c'était un gaucher, il procédait comme ça; et, quand c'était un droitier, il procédait comme ça. » J'avais à côté de moi une maquette, un commencement de maison à poutres équarries ; c'était pour leur montrer ce que c'était. Je disais par exemple : «Les poutres qui allaient d'un bout à l'autre d'une maison étaient tenues dans chaque coin par les équerres qu'il y avait là. Quand on coupait la poutre pour une fenêtre ou une porte, elle n'avait plus de force parce qu'elle était libre, elle aurait pu tomber. On avait une tarière - je leur montrais la tarière -. On perçait un trou dans la poutre et jusque dans l'autre, on perçait une cheville». Et c'était comme ça que je procédais. Je m'apercevais encore là, à l'examen, qu'ils avaient saisi ce que je disais, ce qu'était une tarière, ce qu'était une hache à équarrir, quel était le rôle de la hache à équarrir et comment le forgeron la faisait chauffer à blanc puis ensuite la plongeait dans l'eau... Les haches étaient trempées. Le forgeron, avec sa chiquenaude sur l'acier, voyait par le son, ou parfois c'était son œil, quand l'acier avait atteint une telle teinte, il était certain que c'était assez trempé... C'est tout ça que je leur 
montrais dans ma classe au collège classique, et ensuite quand j'enseignais l'histoire du Moyen Âge à l'université ${ }^{122}$.

\section{"Je me suis branché sur la}

\section{Société historique du Nouvel-Ontario"}

Seulement le fait de me brancher sur une institution sérieuse, c'était déjà quelque chose de précieux pour moi. Je vous dirai bien franchement que la grande raison pour laquelle je me suis branché sur la Société historique du Nouvel-Ontario, c'est que ça me donnait une chance. Mes parents et mes amis, qui ont vu que je commençais à brasser dans l'enquête, m'envoyaient parfois un cadeau pour mes travaux. Si j'avais donné ça au collège du Sacré-Cœur, il était tellement pauvre que je n'aurais jamais vu la couleur de cet argent-là ; tandis que, dans la caisse de la Société historique, je pouvais le sortir n'importe quand. On avait besoin d'acheter des bobines. Au début, j'ai tout effacé les chansons, pas les contes par exemple, mais les chansons que j'ai recueillies sur le système de fil d'acier, parce qu'on était trop pauvre pour acheter cette petite bobine d'acier qui coûtait à peu près huit piastres ${ }^{123}$ et demie ; il fallait y penser à deux fois avant de l'acheter. Comme notre finance était pauvre, qu'on n'avait pas les moyens de payer mon passage à bord de l'autobus, alors la Société historique me garantissait de me redonner l'argent que je lui avais donné.

\section{"Ça vous donnerait de la matière pour une publication"}

J'ai dit : « Je vais probablement recueillir des documents qui vont valoir la peine d'être publiés, ça vous donnerait de la matière pour une publication, une couple par année ». J'ai commencé

122. « À cette époque - un peu après 1961 - l'enquêteur, à la fois professeur d'université et chercheur, put accepter facilement les vieux outils, ou tout autre objet désuet mais conservé dans les familles pionnières. Ces objets étaient très utiles au professeur qui visait à instruire ses étudiants autant par les yeux et le toucher que par les oreilles. Donc, ce qui deviendra, avec les années, le musée du Centre de folklore, n'était à l'origine qu'un matériel pédagogique. » Voir Germain Lemieux, « Mon projet folklorique cinquante ans plus tard », dans L'Euvre de Germain Lemieux, op. cit., p. 32 .

\section{Terme familier pour dollar.}


à enquêter en 1948. Dès 1949, j'ai publié un petit volume de chansons ${ }^{124}$ que je n'ai pas signé parce qu'il y avait une chanson parmi les vingt-quatre ou vingt-cinq que le supérieur n'a pas voulu accepter. J'ai dit : « Écoutez un peu, je n'ai pas le droit de changer des textes que j'enregistre comme ça. Alors je ne signerai pas ». J'étais presque obligé, je ne me rappelle pas du tout quelle chanson, une chanson absolument anodine : J'ai fait une maîtresse il y a pas longtemps ; le mot maîtresse, ce n'était pas acceptable ${ }^{125}$. Tout le monde disait « une maîtresse » à ce momentlà - une maîtresse d'école - et c'est dans le texte de la chanson, je n'ai pas le droit de changer. Il voulait que je change. Et c'est allé comme ça. Monsieur Luc Lacourcière m'a reproché de ne pas avoir signé ma première publication en 1949. La deuxième, c'était en $1950^{126}$. La chicane était passée, le supérieur était changé probablement, et là j'ai signé. C'était un peu osé de ma part, mais je m'entraînais à foncer ; j'étais naturellement timide et puis je réagissais autant que possible contre cette timidité-là. Quand je pouvais défoncer une porte sans me faire assommer, je le faisais. Mes deux premières publications portaient sur les chansons. Il y a une raison économique à ça. On était très pauvre et puis ça m'aurait pris quasiment une bobine de 8000 pieds [ $2438 \mathrm{~m}$ ] pour enregistrer un conte sur ce système-là ; j'en n'aurais peut-être pas eu assez pour finir le conte parce que, des fois, $\mathrm{j}$ 'ai eu des contes qui approchaient ou même qui dépassaient les deux heures. Je me suis lancé sur les chansons puis j'ai enregistré, je pense, un seul conte à Sturgeon-Falls d'un vieux, un ancien Gaspésien, un bonhomme qui était venu au monde en Gaspésie, qui avait appris son conte dans les chantiers du Montana vers les 1870-1872. C'est le seul conte que j'ai enregistré dans le système du fil d'acier ;

124. Folklore franco-ontarien. Chansons [I], op. cit., 1949, 48 p. Recueil de 22 chansons.

125. On trouve en effet la chanson « J' me suis fait une blonde » là où on pourrait attendre «J'ai fait une maîtresse » (ibid., p. 12-13). Pourtant, dans le même recueil, on rencontre, dans « À la claire fontaine », le couplet classique « J'ai perdu ma maîtresse / Sans l'avoir mérité »... (ibid., p. 34-35).

126. Germain Lemieux, Folklore franco-ontarien. Chansons [II], Sudbury, SHNO, « Documents historiques » 20, 1950, 48 p. Recueil de 20 chansons. 
par économie, je transcrivais les chansons aussitôt que possible au cas où je me déciderais de me débarrasser de ces bobines-là ou je serais obligé de les employer à une autre fin. C'est pour ça au fond que j'ai insisté au début sur la chanson.

\section{"L'abbé Bourassa avait une grosse enregistreuse "}

L'abbé Lionel Bourassa ${ }^{127}$, qui était curé à Lavigne, a commencé à enregistrer à peu près en même temps que moi. Il faisait partie de la Société historique. Il assistait à nos réunions, peut-être à tous les mois, puis il était au courant que j'avais présenté mon projet à la Société historique, de faire de l'enquête dans le domaine de la chanson et du conte. Comme il était plus riche que moi, il avait une grosse enregistreuse à ruban de papier, qu'on appelait le paper based $^{128}$; ça dépassait d'emblée mon système de fil d'acier. Il m'a fait don, et de sa collection de rubans sur papier et de sa grosse enregistreuse. Je pense qu'il l'avait payée 675 dollars en 1948. La première fois que je l'ai rencontré, en 1948 ou 1949, il avait déjà cette grosse enregistreuse-là qui était très efficace d'ailleurs. Il m'avait donné certaines chansons qu'on essayait de repiquer sur le fil d'acier et, moi, j'essayais de lui donner d'autres chansons enregistrées sur fil d'acier. C'est pour ça qu'à cette période-là, de 1948 jusqu'à 1952, j'ai enregistré des chansons et c'est toujours sur le système de fil d'acier et, comme les bobines coûtaient cher, je tâchais d'en dépenser le moins possible, d'en acheter le moins souvent possible.

\section{"Il enregistrait les gens qui allaient payer leur dîme "}

Il avait une technique que, moi, je n'aurais pas acceptée, mais il était obligé probablement de l'employer. À ce qu'il m'a conté, il enregistrait les gens qui allaient payer leur dîme ou qui avaient absolument besoin de rencontrer le curé ${ }^{129}$. Avant de partir, il di-

127. Lionel Bourassa (Windsor, Qc, 1899-Verner, Ont., 1989), prêtre séculier et curé de la paroisse Notre-Dame-de-la-Visitation de Lavigne en Ontario. Il était membre du comité de folklore de la SHNO.

128. Ruban à support papier.

129. La lourdeur de l'appareil, qui à première vue paraît expliquer ce choix 
sait : «Attends-moi, attends-moi une minute, tu vas me chanter une chanson ». Le bonhomme était plus ou moins à l'aise, plus ou moins gêné de chanter sa chanson, puis parfois peut-être qu'une chanson lui venait à l'idée et qu'elle n'était pas convenable pour le curé. Une fois que l'informateur avait accepté - « c'est correct, je vais vous chanter une chanson de mon père $»-$, il faisait partir son enregistreuse. Il y avait un décalage d'une fraction de seconde entre le départ de l'enregistreuse et puis l'enregistrement de la voix. Dans au moins quarante-cinq à cinquante pour cent de ces chansons, on n'entendait pas le début des chansons ou bien, parfois, il fermait l'enregistreuse ou le monsieur prenait la porte avant d'avoir fini sa chanson, ses dernières syllabes de chanson. Alors, il y avait le début et la fin parfois qui étaient un peu abîmés. Quand il m'a donné sa collection, comme j'avais les noms, je suis retourné chez les gens ; la plupart des gens, quand j'y suis retourné, étaient morts. Et puis il y avait des descendants. Alors j'allais dans la famille où je savais qu'il y avait un garçon, où je trouvais un garçon qui connaissait la version de son père ; je l'enregistrais, puis je mettais ça à côté de l'autre. Et c'est comme ça que j'ai sauvé cent douze versions que l'abbé Bourassa avait enregistrées $^{130}$; je pense qu'il en avait enregistré au-delà de deux cents. Il y en avait d'autres que je n'ai pas été capable de sauver. Je les ai conservées quand même, mais je ne les ai pas transcrites. À Lavigne, j'allais voir ces gens-là et puis ils me disaient : «Un mon-oncle... un beau-père, qui pourrait vous chanter des chansons ». J'avais toujours sur ma liste une dizaine d'informateurs qui étaient censés m'attendre, soit des conteurs, soit des chanteurs.

L'abbé Bourassa, il m'a donné en plus ses rubans paper based, c'était de l'oxyde de fer qui était sur papier. Un peu plus tard en 1952, quand j'ai acheté ma première enregistreuse sur le plastique, c'était cette même couche d'oxyde qui était sur le

d'enregistrer ses informateurs lors de leur visite au presbytère, ne serait pas seule en cause ; c'est plutôt l'électrification du presbytère, réalisée par ce prêtre bricoleur bien avant le village de Lavigne, qui a imposé cette méthode.

130. En fait, 119 chansons. La collection Bourassa est déposée au CFoF : voir notre Répertoire ethnologique de l'Ontario français, op. cit., p. 162. 
plastique. Le papier se déchirait assez facilement, surtout quand il vieillissait. Quand on a eu le plastique, c'était plus résistant. L'abbé Bourassa avait commencé à transcrire la mélodie dans les cahiers, mais il ne savait pas assez la musique pour la transcrire à l'oreille ; c'était sa ménagère ou sa secrétaire qui retraçait la mélodie à l'accordéon. Parfois il y avait bien des dièses et des bémols ; il n'y avait aucune mesure là-dedans, c'était simplement la courbe mélodique qu'il enregistrait. Tout de même, je me suis servi de ça. Quand j'enregistrais, une fois que j'ai eu organisé mon système de sténographie, à côté du titre j'écrivais mes mélodies en sténographie, je savais tout de suite la courbe musicale, le mode, etc. Avec lui, je n'avais pas ça, je réécoutais simplement sa chanson puis je l'écrivais ; je perdais moins de temps à réécrire ma propre musique que de suivre la sienne.

\section{"Je pourrais faire une corvette canadienne et la faire rafler"}

En 1952, je me suis aperçu qu'on offrait en vente à New-York, et même à Montréal, un système qui était assez précis. On l'appelait le tape recorder, l'enregistreuse sur ruban. Mais ça coûtait 525 dollars. Il fallait y penser deux fois avant de l'acheter ; on n'avait pas 525 dollars dans la caisse. J'ai suggéré au père Cadieux, comme j'étais passablement bricoleur - je venais de la Gaspésie, j'avais fait bien des bateaux dans ma petite vie, avant l'âge de dix ans même -, j'ai dit : " Je pourrais faire un bateau, une corvette canadienne et, si on n'est pas trop malchanceux, on pourra peut-être faire 600 piastres pour cette pièce-là en la faisant rafler ». Il a dit : «Très bien ». Alors, je me suis mis à l'œuvre et, les samedis soirs et les moindres congés, je travaillais à ma corvette canadienne. Et je n'avais pas mal réussi. J'avais une photo d'une corvette canadienne qui avait été très efficace pendant la guerre et je me suis entendu avec un autre bricoleur ; on s'est fait un moteur à vapeur qu'on a installé dans la petite corvette et puis, avec un brûleur - ça c'était dangereux par exemple, j'ai failli avoir des accidents -, un brûleur à l'alcool, on mettait ça en-dessous de la bouilloire et puis ça marchait. Dès les premières 
expériences, le feu a pris à bord du bateau, c'était un bateau en cèdre. Alors j'ai senti le besoin de recapitonner ça en amiante et, petit à petit, comme ça, au bout de quatre ou cinq expériences, on a vu que le bateau était intéressant. Je lui avais organisé un gouvernail automatique qui était branché sur une roue puis la roue avait un excentrique ; aussi longtemps que c'était sur le pourtour régulier de la roue, le bateau allait en droite ligne et, dès que ça arrivait à l'excentrique, le gouvernail changeait de position, et le bateau, lui, faisait le tour. On avait une piscine au collège du Sacré-Cœur, c'était très important. Quand je faisais mes expériences, c'était toujours plein de petits gars. J'ai des photos de petits gars en 1952, quand ils avaient quatorze, quinze ans, qui sont rendus grands-pères actuellement. Et puis ils me surveillaient et je voyais l'intérêt qu'ils mettaient dans cette navigation-là.

\section{"J'en avais assez pour acheter l'enregistreuse"}

Je suis venu à bout de mettre la corvette au point, on l'a fait photographier, on a mis la photo de la corvette sur le billet du tirage. Il s'agissait de vendre des billets. Au début, je donnais dix ou quinze pour cent aux petits gars. Il y en avait un, entre autres, qui venait du Moulin-à-Fleur ${ }^{131}$, un petit bonhomme, très débrouillard, il avait peut-être sept ans ; il ne savait ni lire ni écrire, je m'en suis aperçu après coup. Je lui ai dit : «Comment fais-tu pour vendre tes billets puis écrire les noms, tu ne sais pas écrire ? » Il dit : «Je leur donne le billet puis, s'ils se trompent, tant pis pour eux autres $»$. Il avait du front et de l'initiative ce petit bonhomme-là et puis il m'en a vendu des centaines. Il a dit : « Je m'en vais à telle taverne et puis, tu sais, quand les gens ont pris deux, trois verres de bière, ils sont floches $^{132}$; alors ils prennent

131. Quartier français de Sudbury, qui tire son nom du moulin à farine (Flour Mill) et des silos à grain construits en 1911, où était établi le collège du Sacré-Cour et où vivait une grande partie de la classe ouvrière canadienne-française. La fermeture de la compagnie en 1917 a entraîné la démolition du moulin en 1920 ; il ne reste que les six silos de ciment.

132. Ce mot qui, appliqué à la torsion d'un fil, signifie faible, a ici le sens de détendu, généreux. Le Glossaire du parler français au Canada, op. cit., l'inscrit toutefois sous Flush : «adj. et s. Dépensier, généreux, prodigue. Étym. - Ang. flush = m. s. » 
facilement des billets ». C'est lui qui m'en a vendu peut-être le plus. À la fin, la dernière semaine, je donnais cinquante pour cent. Le billet était de vingt-cinq sous je pense et cinq pour une piastre. On est allé jusqu'à Lavigne, jusqu'à Field, on emportait la corvette dans notre voiture et puis, quand il y avait de l'eau, on faisait une démonstration et puis les gens achetaient des billets. On en a vendu pour au-delà de 2000 dollars de billets pour cette petite corvette-là. J'en avais assez pour acheter l'enregistreuse et acheter un bon bagage de rubans sonores ${ }^{133}$.

\section{"Le ruban pouvait résister beaucoup plus longtemps"}

Au début, par économie toujours, il y avait un programme spécial, Radio Sacré-Cœur, à Montréal. C'étaient des jésuites qui avaient ça et ils employaient des rubans de première qualité. Ils n'avaient pas le droit d'employer deux fois le même ruban parce qu'il fallait que ça passe dans sept ou huit studios. Moi, je savais que, si on faisait un premier enregistrement et qu'on effaçait, le ruban pouvait résister beaucoup plus longtemps et puis on avait un meilleur rendement. C'étaient des rubans de sept piastres et demie ou huit piastres; je les achetais pour deux piastres et demie. Je n'ai jamais eu un seul accident avec cette affaire-là. J'ai eu au-delà de 255 rubans sonores qui m’ont donné une très bonne qualité. On les a fait repiquer il y a deux ans. Ils avaient déjà une quarantaine d'années, ils étaient en très bonne condition. C'est l'histoire du début de mon enquête sérieuse avec une enregistreuse qui était pesante, mais qui donnait un très bon résultat.

\section{"Sortir des sentiers battus"}

De 1948 à 1958, j'ai enquêté seulement par le moyen du transport commun, l'autobus. C'était embêtant parce que je ne pouvais

133. Dans une note communiquée au CFOF, Pierre LeRiche de Sturgeon-Falls écrit : «Vers 1950-1951, quand j'étais dans ma première année au collège du SacréCœur de Sudbury, j'ai été l'heureux gagnant d'un tirage, un bateau miniature fabriqué par le père jésuite Germain Lemieux. C'était une maquette d'une corvette de la Seconde Guerre mondiale. [...] Pour moi, jeune adolescent, c'était un objet presque mythique, qui cachait toutes les expertises requises à sa confection. [...] J'ai encore ce voilier maintenant, le 27 juillet 2008, chez moi à Sturgeon-Falls. » 
pas quitter la route $17^{134}$. J'ai eu aussi de l'aide précieuse de la part des membres de la Société historique ${ }^{135}$. Je pense encore à Maurice Lacourcière, le fils d'Émile, actuellement juge à Toronto $^{136}$. Il était jeune avocat quand j'ai commencé mes enquêtes en 1948-1950, il venait d'arriver à Sudbury. C'était le neveu du fameux Luc Lacourcière de Laval. Il était au courant de ce que son oncle faisait et, quand il a vu que je voulais me lancer dans la même ligne, ça l'intéressait, lui aussi, non seulement de me voiturer, mais d'assister à l'enquête. C'est un des premiers. Un monsieur Bergeron aussi qui m'a voyagé passablement en ville. À l'extérieur, je prenais l'autobus, mais à l'intérieur de la ville, cela aurait été embêtant de prendre l'autobus avec tout mon bagage. $\mathrm{Au}$ moins quatre ou cinq membres de la Société historique, des bénévoles, des gens qui étaient intéressés par mes enquêtes, me sont venus en aide.

Dès que j'ai eu une voiture, j'ai été à même de quitter la route principale et d'aller dans les rangs ${ }^{137}$, comme on disait, de sortir des chemins battus ; là, j'ai pu rencontrer beaucoup plus d'informateurs. Pour cette voiture, encore là, il y a toute une histoire ; j'aurais un roman à écrire là-dessus.

134. Portion de la route transcanadienne qui traverse l'Ontario entre le Québec et le Manitoba. Le père Lemieux l'a empruntée pour ses enquêtes, entre Mattawa et Sault-Sainte-Marie surtout.

135. La Société historique du Nouvel-Ontario avait formé un Comité de folklore de douze membres, dont on trouve la liste dans le " Documents historiques " 30, 1955, p. 2 : « R. P. Germain Lemieux, s.j., M. le curé Lionel Bourassa, M. Léoda Gauthier, m.p., $\mathrm{D}^{\mathrm{r}}$ Horace Paiement, $\mathrm{M}^{\mathrm{e}}$ Maurice Lacourcière, $\mathrm{M}^{\mathrm{me}}$ Osias Godin, M. Ivan Lemieux, $\mathbf{M}^{\text {me }}$ Albert Philion, $\mathbf{M}^{\text {lle }}$ Gilberte Proulx, M. Donat Poirier, M. Maurice Gravelle, M. Laurent Roy ». La propriété de la collection de folklore du père Lemieux, confiée à la SHNo depuis le début, fera l'objet d'un débat au sein de cette société entre 1959 et 1968, car la nouvelle Université de Sudbury la réclame. Elle sera finalement cédée à l'Institut de folklore, que dirige le père Lemieux, « dans le but d'obtenir l'incorporation officielle de son Institut de folklore ». Voir Daniel Bouchard, op. cit., p. 101-104.

136. Maurice Norbert Lacourcière, juge de la Cour suprême de l'Ontario (19201999). «Pendant ses études de droit, il avait, lui aussi, goûté à la poésie de l'enquête folklorique en compagnie de son oncle Luc. » Voir Germain Lemieux, " Mon projet folklorique cinquante ans plus tard », dans L'Euvre de Germain Lemieux, op. cit., p. 31.

137. «Type d'habitat aligné », particulier au Canada français, selon la définition qu'en a donnée Louis-Edmond Hamelin, dans Le Rang d'habitat. Le réel et l'imaginaire Montréal, Hurtubise HMH, « Cahiers du Québec », 1993, 328 p. 


\section{"Mon premier mémoire sur la technique de l'enquête "}

Un confrère me trouvait trop original pour sortir deux, trois soirs par semaine, surtout en fin de semaine ${ }^{138}$. Mais, la fin de semaine, quand j'allais en ministère, il ne le savait pas [que je faisais de l'enquête]. Des fois, je faisais entendre de ces chansons. Il a écrit à notre provincial, notre supérieur de Montréal, lui disant que c'était scandaleux, que j'étais allé deux fois dans la même semaine chez un informateur tout seul, sans surveillance et puis dans une famille. Alors le provincial m'écrit, il disait que c'était scandaleux et demandait ce qui se passait ${ }^{139}$. Ça m'a donné une chance d'écrire mon premier mémoire sur la technique de l'enquête. Ils m'ont forcé pratiquement à dire au provincial comment ça se fait de l'enquête, comment ça doit se faire. On n'arrive pas là avec l'enregistreuse et dire : « Vous allez me chanter une chanson, vous allez me conter un conte ». Ça ne se fait pas comme ça; il faut y aller tranquillement, il faut se faire admettre dans la famille. J'ai dit : « J'y suis allé cette date-là que vous me donnez, c'est exact; mais remarquez bien que la madame avait 82 ans et que l'informateur avait 84 ans, que nous étions tous les trois dans la cuisine et qu'il n'y avait aucun danger au point de vue moral. Retourner souvent pour faire de l'enquête, ça, je l'ai fait, et il faut y aller souvent. Dès qu'on a trouvé un bon informateur, pour montrer qu'on est sérieux, il faut y retourner, pour montrer qu'on est intéressé ; c'est une des bases de l'enquête ». Le provincial m'a répondu et puis il m'a dit : « On va y repenser ». Je lui ai dit : « Pour vous faire plaisir, je vais abandonner l'enquête, mais je suis certain que vous allez me dire de recommencer $»$.

138. Ce serait le père Guillaume Belcourt (1899-1995), qui, quoique membre de la Société historique du Nouvel-Ontario, ne tenait pas en haute estime les travaux de son confrère Lemieux.

139. « Mais, imagine-t-on les problèmes que devait affronter un jésuite avant 1950 ? Marcher en dehors des sentiers battus aurait pu déclencher des représailles sévères ! Tout de même, quand on est jeune - j'avais 35 ans, à cette époque - et qu'on a confiance en ses supérieurs, le problème se simplifie. » Voir Germain Lemieux, "Mon projet folklorique cinquante ans plus tard », dans L'Euvre de Germain Lemieux, op. cit., p. 27. 


\section{"On commençait à parler d'une université "}

À ce moment-là, en 1955-1956, on commençait à parler d'une université. Alors, nous autres, les jésuites, qui étions bien importants puis qui avions la réputation d'être très savants, nous n'avions pas de brevet, pas de doctorat ni de maîtrise pour enseigner dans une université ${ }^{140}$... Mon projet a peut-être compté. Il y a un autre facteur aussi qui a compté dans cette histoire-là. C'est qu'un chercheur d'une autre région voulait venir s'installer soit à Sturgeon, soit à North-Bay pour recueillir le folklore de la région ${ }^{141}$. Un de mes amis de l'extérieur m'a averti : «Un tel se prépare à aller s'installer, pas pour te couper les jarrets, mais parce qu'il sait, d'après tes publications, que c'est très riche dans ton coin ». J'ai dit ça à mon supérieur : « Si on abandonne, on abandonne ; on ne peut pas être deux dans le même champ ». Alors il a dit : «Pensez-vous recueillir assez de documents pour occuper votre vieillesse ? J'ai dit : « Cela ne fait pas dix ans que j'enregistre et j'ai déjà assez de documents pour occuper deux vieillesses ». Il m'a dit : « Envoyez fort ». Il savait que l'université allait commencer : «Ayez une voiture, achetez-vous ce qu'il vous faut et allez-y, je vous appuierai ». J'ai commencé, mais il fallait avoir une voiture et le collège était trop pauvre pour m'en fournir une.

\section{"C'est comme ça que j'ai eu une voiture "}

Voici que le père Cadieux a fait des démarches et puis il a obtenu deux mille dollars pour faire l'index de toutes les publications de la Société historique. On m'a confié la charge de faire cet index-là, un index qui est encore très utile. Je l'ai fait. Alors il m'a payé avec cette bourse-là. Et c'est comme ça que j'ai eu une voiture, une petite voiture toute petite qu'on appelait une punaise, de l'Angleterre, seulement vingt-quatre forces ; mais

140. Cette situation n'était pourtant pas exceptionnelle, puisque « les religieux et les prêtres n'ont pas été à l'université avant 1920 et que les diplômés sont restés minoritaires même après 1960. » Voir Claude Galarneau, op. cit., p. 107.

141. À part Joseph-François Brassard (Saint-Jérôme, Lac-Saint-Jean, Qc, 1908-Québec, Qc, 1976), compositeur et ethnomusicologue, qui a fait des enquêtes dans le nord de l'Ontario dans les années quarante, on ne connaît pas cet autre chercheur qui comptait s'établir à Sturgeon-Falls. 
on pouvait grimper dans la face d'un homme si on mettait ça sur le bœuf [prononcé beu], comme on disait, en petite vitesse. On ne pouvait pas faire énormément de vitesse, mais ça m'a donné une chance de parcourir les campagnes. J'ai acheté ça en 1958. Ça faisait dix ans que j'enquêtais. Avec l'autobus, j'étais obligé de suivre toujours la route 17 ; là, je suis sorti à l'extérieur, j'ai pu aller dans les campagnes. Je suis allé jusqu'à Timmins pour rencontrer un vieillard de 97 ans. Je pensais qu'il était à la veille de mourir, mais il est mort à 101 ou 102 ans, puis il m'a donné cent cinquante chansons, peut-être plus que ça. Je suis allé à d'autres endroits, dans le Sud et puis dans le Nord. C'est comme ça que mon enquête a complètement changé d'allure, le rythme a changé à ce moment-là, dès que j'ai eu une voiture.

\section{"Les Jongleurs du billochet"}

Je pense que Les Jongleurs du billochet a été écrit en trois semaines, en dedans d'un mois en tout cas. J'avais la grippe, et, dans une poche de ma souquenille, j'avais des pilules pour la grippe, puis je passais devant les toilettes et puis il y avait de l'eau après les pastilles, et puis j'ai écrit ça d'un bout à l'autre sans diviser les chapitres ; c'est un peu comme je disais, va comme je te pousse. Cadieux me disait : « Il faut absolument finir pour telle date, à la fin du mois, parce qu'on n'a pas eu de publication depuis tel temps... » Il s'informait à tous les soirs comment ça allait. Une fois que j'ai eu fini, on s'est assis tous les deux puis on a relu le manuscrit. Il disait : « Ça, il faudrait séparer ici, on va faire un chapitre avec ça ». À la fin de la session, il a dit : « On va relire le manuscrit pour corriger certaines redites... ». Et puis ensuite il l'a envoyé à l'imprimeur et ç'a donné Les Jongleurs $d u$ billochet $^{142}$. À ce moment-là, je connaissais déjà le sens de jongleur, par le jongleur du Moyen Âge, mais le billochet ${ }^{143}$, je

142. Germain Lemieux, Les Jongleurs du billochet, op. cit. Voir la note 5. Germain Lemieux a aussi relaté cette anecdote à Daniel Bouchard qui la cite en exemple de la direction énergique du père Lorenzo Cadieux pour maintenir la SHNo en vie. Voir Daniel Bouchard, op. cit., p. 100-101.

143. Dérivé de billot, le mot billochet désigne une pièce de bois, ou bûche, posée 
ne le connaissais pas. Je venais de l'apprendre. Un monsieur Roy de Cache-Bay m'a dit que c'était le siège officiel du conteur dans les chantiers. Je lui avais demandé combien d'années il avait été conteur dans les chantiers. Il m'a répondu : «J'ai été onze ans sur le billochet ». J'ai noté ça, mais je n'ai pas compris. À la fin de notre session, j'ai dit : «Qu'est-ce que ça veut dire : être sur le billochet? - Vous ne savez pas ça, il dit, c'était le siège officiel du conteur ; les autres n'avaient pas le droit de se servir du billochet. Puis, quand j'étais sur le billochet, j'avais l'autorité sur toute la communauté. Si quelqu'un faisait une farce, faisait une blague, je pouvais le faire sortir, tout le monde obéissait. J'avais même une autorité supérieure à celle du jobbeur ${ }^{144}$ quand j'étais assis sur mon billochet ». C'est comme ça que j'ai connu le sens du mot billochet. Alors je l'ai mis comme titre. Puis le jongleur, ça veut dire celui qui fait des blagues, fait des farces, fait rire ; joculare en latin; le joker anglais vient de là. Les jongleurs sur le billochet, c'était ça : ils faisaient rire ou ils faisaient pleurer leur auditoire, mais c'était pour les réjouir : ils jonglaient pour leur faire passer le temps agréablement.

\section{ÉPILOGUE}

Ici s'arrête le premier volet de cette longue entrevue que le père Germain Lemieux a bien voulu nous accorder en 1995. Pour la première fois, il exposait des souvenirs à peu près complets sur les années qui ont précédé son séjour à Sudbury et qui fournissent un nouvel éclairage pour mieux appréhender son action. Il y relate en effet ses premiers moments de vie dans sa famille, cadre de son enfance gaspésienne et lieu d'éveil chez lui d'une prédisposition pour la tradition orale, dont il fera plus tard son profit (19141928) ; sa fréquentation de l'école primaire à Cap-Chat et ses

\footnotetext{
verticalement qui sert de banc ; l'expression « tire-toi une bûche » signifie d'ailleurs « assieds-toi », « prends une chaise ». La maison d'édition Les 400 coups en a fait une collection de livres pour la jeunesse (collection « Le Billochet ») dans laquelle une douzaine de titres ont paru depuis 1999. Le prix annuel du patrimoine que décerne le CFOF depuis 2003 s'intitule le Billochet du jongleur.

144. De l'anglais job, entrepreneur dans un chantier forestier. Voir Glossaire $d u$ parler français au Canada, op. cit.
} 
études classiques en internat au séminaire de Gaspé (1928-1935), période intense de travail et d'initiation à la discipline intellectuelle, marquée par l'exemple de professeurs dévoués, mais aussi par le clivage entre la ville et la campagne, qui le mènera chez les jésuites à Montréal ; les étapes de sa formation religieuse dont il résume les divers passages (1935-1950); son affectation première à l'enseignement des humanités au collège du Sacré-Cœur, où le pédagogue débrouillard découvrira la valeur des traditions qu'il porte (1941-1944) et l'orientera définitivement vers l'ethnographie des populations françaises du nord de l'Ontario ; en ciblant particulièrement la littérature orale, il inventera de toute pièce une méthode de terrain adaptée à son milieu et sa passion le conduira au seuil d'un projet remarquable (1948-1958). Ces confidences balisent d'éléments inédits le cheminement de Germain Lemieux et expliquent même quelques traits de sa personnalité. Jusquelà, on ne connaissait, sur ses origines et sa formation, que les trop brèves confidences que Michel Morin avait pu recueillir pour l'émission Le Voisin de la semaine, diffusée le 18 décembre 1982 sur les ondes du réseau français de Radio-Canada à Sudbury ${ }^{145}$. À travers ses souvenirs, Germain Lemieux se livre ici avec plus de profondeur, toujours avec modestie et simplicité. Ses propos, parfois teintés d'une grande naïveté, montrent néanmoins comment cet homme volontaire, en dépit de moyens limités et des contraintes de son état, trace sa voie en s'attirant des collaborateurs et se construit une carrière unique. Aussi, le témoignage autobiographique qu'il porte après coup sur son parcours singulier recèle-t-il une valeur documentaire de premier ordre.

145. Animé et réalisé par Michel Morin de la station radio CBOn à Sudbury dans le cadre du programme «Enfin Samedi », sous la direction de la réalisatrice Nicole Beauchamp, cet entretien d'environ 20 minutes a été publié : Michel Morin et JeanPierre Pichette, "Entrevue avec le père Germain Lemieux, ethnologue ", dans la Revue du Nouvel-Ontario, $n^{\circ}$ 5, « Sudbury 1883-1983 », 1983, p. 151-159 : ce rapide coup d'œil sur son enfance et sa vie d'étudiant traitait en outre de ses études à l'Université Laval, de ses publications et de ses rêves. Par contre, l'allocution de Germain Lemieux, "Mon projet folklorique cinquante ans plus tard ", à laquelle nous avons référé çà et là dans cet article, résume, « aussi brièvement que possible, les principales étapes de [s]a carrière en insistant davantage sur les cinquante dernières années », soit les années 1941-1991. Voir L'Euvre de Germain Lemieux, op. cit., p. 24. 